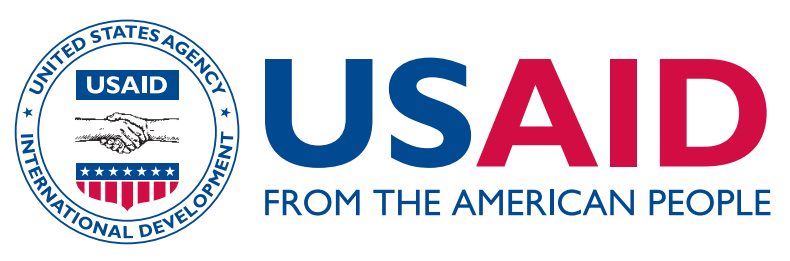

\title{
Stability in Key Areas (SIKA)-West
}

\section{Final Report}

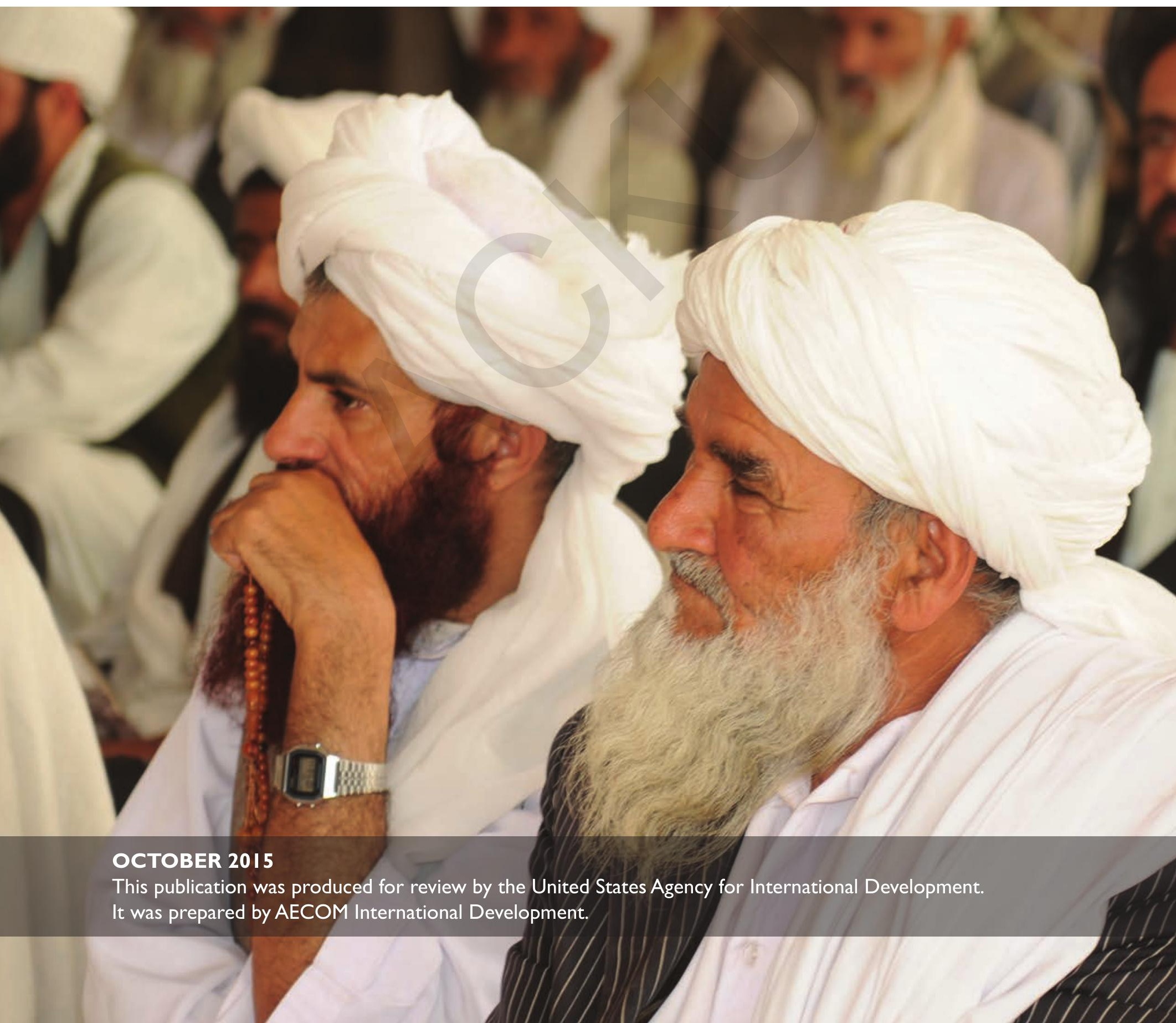




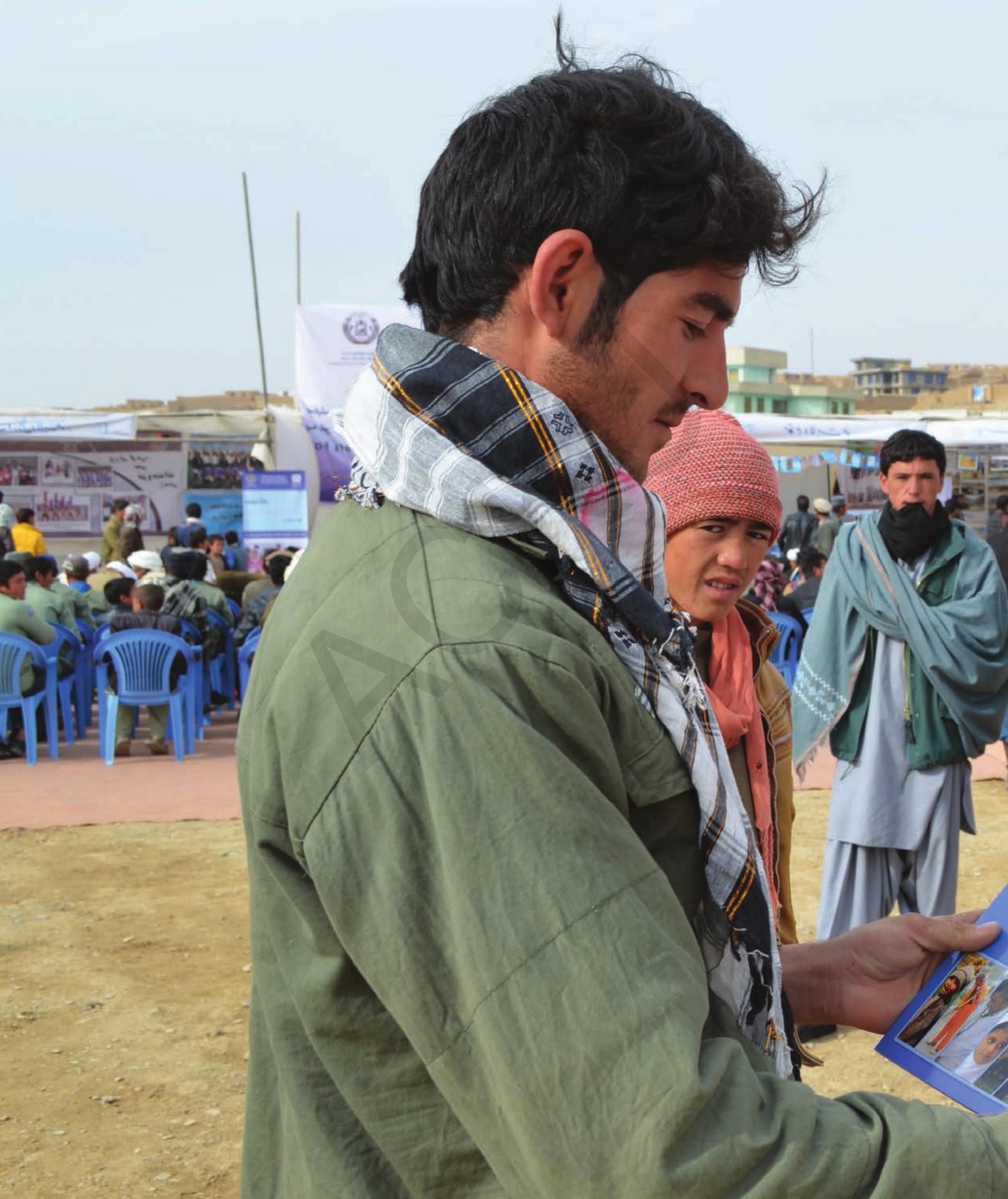




\section{Stability in Key Areas (SIKA)-West}

\section{Final Report}

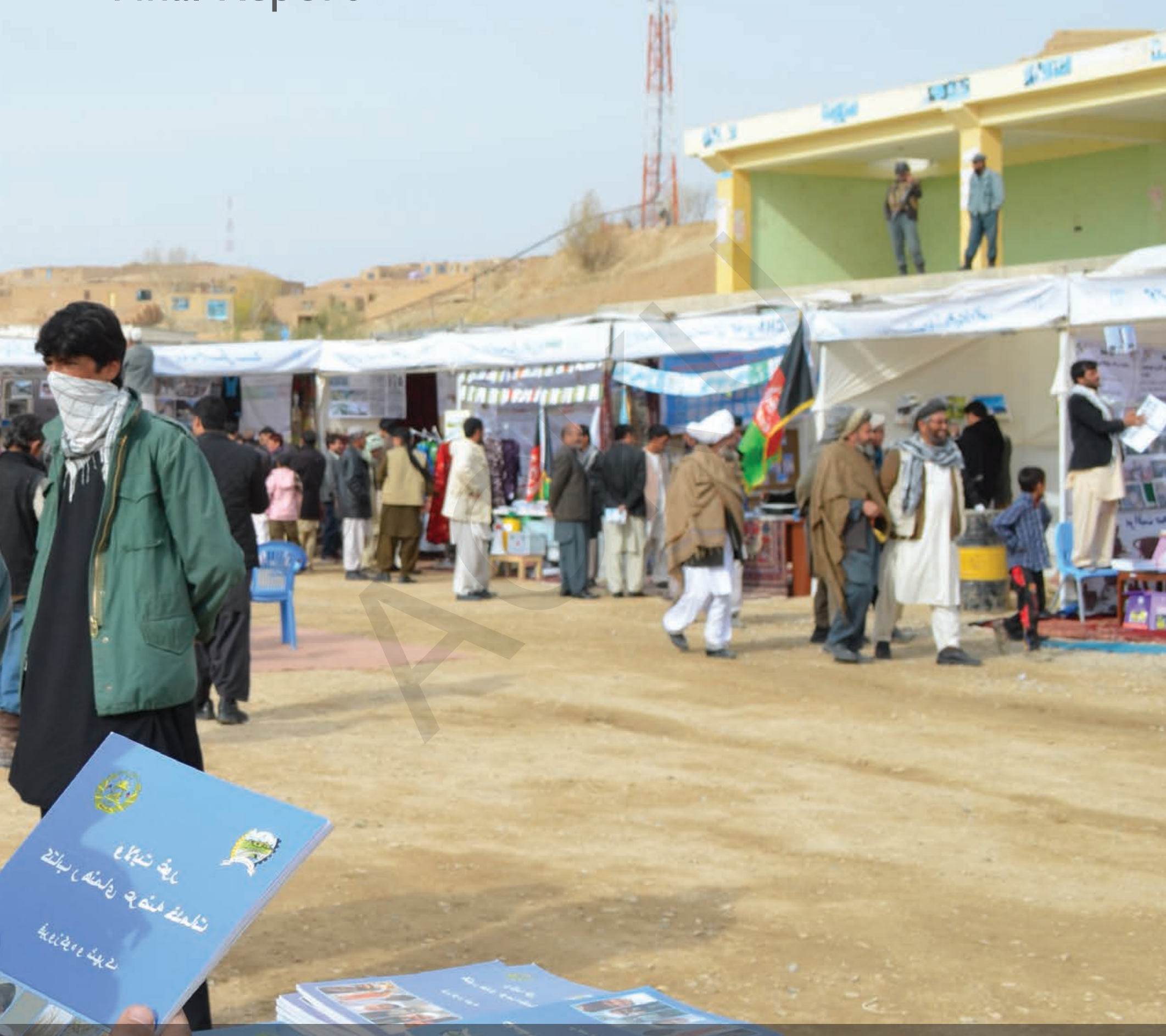

The authors' views expressed in this document do not necessarily reflect the views of the United States Agency for International Development or the United States Government. 


\begin{tabular}{|c|c|}
\hline Name of USAID Activity: & Afghanistan Stability in Key Areas (SIKA)-West \\
\hline Name of Prime Contractor: & AECOM International Development \\
\hline Total Funding: & USD $\$ 54,000,000$ (for base and option periods) \\
\hline Start Date: & January 29,2012 \\
\hline End Date: & August 31,2015 \\
\hline Geographic Locations: & $\begin{array}{l}\text { Farah Province: Farah Center, Bala Baluk, Pusht-e Rod, Khak-e-Safed, } \\
\text { and Lash Wa Juwayn } \\
\text { Herat Province: Pashtun Zarghun, Shindand, Kushk-e Rabat Sangi, } \\
\text { Guzara, and Kohsan } \\
\text { Badghis Province: Qadis, Muqur, and Qala-i-Naw } \\
\text { Ghor Province: Chaghcharan, Shahrak, and Du Layna }\end{array}$ \\
\hline Overall Goals and Objectives: & $\begin{array}{l}\text { SIKA-West was an initiative led by the Ministry of Rural Rehabilitation } \\
\text { \& Development (MRRD) and the Independent Directorate of Local } \\
\text { Governance (IDLG).The SIKA-West program was designed to } \\
\text { promote stability in key areas by assisting provincial authorities and } \\
\text { district-level government entities to improve governance programming } \\
\text { and increase the provision of priority basic services. The intended } \\
\text { result of SIKA-West was to increase citizen confidence in and support } \\
\text { for the Government of the Islamic Republic of Afghanistan (GIROA). } \\
\text { - Provincial and District entities increasingly addressed sources of } \\
\text { instability (community major problems) and take measures to } \\
\text { respond to the population's development and governance concerns. } \\
\text { - Provincial and District entities understand what organizations and } \\
\text { provincial line departments work within their geographic areas, what } \\
\text { kind of services they provide, and how the population can access } \\
\text { those services. } \\
\text { Provincial authorities improved their ability to communicate with } \\
\text { district entities to help them better understand their population's } \\
\text { needs and prioritize basic delivery interventions. } \\
\text { - Provincial authorities improved basic service delivery by using } \\
\text { GIRoA, CDCs, DDAs, and ASOP DCCs, which gain capacity to plan, } \\
\text { design, implement, and monitor projects, with a focus on labor- } \\
\text { intensive projects or productive infrastructure. } \\
\text { Built and improved upon current administrative and service } \\
\text { delivery knowledge and skill sets, that improve the effectiveness and } \\
\text { resiliency of GIRoA and equip provincial and district partners with } \\
\text { the tools necessary to address local government stabilization and } \\
\text { governance objectives. } \\
\text { - Gender mainstreaming programming was aligned with current IDLG, } \\
\text { MRRD, and DoWA gender mainstreaming frameworks and guidelines } \\
\text { and to be primarily focused on ensuring responsiveness to male and } \\
\text { female district resident concerns with respect to basic service delivery. }\end{array}$ \\
\hline
\end{tabular}




\section{Contents}

ACRONYMS

EXECUTIVE SUMMARY.

PROGRAM OVERVIEW...

I. STABILIZATION

II. RESOURCE DEVELOPMENT..

III. COMMUNICATIONS AND OUTREACH

IV. COMMUNITY DEVELOPMENT

V. GOVERNANCE.

GENDER MAINSTREAMING

MONITORING AND EVALUATION

WAY FORWARD 


\section{Acronyms}

\begin{tabular}{|c|c|}
\hline ANA & Afghan National Army \\
\hline ANP & Afghan National Police \\
\hline ANSF & Afghan National Security Forces \\
\hline $\mathrm{CCl}$ & Community Cohesion Initiative \\
\hline CDC & Community Development Council \\
\hline CIDD & Capacity Institutional Development Directorate \\
\hline CLDD & Community Led Development Directorate \\
\hline CMP & Community Major Problem \\
\hline $\mathrm{COP}$ & Chief of Party \\
\hline DAIL & Department of Agriculture, Irrigation, and Livestock \\
\hline DCOP & Deputy Chief of Party \\
\hline DDA & District Development Assembly \\
\hline DDP & District Development Portfolio \\
\hline DE & District Entities \\
\hline DG & District Governor \\
\hline $\mathrm{DGO}$ & District Government Office \\
\hline DoE & Department of Education \\
\hline $\mathrm{DoH}$ & Department of Health \\
\hline DoLSA & Department of Labor and Social Affairs \\
\hline DoPW & Department of Public Works \\
\hline DoWA & Department of Women's Affairs \\
\hline DP & District Profile \\
\hline DPP & District Project Portfolio \\
\hline DRRD & Directorate of Rural Rehabilitation and Development \\
\hline DSF & District Stability Framework \\
\hline DSM & District Stability Matrix \\
\hline DST & District Support Team \\
\hline DSW & District Social Worker \\
\hline $\mathrm{FOG}$ & Fixed-Obligation Grant \\
\hline GPS & Global Positioning System \\
\hline GIRoA & Government of the Islamic Republic of Afghanistan \\
\hline ICMA & International City/County Management Association \\
\hline ICRC & International Committee of the Red Cross \\
\hline IDLG & Independent Directorate of Local Governance \\
\hline IL & Implementation Letter \\
\hline IP & Implementing Partner \\
\hline $\mathbb{R}$ & Intermediate Result \\
\hline KSW & Komite Sobate Woleswali \\
\hline MISTI & Measuring Impacts of Stabilization Intervention \\
\hline MoE & Ministry of Education \\
\hline MRRD & Ministry of Rural Rehabilitation and Development \\
\hline NABDP & National Area-Based Development Program \\
\hline NDS & National Directorate Service \\
\hline NSP & National Solidarity Program \\
\hline ODG & Office of Democracy and Governance \\
\hline OSC & Overseas Strategic Consulting \\
\hline PDP & Provincial Development Plan \\
\hline PE & Provincial Entity \\
\hline $\mathrm{PGO}$ & Provincial Government Office \\
\hline
\end{tabular}




$\begin{array}{ll}\text { PMP } & \text { Performance Management Plan } \\ \text { PMT } & \text { Project Management Training } \\ \text { PPA } & \text { Project Priority Agreement } \\ \text { PST } & \text { Provincial Support Team } \\ \text { SAM } & \text { Stability Analysis Mechanism } \\ \text { SIKA } & \text { Stability in Key Areas } \\ \text { SOI } & \text { Source of Instability } \\ \text { SPC } & \text { Service Providers Catalogue } \\ \text { SSM } & \text { Sector Stability Meeting } \\ \text { STAB-U } & \text { Stabilization Unit } \\ \text { STEP } & \text { Social, Technical, Economic, and Political (Assessment) } \\ \text { SWOT } & \text { Strengths, Weaknesses, Opportunities, and Threats (Analysis) } \\ \text { TCNs } & \text { Third Country Nationals } \\ \text { TCRC } & \text { Tribal Conflict Resolution Committee } \\ \text { USAID } & \text { United States Agency for International Development }\end{array}$

In Western Afghanistan, the SIKA Program is referred to as "Sobat," using the Dari word for stability. 


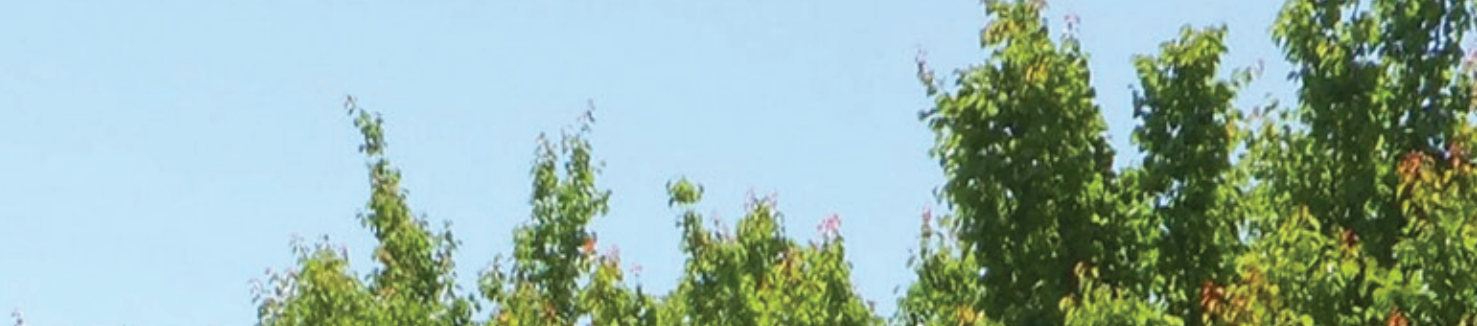

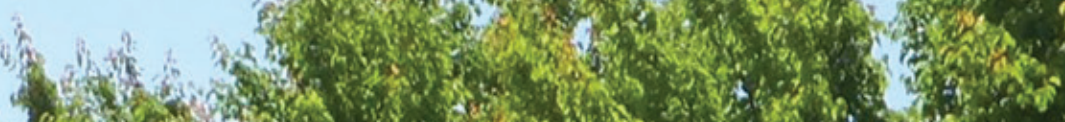
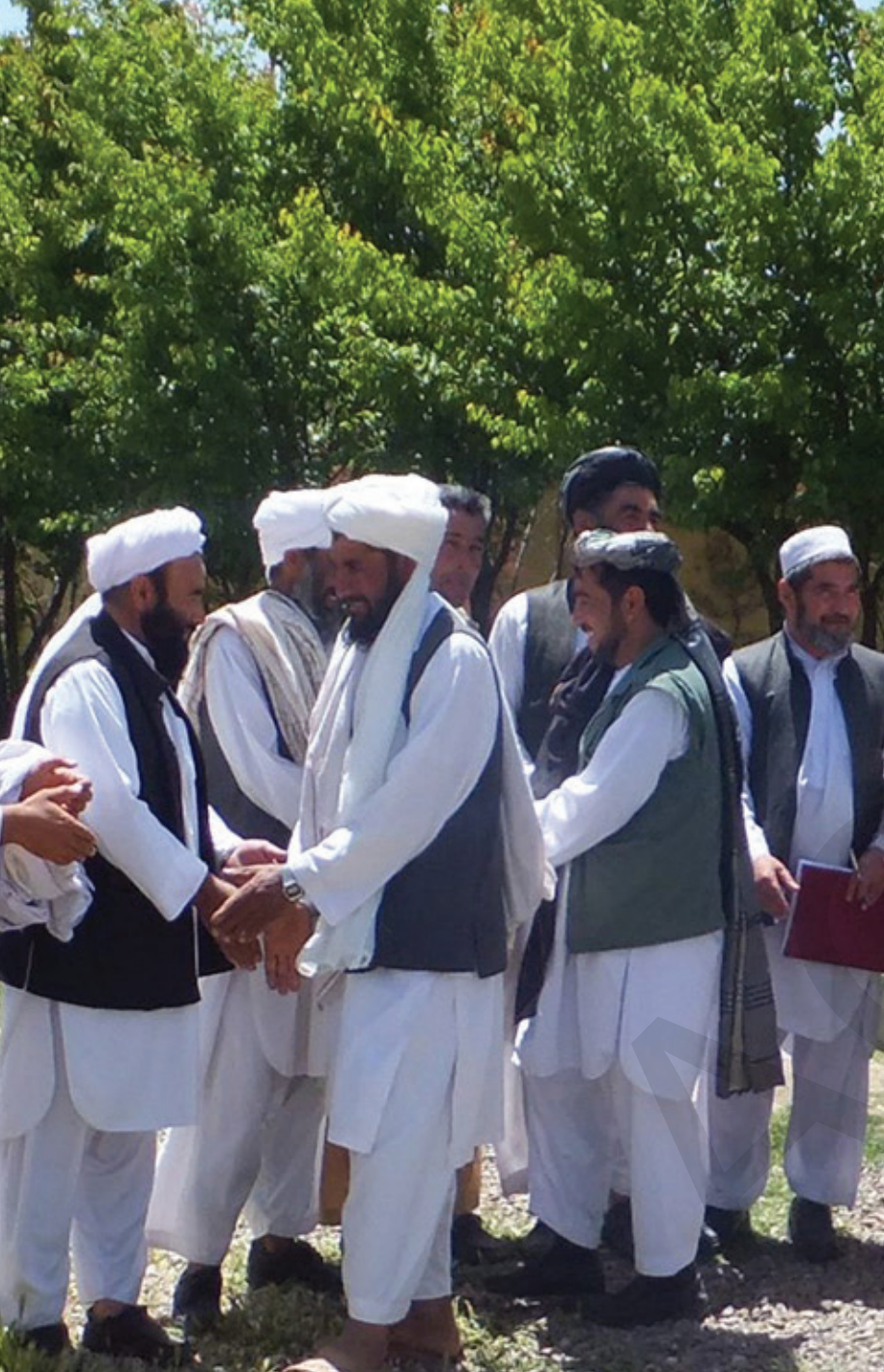

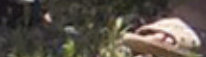

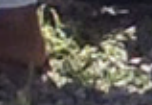

$2(3,2(3), 2)$
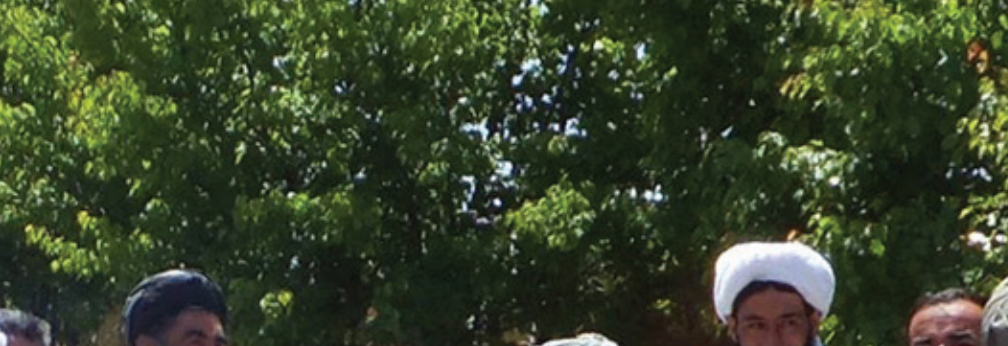


\section{Executive Summary}

The SIKA-West program ran from January 29, 2012 to August 31 , 20 I 5. During this period, the program empowered 13 District Government Offices (DGOs) and associated line departments, three Provincial Government Offices (PGOs) and associated line departments, four Provincial Department of Rural Rehabilitation and Development (DRRD) Offices, 16 District Development Assemblies (DDAs), and more than 800 Community Development Councils (CDCs) to take a leading role in the development of local communities.

The intended aim of SIKA-West was to improve local governance and stabilization efforts through increased citizen participation and service delivery. SIKA-West enabled communities to identify and address drivers of instability within their respective districts; improve local governance efforts; recognize and apply available resources to address community needs; and increase the range, scope, and effectiveness of communications between local government and district populations. SIKA-West also increased the stakeholder roles of both male in the management of grant funded infrastructure and vocational service delivery.

SIKA-West, in partnership with IDLG and MRRD, supported our GIRoA partners to

- build and demonstrate increased internal capabilities to address a range of "Community Major Problems" (CMPs)/ Sources of Instability (SOls) within our target districts;

- effectively identify and employ existing GIRoA resources in a resilient manner;

- improve communications both internally within provincial and district GIRoA structures and externally between local government and district populations;

- employ gender mainstreaming techniques to integrate both male and female perspectives — an approach required for effective local governance and district development;

- build on existing PGO and DGO capacities and services to improve their reach and effectiveness; and finally,

- oversee local government-led and managed district development programming.

The support provided to our provincial and district GIRoA partners enabled them to positively impact I,290, I I 6 local residents within 16 selected districts of Farah, Ghor, Badghis, and Herat provinces during the life of the project.

\section{SIKA-WEST PROGRAMMING}

With the support of our national, provincial, and district GIRoA partners, we moved forward to establish our stabilization and local governance programming. The pivot point for all of our programming components was the Komite Sobate Woleswali (KSW), which is the Dari translation of District Stabilization Committee/Council.

Based on existing District Government-led forums (Shuras), the KSW was designed to achieve multiple objectives:

- incorporate all district entities in one location so that all district leadership could participate in discussions on significant community grievances within their districts and agree on steps that could be taken by local government actors to address these grievances, reflecting an improved and responsive service delivery capability;

- ensure full participation and perspective from both male and female district residents to maximize programming effectiveness;

- publicize and promote local government responsiveness through improved communications and public outreach;

- enable GIRoA and District Entities to identify and utilize all available existing resources; and

- support GIRoA-led multi-tiered monitoring and evaluation efforts.

\section{PROVINCIALAND DISTRICT ENTITY PARTNERS}

- 4 Provincial Government Offices

- 4 Provincial DRRD Offices

- 13 District Government Offices

- 16 District Development Assemblies

- $800+$ Community Development Councils 


\section{PARTNERS}

To support the project's broad programming goals, SIKAWest provincial and district personnel were embedded within our IDLG and MRRD partners' offices, working closely to support them on current local governance and service delivery concerns. Working in such close proximity to our provincial and district GIRoA colleagues enabled our program to observe their performance firsthand, provide immediate mentoring and technical support, establish a close rapport, and ensure that our efforts were perceived by the district populations as GIRoA-led. The inclusion of both male and female perspectives, prioritization and resolution of concerns, and overall perception of local government responsiveness to both genders' needs were critical to the success of our district programming. Female district leadership, drawn from DDAs, CDCs, and Women's Councils, were a key component of the KSW, bringing valuable insight to the role that local government can play in addressing district resident service delivery needs.

Sustainability of SIKA-West programming was always a key concern throughout the Base and Option Periods. By the end of 20I4, in agreement with USAID, MRRD, and IDLG, SIKAWest shifted focus from collaborating directly with MRRD and IDLG on stabilization and governance programming to playing a much more limited supporting role, reducing the range of direct funding provided and handing over programming responsibility to its partners.

\section{LONG-TERM VISION}

Recognizing the limitations on the longer term availability of GIRoA financial resources, SIKA-West's handover of programming focused on key areas within stabilization, governance, resource development, and communications, which our GIRoA partners would be able to manage effectively. Notable successes include the following:

- handover and continued performance of Komite Sobate Woleswalis (KSWs) with long-term funding agreed to and provided by IDLG;

- linkage of KSWs to third-party service providers, enabling District Governments to continue to identify critical district needs and allocate resources;

- handover and continued use of District Government Communication Hotlines with long-term funding agreed to and provided by IDLG, enabling DGOs to continue to send out SMS messages on local government activities and ensuring that district populations can quickly contact their DGO representatives to receive feedback on available services;

- handover and continued use of the Provincial DRRD Service Provider Hotlines with long-term funding agreed to and provided by MRRD, enabling provincial and district residents to quickly find contact details for provincial and district government line departments and nongovernmental organization service providers.

It was not sufficient just to hand over these programming components at the end of the project's contractual period; SIKA-West also needed to ensure the sustainability of these activities. For this reason, SIKA-West began to withdraw funding from these activities in December 2014 and ended all financial and logistical support by February 20 I 5. From March to July 20 I5, the program observed and reported on these independent activities, reinforcing the view with MRRD, IDLG, and USAID that when program stakeholders play a key role in the development and implementation of programming, there is a greater chance for success in sustaining these activities.

This approach was in line with SIKA-West's overall strategic objective: Afghans have increased confidence in their Districtlevel government, leading to the expansion of GIRoA provincial authority and legitimacy at the community level. 


\section{SIKA-WEST}

\section{I.5 Million $70,000+$}

$20,900+$

12,562

Residents that had local grievances addressed, including improved service delivery.

Number of days women attended jointly sponsored SIKA-West and partner training. This included the training of over 3,000 women to use Service Provider Catalog, implement communications and outreach, address SOls, and participate in KSWs.

Participants at the 315 Komite Sobate Woleswalis (KSW) chaired by DGOs. Participants included district entity stakeholders, who took a leading role in discussing and assessing district wide 'community major problems' (CMPs)/ Sources of Instability (SOls) and publicly supporting local government led solutions. For many stakeholders, this was the first time they had a role in supporting and assisting their local government to effectively allocate available resources.

Afghans (24\% female) trained at 826 Capacity Building sessions on capacities that KSWs identified as needing strengthening including: communications, project management training, monitoring and evaluation (M\&E), resource identification and development, community development, gender mainstreaming, administration, and governance. Trainees also included 986 GIRoA officials and District Entity leaders.

GIRoA-led solutions (soft capacity building and hard infrastructure) to 21 $\mathrm{CMPs} / \mathrm{SO}$ s identified through the KSWs in 16 districts and incorporated into IDLG and MRRD approved Project Priority Agreements (PPAs) and District Project Portfolios (DPPs)

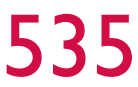

Grants in 16 target districts valued at USD $\$ 9.7$ million completed that were identified, designed, awarded, implemented, and managed by MRRD, IDLG, and District Entity program through a public and transparent Komite Sobate Woleswali process to improve service delivery within our, benefitting over I.5 million residents. These grants targeted transportation, agriculture and irrigation, education and health, governance, and vocational solutions and included 343,053 employment days provided to implement the grants and 104,530 training days.

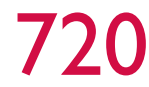

Communications and outreach events to improve district government partners' communications capabilities internally within GIRoA structures and externally with district populations. Events included 18 radio and television engagements, 444 public meetings, forums, and town hall events, 240 communications and public outreach trainings, I4 SMS campaigns that included 6,072 messages, and four provincial service provider fairs. 


\title{
ACCOMPLISHMENTS
}

\author{
Access
}

\section{Empowerment}

Improved access of 1.5 million residents in western Afghanistan to government services by successfully supporting provincial and district stakeholders to implement activities such as Service Provider Catalogs, SMS messaging, public forums and town halls, hotlines, social media, service provider fairs, and advocacy efforts.

Local citizens are more empowered to solve development constraints. They work directly with government sector representatives to identify community development hurdles and implement local solutions in health, education, security, and agriculture sectors.

District and provincial entities acquired the ability to plan, develop, manage, and monitor local development through participation in joint monitoring visits of SIKA-West grants.

\section{Improvement}

\section{Collaboration}

\author{
dge
}

Women

\section{Sustainability}

Secured IDLG, MRRD, and DOWA agreement and funding to sustain and continue KSWs, DGO Communication Hotlines, DRRD Service Provider Hotlines, and Provincial Gender Mainstreaming Working Groups. Sustainable $\mathrm{KSW}$ s are now in place within 15 districts. 


\section{Program Overview}

The SIKA-West program, in collaboration with MRRD and IDLG, supported Government of the Islamic Republic of Afghanistan (GIRoA)-led district-based stabilization and good governance programming in 16 districts. The program used the term Komite Sobate Woleswali (Dari translation of District Stabilization Committee) to describe the monthly forums that were the pivot points for all program activities.

SIKA-West was highly Afghanized, responsive to regional realities, demand driven, and owned by GIRoA counterparts. It was integrated with Afghan programs such as the National Solidarity Program (NSP) and National Area-Based Development Program (NABDP); supported, mentored, and empowered the GIRoA; built the capacity of provincial and district entities; and procured goods and services locally whenever possible following the Afghan First policy. Activities were implemented with the GIRoA at the district level and coordinated at the provincial and national levels.

Instability and insecurity are the most pervasive challenges facing Afghanistan's development and reconstruction.

Cognizant of these factors, the program engaged with existing District and Provincial Entities to implement community-led development and governance initiatives to address Sources of Instability (SOls), increasing provision of basic services and the capacity to deliver and manage these services.

\section{THE SIKA-WEST FRAMEWORK}

SIKA-West's approach was defined by the Results Framework, which had the strategic objective "Afghans have increased confidence in their district-level government, leading to the expansion of the GIRoA's provincial authority and legitimacy at the community level." This was supported by the program objective "To assist GIRoA officials at the district and provincial levels to respond to the population's development and governance concerns, to better instill confidence and build stability, provide the improved functioning of government, and enable the provisioning of priority GIRoA-led basic services to better instill confidence and build stability."
These objectives are linked to the following expected results (and described in the subsequent chapters of this report):

I. Stabilization: Provincial and District: Entities to increasingly address sources of instability (community major problems) and take measures to respond to the population's development and governance concerns.

II. Resource Development: Provincial and District Entities to understand what organizations and provincial line departments work within their geographic areas, what kind of services they provide, and how the population can access those services.

III. Communications and Public Outreach: Provincial authorities to improve their ability to communicate with district entities in order to help them better understand their population's needs and prioritize basic delivery interventions.

IV. Community Development: Provincial authorities to be able to improve basic service delivery by using GIRoA, CDCs, DDAs, and ASOP DCCs, which gain capacity to plan, design, implement, and monitor projects, with a focus on labor-intensive projects or productive infrastructure.

V. Governance: To build and improve upon current administrative and service delivery knowledge and skill sets, which will improve the effectiveness and resiliency of GIRoA and equip provincial and district partners with the tools necessary to address local government stabilization and governance objectives.

VI. Gender Mainstreaming: Gender mainstreaming programming to be aligned with current IDLG, MRRD, and DoWA gender mainstreaming frameworks and guidelines and to be primarily focused on ensuring responsiveness to male and female district resident concerns with respect to basic service delivery. 


\section{PROGRAM PARTNERS}

\section{Independent Directorate of Local Governance (IDLG)}

The mission and mandate of IDLG is to ensure peace and stability, achieve development and balanced economic growth, and improve service delivery by supporting strong and capable governance entities to employ just and democratic processes at the local level.

\section{Ministry of Rural Rehabilitation and Development (MRRD)}

MRRD strives to ensure the social, economic, and political well-being of rural societies, especially poor and vulnerable communities, through the provision of basic services, strengthening local governance, and promoting sustainable livelihoods.

\section{Department of Women's Affairs (DOWA)}

DOWA strives to ensure that Afghan women's legal, economic, social, political, and civic rights, including their right to be free from all forms of violence and discrimination, are respected, promoted, and fulfilled.

\section{National Area-Based Development Program (NABDP)}

MRRD launched NABDP in 2002 with the support of UNDP to contribute to the sustainable reduction of poverty and an improvement in livelihoods in rural communities by investing in social organization, infrastructure, local economic development, and sub-national governance initiatives.

\section{National Solidarity Program (NSP)}

MRRD created the NSP in 2003 to develop the ability of Afghan communities to identify, plan, manage, and monitor their own development projects. Communities elect their own leaders and representatives to form voluntary Community Development Councils (CDCs) through a transparent and democratic process.

\section{Community Development Council (CDC)}

Communities select members (both men and women) to serve as their decision-making bodies. CDCs are responsible for implementing and managing development projects and are key liaisons between the community and both government and non-governmental organizations.

\section{District Development Assembly (DDA)}

DDAs were designed to represent the rural communities at the district level, with CDCs electing DDA members through a transparent and democratic process. DDAs play a pivotal role in rural development by incorporating district priorities into District Development Plans (DDPs). NABDP instituted DDAs to represent the voice of rural Afghans (including women) and to promote engagement with the central government, incorporating district priorities into Provincial Development Plans (PDPs). Since the inception of DDAs, NABDP has set out to support and strengthen their capacity. CDC cluster representatives make up DDA membership.

\section{SUBCONTRACTORS}

International City/County Management Association (ICMA) as a subcontractor to AECOM provided inputs and leadership for the IR4 Community Development component as well as in capacity building activities. During the Option Period of SIKA-West, ICMA's contributions were increasingly targeted and focused on the District Government Capacity Index.

Overseas Strategic Consulting, Ltd. (OSC) as a subcontractor to AECOM designed and implemented the communication and outreach strategy for SIKA-West. OSC's work centered on involvement, collaboration, and cooperation with IDLG, district governor s, and district entities. 
Although the program launched in January 20 I2, SIKA-West could undertake activities only after the Implementation Letter (IL) was signed between USAID, MRRD, and IDLG on September 3, 20 I2. Due to the delay with the IL, the program received a seven-month extension, shifting the base period from 18 months to 25 months. SIKA-West moved quickly to mobilize into its first round of ten districts within the four provinces of Farah, Badghis, Ghor, and Herat (which were identified and approved by USAID, MRRD, and IDLG) for the base period.

\section{DISTRICT ENTITIES DEFINED}

SIKA-West defines District Entities as "institutions that are Afghan led and work at the district level. These institutions include District Governors (DG) and their partners; MRRD/NABDP-established District Development Assemblies (DDAs); MRRD/NSP Community Development Councils (CDCs); and, where none of these exist, traditional District Shuras."

It is important to note that SIKA-West was designed to work exclusively at the district level. Although the program engaged with and maintained close working relationships with provincial governments, it did so to further district programming activities, not to actively engage in programmatic support at the provincial level.

To ensure that these efforts were sustainable, it was critical that SIKA-West worked with existing district entities and their current capacities for stabilization and local governance programming. The program avoided any efforts that would result in the creation of new entities so as not to see these efforts fail after the program closed due to a lack of GIRoA interest, resources, or capacities.

SIKA-West implemented activates in close collaboration with MRRD and IDLG at the national, provincial, and district level, ensuring that stabilization and governance programming aligned with and built on existing GIRoA frameworks, practices, and guidelines. SIKA-West received significant support from the MRRD and IDLG SIKA units, which served as liaisons between SIKA-West and GIRoA ministries. With these units, SIKA-West was able to collaborate more effectively with provincial and district partners and obtain greater access to district entity work product and records. Most important, SIKA-West was able to receive a comprehensive picture of the current structure and capacities of PGOs and DGOs under IDLG, District Development Assemblies (DDAs), and Community Development Councils (CDCs). SIKA-West also received background on past and current GIRoA-led district development programming under the National Solidarity Program (NSP) and National AreaBased Development Program (NABDP).

\section{ENGAGING PROGRAM PARTNERS}

SIKA-West relied on existing and sustainable GIRoA structures to implement activities. The approach used was a "Community Engagement Matrix" as described later in this report. Key to implementing this approach were the Komite Sobate Woleswalis (KSWs) located in each program district.

A KSW is made up of district government officials, District Development Assemblies (DDAs), Community Development Councils (CDCs), Tribal Elders, and community leaders, organized and led by the district governor. KSWs work to identify and resolve problems within their communities. DDAs and CDCs operate at the district level to ensure that community inputs are incorporated in the identification of community grievances, recommendations on solutions, and design of grant-funded interventions.

The MRRD and IDLG SIKA units played a critical role in providing materials that enabled SIKA-West to build on, reinforce, and expand existing stabilization, governance, resource development, communications, gender, and community development skills that were previously developed by GIRoA. SIKA-West also relied on these units to provide programmatic guidance through the employment of SIKA steering committees, coordination meetings, and/ or on-site visits to SIKA program offices in Herat. This level of coordination enabled SIKA-West to communicate its programming objectives effectively to provincial and district partners, address programmatic challenges, publicize and promote achievements, and maintain effective communication channels between provincial and district partners, MRRD and IDLG SIKA units, and the national ministries.

\section{FEMALE EMPOWERMENT}

Recognizing that the involvement of women is vital to good governance, as a cross-cutting objective, SIKA-West promoted GIRoA's National Action Plan for Women of Afghanistan (NAPWA) and MRRD's gender policy. The program built on the successful efforts of other initiatives such as the MRRD District Development Assemblies (DDAs) and the Community Development Councils (CDCs) of the National Solidarity Program (NSP).

SIKA-West relied on the constant support of the Provincial Departments of Women's Affairs in Farah, Badghis, Herat, and Ghor to implement gender-mainstreaming activities. While not a contractual partner, the program recognized the importance of building on past and current gender initiatives 


\section{DISTRICT SELECTION CRITERIA}

The districts were selected at the national level based on the following USAID-approved district criteria:

I. Potential for functioning CDCs/DDAs, with linkage to DCCs where appropriate, that are able to prove that they meet regularly, are perceived as a lead entity in development activities, and are formally recognized by MRRD.

2. Likelihood that SIKA will facilitate conditions for follow-up assistance programs to complement SIKA's efforts and provide support after SIKA is no longer operational in the district.

3. Security conditions allow MRRD, USAID, and the Implementing Partner the ability to effectively operate and monitor SIKA activities in the district.

4. The district has GIROA representation, including a functioning District Governor, Ministry of the Interior, and MRRD to provide support and leadership.

5. The district represents a strategic priority by containing a substantial population center, has potential for a strategic economic contribution to Afghanistan's economy, and represents a strategic transportation corridor.

\section{GEOGRAPHIC STRATEGY}

The base period districts were Bala Baluk, Pusht Rod, Khake-Safed, Shindand, Pashtun Zarghun, Kushk-e-Rabat Sangi,

Shahrak, Chaghcharan, Qadis, and Muqur. The program start dates within these districts were staggered based on approval received from USAID, MRRD, and IDLG. By June 20I3, SIKAWest was active within all regions.

\section{AREAS OF OPERATION}

The districts are listed under each province.

$\begin{array}{ll}\text { Farah Province } & \text { Herat Province } \\ \text { Bala Baluk } & \text { Shindand } \\ \text { Pusht Rod } & \text { Kushk-e-Rabat Sangi } \\ \text { Khak-e-Safed } & \text { Pashtun Zarghun } \\ \text { Lash Wa Juwayn } & \text { Guzara } \\ \text { Farah Center } & \text { Kohsan }\end{array}$

$\begin{array}{ll}\text { Ghor Province } & \text { Badghis Province } \\ \text { Shahrak } & \text { Muqur } \\ \text { Du Layna } & \text { Qadis } \\ \text { Chaghcharan } & \text { Qala-e-Naw }\end{array}$

BASE PERIOD OPTION PERIOD 10 Districts 16 Districts

Jan 2012-Feb 2014 Feb 2014 - Aug 2015

\section{OPTION PERIOD DISTRICTS}

Expansion Districts: Program focus was on stabilization activities (with gender-mainstreaming support for KSWs only), community development, and monitoring and evaluation programming only. SIKA used a minimal number of new district staff (where required) while also employing the full resources and personnel from neighboring districts and provincial offices to provide technical support. SIKA-West had three expansion districts during the option period: Guzara (Herat Province), Du Layna (Ghor Province), and Farah Center (Farah Province).

New Districts: Program focus was on stabilization, resource development and communications/public outreach, community development, governance, gender mainstreaming, and monitoring \& evaluation. Where required, new standalone District Support Teams (DSTs) were set up. SIKA-West had three new districts: Kohsan (Herat Province), Lash Wa Juwayn (Farah Province), and Qala-e-Naw (Badghis Province).

In February 2014, discussions began between USAID, MRRD, and IDLG to select six additional districts utilizing the same district selection criteria. Recognizing that not all of the base period districts met the required criteria, SIKA-West was proactive in working with IDLG and MRRD to ensure that these criteria were shared with Provincial and District Government Offices and DRRD Offices within its four provinces so that residents would be able to provide key inputs.

On May 06, 20I4, SIKA-West received instruction from USAID, MRRD, and IDLG to expand its list of target districts to include Farah Center, Guzara District, Kohsan Dist rict, Du Layna District, and Qala-e-Naw Center. This left the program with a total of 16 target districts between May 2014 and the program closedown date of August 3I, 20I5. Within its target provincial and district regions, SIKA-West engaged, supported, and collaborated with four Provincial Government Offices (PGOs), four Provincial DRRD Offices, 13 District Government Offices (DGOs), 16 District Development Assemblies (DDAs), and more than 800 Community Development Councils (CDCs).

Within the 16 districts, the total population was estimated at I,24I,400 residents. ${ }^{4}$ Major population centers included Farah Center ( 106,400 residents), Shindand (170,900), Kushk-eRabat Sangi (I | 8,800), Guzara (|40,000), and Chaghcharan $(129,600)$, while remaining districts contained less than 100,000 residents each.

4 Population figures were drawn from SIKA's District Profiles. Please see Annex E. 


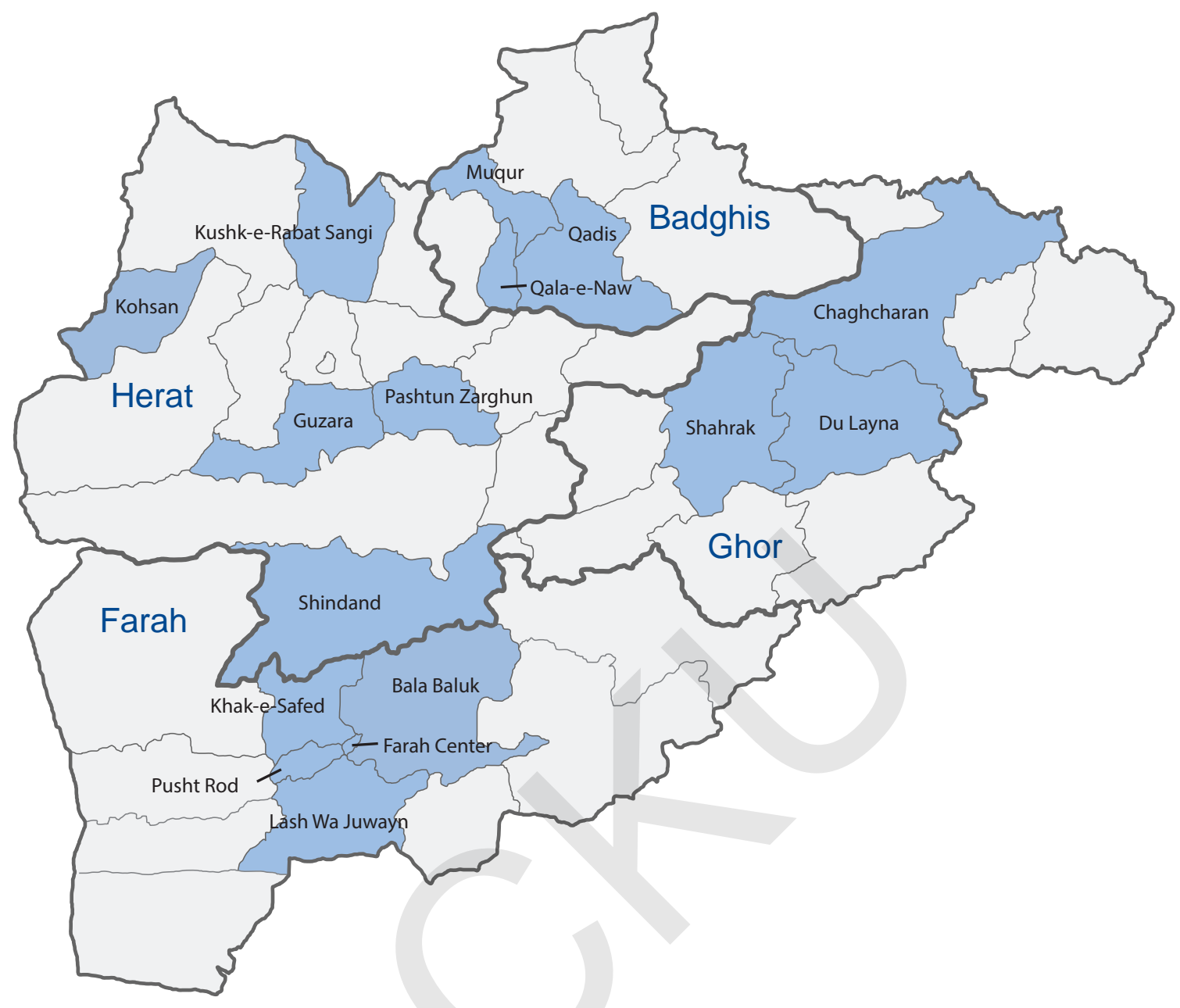

\section{District Profile Overview}

\section{FARAH PROVINCE}

Bala Baluk, Pusht Rod, Lash Wa Juwayn Districts

- Dominant tribes are Pashtun

- Economies depend on agriculture, livestock, handicrafts, and migrant labor

- 3 DDAs, 223 CDCs

\section{HERAT PROVINCE}

Kushk-e-Rabat Sangi, Pashtun Zarghun, Shindand, Kohsan Districts

- Dominant tribes are Pashtun and Tajik

- Economies depend on agriculture, livestock, and migrant labor

- 4 DDAs, 543 CDCs

\section{BADGHIS PROVINCE}

Muqur, Qadis, Qala-e-Naw Districts

- Dominant tribes are Tajik and Pashtun

- Economies depend on trade, agriculture, livestock, and handicrafts

- 3 DDAs, 354 CDCs

\section{GHOR PROVINCE}

Chaghcharan, Shahrak Districts

- Dominant tribes are Aimaks and Tajiks

- Economies depend on agriculture, livestock, trade, and handicrafts

- 2 DDAs, 43 I CDCs 
In line with the district criteria, SIKA-West collaborated with MRRD and IDLG to identify active District Entities (DDAs, CDCs, and District Shuras) that were capable of taking a leading role in district governance and stabilization affairs. To implement successfully, SIKA-West needed to recognize both the capabilities of District Entities and the surrounding environment within which they lived and operated. While the level of tribalization varied from region to region depending on how urbanized the population had become, tribal affiliations, patronage networks, regional loyalties, and family networks remained critically important, requiring the program to understand these relationships. To do so, SIKA-West developed District Profiles (DPs). ${ }^{4}$ Please refer to Annex E for the program's DPs.

While the program worked in collaboration with its partners to develop the DPs, SIKA-West also developed district rollout Plans, which provided a complete overview of the program's approach when engaging with its target districts. Please see the following step-by-step process.

\section{DISTRICT ROLLOUT PLAN}

- Establish working relationships with provincial DRRD and provincial and district government partners to outline the scope and stated aims of the SIKA-West stabilization and governance activities. SIKA's role in supporting MRRD and IDLG is to address district communities' "Sources of Instability (SOIs)" through the use of the Stability Analysis Mechanism (SAM) and to enable a GIRoA-led effort to provide viable solutions to major problems and improved service delivery to district populations.

- Complete a security review of district environment and the establishment of robust communications and strong working relationships with local security forces.

- Assess existing conditions and space requirements within DRRD and DGO facilities to embed SIKA personnel at the provincial and district levels.

- Recruit provincial and district program personnel using procedures that include a role for DRRD and DGO personnel.

- In collaboration with MRRD and IDLG, prepare a record of District Entities (DDAs, CDCs, tribal leaders, Ulema, and MRRD District Social Workers) for KSW membership under the leadership of the district government.

This approach was replicated across all ten districts during the base period. As outlined earlier in this report, SIKA-

\footnotetext{
2 SIKA-West developed 12 comprehensive District Profiles. There were no District Profiles for Guzara District (Herat Province), Du Layna District (Ghor Province), and Farah Center (Farah Province) because these districts were classified as "Expansion Districts" and did not include Communications and Public Outreach programming. In addition, due to the destruction of the Khak-e-Safed DGO in April 20 I4, CPOD activities were suspended until the end of the contract, preventing the creation of a profile for that district.
}

West was awarded six more districts during the option period. These districts were further classified into "expansion districts" and "new districts." The driving aim behind this additional classification was to factor in the pending reduction in programming spending as a result of USAID's reduction to the SIKA-West budget. By adding the classification of expansion districts, SIKA-West could at least undertake stabilization and community development programming within a district, reducing overall programming costs but continuing to materially assist MRRD and IDLG partners to respond to district population needs.

The initial security review of each assigned district was a critical step prior to committing resources and launching programming components. Security conditions varied considerably across districts. This was a reflection of GIRoA investment within local security forces, ongoing campaigns, insurgent activities, unresolved tribal disputes, and current criminal behavior. The program's first actions were to establish working relationships with provincial and district security forces to gain a firsthand understanding of the security challenges inherent within each region. In collaboration with its MRRD and IDLG partners, SIKA-West established close and productive working relationships with the Afghan National Army (ANA), Afghan National Police (ANP), and National Directorate Service (NDS) within the program's provinces and districts. This proved to be invaluable and enabled SIKAWest to mobilize safely and with a great deal of confidence as it launched district activities.

\section{TRANSITION AND HANDOVER}

With the support of USAID, a transitional working group was established in January 20 I 5. SIKA-West, East, South, and North coordinated with MRRD, IDLG, and USAID to agree on work product and programming materials to be handed over to our partners at the ends of the programs. SIKA-West prepared communications, governance, gender, and monitoring and evaluation programming materials (hard and soft records), which were handed over to district governments, provincial DRRD offices, and the respective MRRD and IDLG SIKA units between May and August 2015. 


\section{The SIKA Impact}

\section{LONG-TERM SUSTAINABLE KOMITE SOBATE}

Woleswalis Sustainable KSWs are now in place within 15 districts, employing current GIRoA funding. These public and transparent forums will continue to identify and address community grievances, apply available resources, and improve both service delivery and district development programming efforts. KSWs are linked to NABDP and NSP programming and in certain districts to other $\mathrm{NGO}$ and other USAID programs.

\section{STRENGTHENED PARTICIPATION OF MALE AND FEMALE DISTRICT RESIDENTS}

SIKA-West has seen strong participation among male and female district residents within all of its programming components. The program strived to reinforce the view that both male and female inputs, experiences, and perspectives were critical to effective local governance and district development programming. The project was rewarded with a strong commitment from its IDLG and MRRD partners, ensuring full participation of male and female residents within the overall stabilization and governance programming.

\section{INCREASED ACCESS TO AVAILABLE RESOURCES}

SIKA-West successfully supported our provincial and district stakeholders in identifying and employing available GIRoA and third-party donor resources. This was a first for many DGOs, which were not accustomed to searching for outside resources. Through Service Provider Catalogs (SPCs), SMS messaging, public forums and town halls, hotlines, social media, service provider fairs, and advocacy efforts, DGOs and District Entities were taught how to find and allocate available provincial and district resources. This resulted in KSWs independently managing and addressing 22 community grievances without grant funding from SIKA-West.

\section{IMPROVED COORDINATION FOR DISTRICT DEVELOPMENT PROGRAMMING}

Through the use of the KSWs, DGOs are now much more aware and better informed by DEs on existing district development programming activities. The KSWs have provided simple public forums where all district governance and development programming are discussed, enabling DGOs to have a comprehensive overview of activities, maximize coordination, and avoid duplication. This coordination will continue as DGOs link their KSWs to future GIRoA and donor-funded district governance and development efforts.

Government Officials Cut the Ribbon To Inaugurate the Two-Day Badghis Service Providers Fair

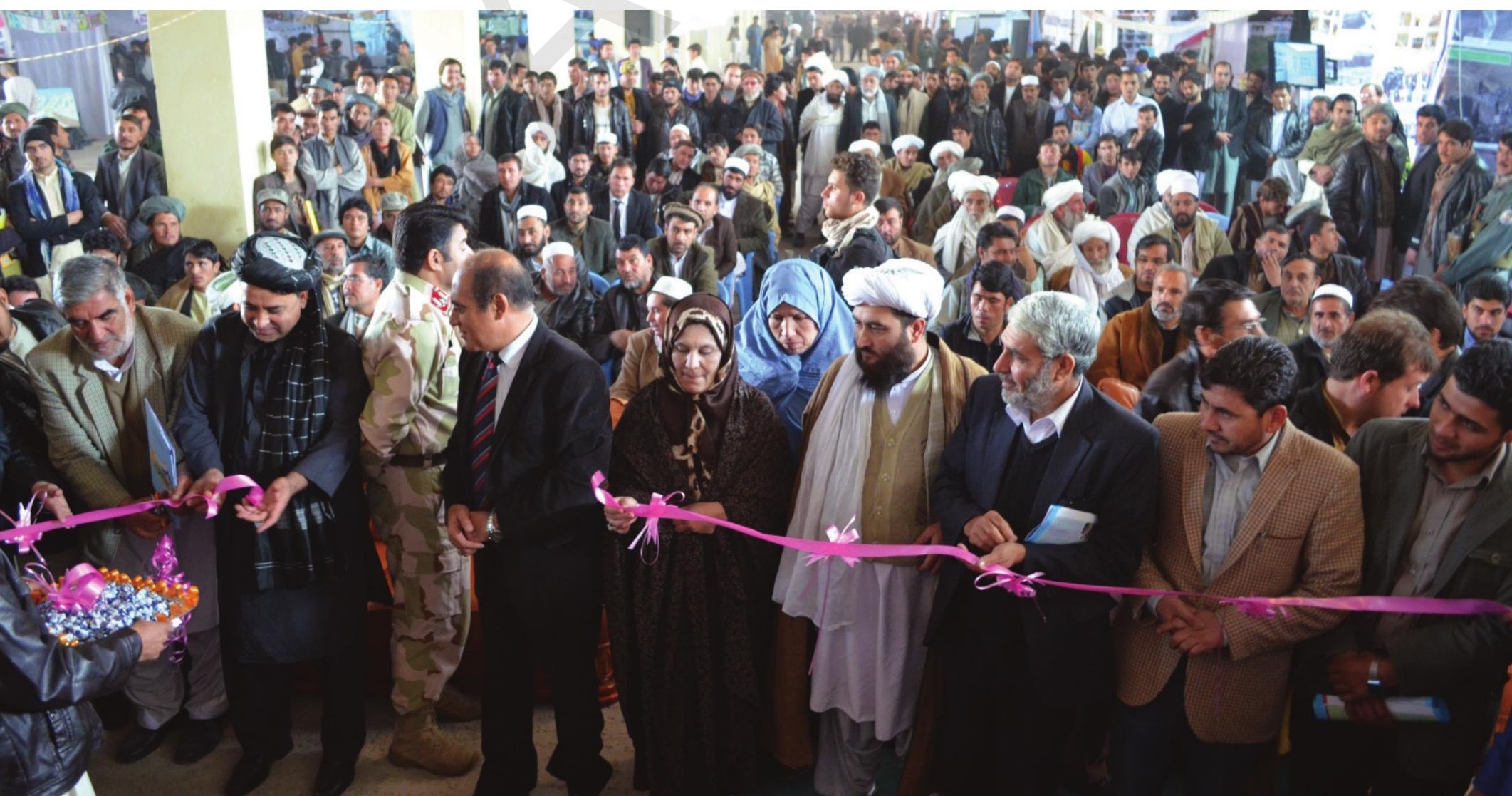




\section{Kushk Rabat-e Sangi}

\section{Agriculture Factsheet}

\section{Agriculture is the main pillar of the Kushk Rabat-E Sangi district economy. Good agriculture practices will increase farmer productivity.}

\section{Join the Farmers' Cooperatives of Kushk Rabat-e Sangi}

Farmers' cooperatives are non-governmental entities working on behalf of district farmers to help improve their agricultural businesses. A cooperative is made up of two boards - the administrative and the monitoring board. The administrative board is responsible for the implementation of the day-to-day functions and planning, as well as communicating farmer concerns and problems to DAIL and the district government, and interacting with the other district cooperatives. The monitoring board monitors the implementation of the cooperative's activities.

These small district cooperatives are part of a larger entity called the Cooperative Union. Each district has one Cooperative Union.

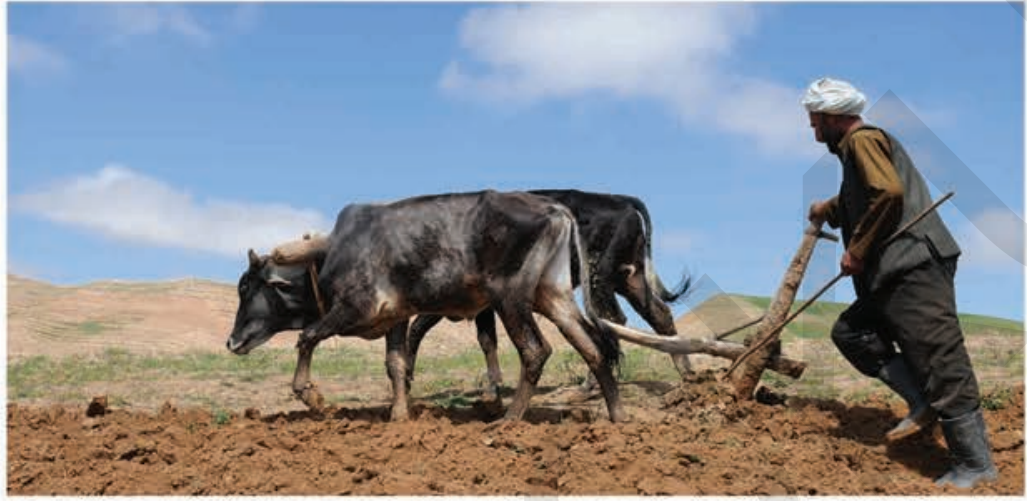

How can farmers' cooperatives contribute to the sustainable development of your agricultural business?

- Cooperatives provide members with agricultural tools and other important resources and services:

One of the responsibilities of farmers' cooperatives is to provide farmers with necessary items at a reasonable cost and in a timely manner. Farmers' cooperatives provide materials including fertilizers, sprays, and seeds.

- Cooperatives prepare loans:

Cooperatives as a legitimate entity can apply for loans. The loans are allocated to the cooperative. The cooperative will spend the money for purchasing the agricultural implements, seeds, and other needed farming materials.

- Cooperatives regulate and stabilize local markets:

Cooperatives can foster good business relations and promote economic organization in order to develop a strong and sustainable market for agricultural crops. This can lead to overall strengthening of the district economy.

- Cooperatives provide training and promotion:

Farmers' cooperatives can train farmers in new agricultural technologies and farming techniques. This can increase the productivity of farmers.
How you can join a farmers' cooperative in your village?

- To join a cooperative you must first have 1,000 AFS in order to hold a share in the cooperative. This money will be transferred to the Cooperative Management's bank account. The Cooperative Management works inside the district under the DAIL. It is responsible for connecting the individual cooperatives with the DAIL. Government will use this money and invest to improve the agriculture business of the members of the cooperatives.

- To be a member of the cooperative you need to do some paper work. You must pay a membership fee of 520 AFS to complete the process.

Working with others makes it easier for farmers to improve their agricultural businesses and acquire the resources necessary for successful farming. Cooperatives provide you with more power as a farmer and member of the community. You are part of a group of people with a single goal, and in a cooperative you can work together to achieve it. 


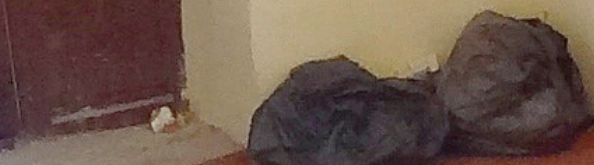




\title{
I. Stabilization
}

\author{
Provincial and District Entities to address sources of instability \\ and take measures to respond to the population's development \\ and governance concerns.
}

SIKA-West stabilization programming was designed around the understanding that District Entities (DEs), District Government Offices (DGOs) and Line Departments, the Department of Rural Rehabilitation and Development (DRRD), District Development Assemblies (DDAs), Community Development Councils (CDCs), tribal elders, community leaders, and ulema (religious leaders) are best placed to identify drivers of instability within their communities and to prioritize and implement locally appropriate solutions. Based on USAID's District Stability Framework (DSF), the SIKA-West Stability Analysis Mechanism (SAM) was an Afghanized tool used to identify and address district communities' major problems (CMPs) and Sources of Instability (SOls) in an inclusive and effective fashion. The SAM is based on the premise that local government and district entities can identify CMPs that divide communities, alienate populations from their local government, and provide opportunities for insurgents to exploit existing and longstanding grievances. Additionally, local government can recognize how to address and resolve these grievances while reinforcing the legitimacy of the district government as a competent and responsive service provider.

\section{KEY RESULTS AND ACHIEVEMENTS}

3 I 5 KSWs chaired by DGOs, with a tracked attendance of 20,909 district entity stakeholders (approximately 10\% women), assisted local governments to identify and address CMPs/SOIs.

22 KSWs established in 16 districts where IDLG and MRRD utilized the Afghanized SAM to increase GIRoA's legitimacy and improve its ability to deliver on basic services.

650 GIRoA-led solutions to 21 common CMPs/SOls across the 16 districts identified through the KSWs and incorporated into IDLG and MRRD-approved Project Priority Agreements (PPAs) and District Project Portfolios (DPPs).

I 7 DPPs created, resulting in 535 GIRoA-led solutions, identified and implemented by $22 \mathrm{KSW}$ s to address longstanding community grievances while improving local government service delivery efforts. 
SIKA-West began with the establishment of District Stabilization Committees (DSCs), which were later renamed Komite Sobate Woleswalis (as part of the Afghanized approach). Within 16 districts, $22 \mathrm{KSWs}$ were established (ten mixed, six male, and six female where deemed culturally appropriate by GIRoA partners). KSW members included DGOs, DDAs, CDCs, tribal elders, and ulema. This broad range of influential individuals and groups helped shape collective views, uphold communal decisions, and strongly support local government efforts to assume a greater responsibility to improve GIRoA-led service delivery. The KSWs also included existing GIRoA-led district development, primarily MRRD, NABDP, and NSP, as well as other donor efforts to leverage resources.

\section{Capacity Building}

SIKA-West capacity-building efforts enabled GIRoA to lead its own KSW-based district stabilization and governance efforts, employing the SAM to identify district CMPs, reasons for these problems, and solutions directly addressing causes of instability within their districts, furthering the delivery of critical services and responding to district populations' governance concerns. To ensure longer term sustainability and effectiveness, SIKA-West focused on the following support:

- Provided clear, concise training on the purpose, aims, and benefits of the stabilization program, educating provincial and district stakeholders on how SIKA-West should be used to assist local governments to identify and resolve significant community grievances through the use of improved service delivery.

- Ensured that the program's GIRoA partners had a complete understanding of their districts in terms of population, ethnic breakdown, tribal structure, power brokers, influential actors, economic factors, the range of existing services, and so forth. Collaborating with DGOs and DRRD on the creation of DPs guaranteed that they were better informed when discussing district-wide concerns during KSW meetings.

- Developed the SAM in an Afghanized fashion, meaning that complex language and definitions were removed

\section{2,562 Agranas a cauires skilis} in communications, project management training, M\&E, and administration and governance through 826 capacity-building sessions.

or converted into easily understood terms. "Sources of Instability" (SOls) was changed to "Community Major Problems" (CPMs). "Rationale" was changed to "reasons," and "mitigation activities" was changed to "solutions." These changes, among others, made it far easier for KSW members to understand the process. District entities were also provided with the opportunity to identify their own CMPs (as opposed to being informed of them) so that grassroots community perspectives were considered from the very beginning, avoiding the imposition of outside solutions, increasing stakeholder engagement, and further strengthening the SAM process.

- SIKA-West did not impose any deadlines on the SAM process and worked closely with its counterparts to ensure that grievances were fully aired and that DEs

\section{Trainees by Gender}

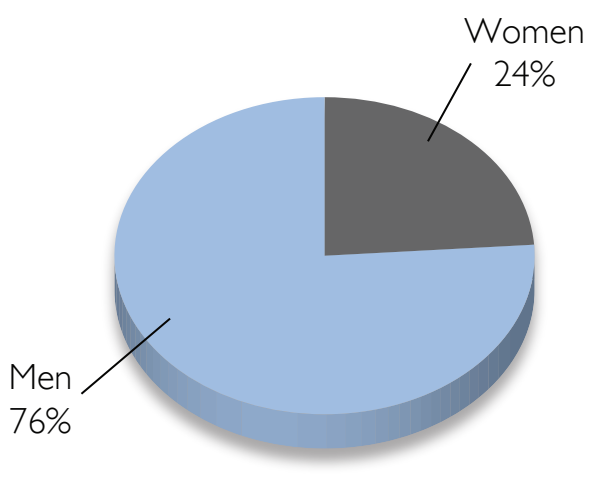

\section{Types of Training}

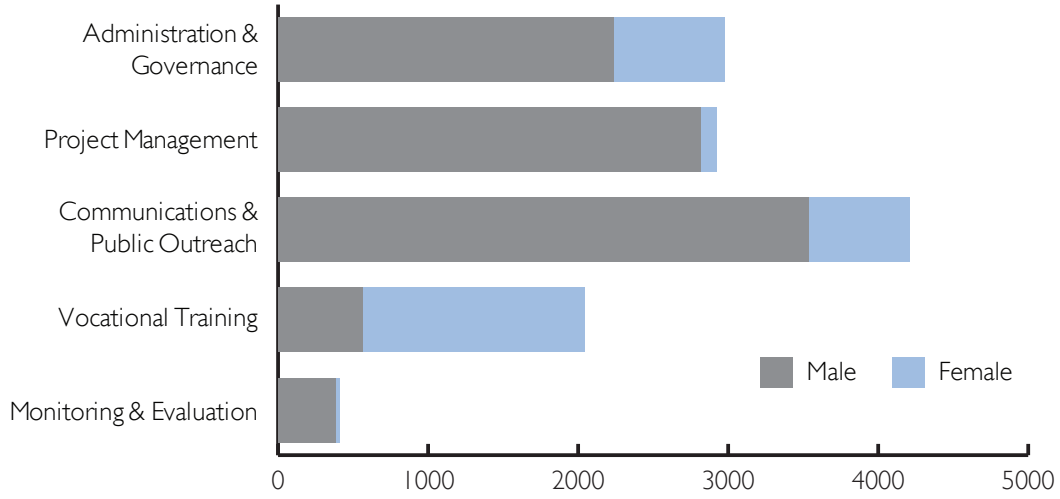


arrived at solutions, through consensus, at their own pace. It was critical that stakeholders had the opportunity to speak on matters and were satisfied that their viewpoints were taken into account. For this reason, SIKA-West collaborated with DEs on monthly KSWs so that issues could be discussed at length, concerns refined, and solutions thought through before seeking to allocate

\section{KSWWorkflow}

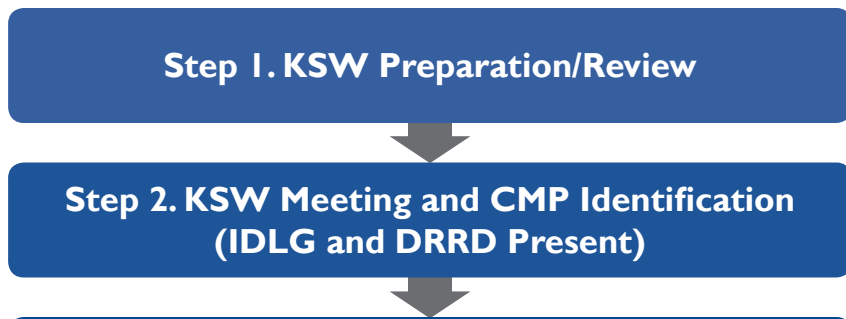

Step 3. IDLG/DRRD Project Prioritization

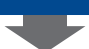

Step 4. DPP Preparation and MRRD Approval

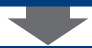

Step 5. DPP and Grant Approval Received From

Step 6. CDC/DDA Grant Implementation

Step 7. MRRD/IDLG Grant Monitoring

Recognizing the existing capacities present among DGO personnel, DDA members, and CDC leaders within the target districts, the KSW was modeled on past and current DGO, NSP, and NABDP programming, in which influential district stakeholders gathered under the leadership of IDLG and MRRD to discuss individual community development needs and concerns. The key difference between these types of programs and the KSW was the focus on a SAM-driven agenda that looked beyond individual community needs and addressed longer term drivers of instability that continued to divide communities, alienate populations from their local government, provide grievances for insurgents to exploit, and undermine the legitimacy of local governments. By providing the KSW forum for DEs to discuss broader concerns, local government and community leaders recognized that they had resources. SIKA-West KSWs were continuing to discuss new district concerns through the end of 2014.

- Worked with IDLG and MRRD district entity counterparts to establish a KSW workflow, which incorporated existing practices that were familiar to existing DGO, NSP, and NABDP programming. a key stakeholder role in addressing district grievances through the allocation of available GIRoA and SIKA-West resources.

The KSWs presented the first opportunity for many DEs to sit together, discuss shared concerns, and reach consensus on the full extent of major problems within district communities With the support of IDLG, SIKA-West worked with DGO personnel to ensure they were capable of leading the KSWs, utilizing the Afghanized SAM approach, screening grievances through established criteria, prioritizing CMPs, and identifying solutions by employing available GIRoA and third-party resources or SIKA-West grant funding.

Traditionally, smaller micro-communities lacked sufficient CDC or DDA leadership due to their low population numbers. Consequently, they banded together with similarsized communities to form clusters, greatly enhancing their representative leadership and ensuring that their particular grievances were heard. To the extent possible, GIRoA-led grant-funded solutions were targeted to assist as many communities as possible to maximize community benefits and available financial resources. SIKA-West, with the support of MRRD, worked in tandem with the local government to implement GIRoA-led solutions.

The District Government would open up monthly KSW discussions by reiterating the need to work together to identify key district problems in line with the stabilization programming criteria. KSW members were invited to speak, discussing a wide range of problems including security conditions and requirements, need for improvement in basic local government services (education, health, agriculture, public infrastructure, etc.), absence or inefficiency of local government, presence or absence of existing donor funded programming, and challenges with respect to district community relations. If there was sufficient consensus reached on any one of these concerns, then the reasons for the concern would be identified and screened through the stabilization criteria to determine if they were in fact CMPs that acted as drivers for further instability within the district. SIKA-West personnel were present at these KSWs but 
placed no requirements to KSW members on the number of concerns that needed to be reviewed, filtered, or prioritized, instead waiting patiently for DEs to arrive at their own conclusions on their own timeline. SIKA-West supported DGOs and DEs to hold KSWs on a monthly basis throughout the life of the program, enabling key concerns to be addressed over multiple meetings until such time as a common course of action could be agreed upon.

Once key CMPs were identified, screened, and provided with agreed upon solutions, the district government would publish these solutions as a Project Priority Agreement (PPA). Copies were then shared with the MRRD District Social Workers (DSWs) to ensure that proposed project solutions were in accordance with MRRD programming guidelines and were not being duplicated. KSW members were mentored by SIKAWest while they prioritized and screened CMPs to ensure that GIRoA-led solutions were in line with IDLG, MRRD, and USAID policies.

\section{COMMONTYPES OF CMPS}

I. Youth opium addiction

2. Lack of economic opportunities

3. Lack of water management infrastructure

4. Poverty and unemployment

5. Poor performance of $\mathrm{GIRoA}$ officials

6. Illiteracy and lack of educational facilities

7. Community water disputes

8. Presence of insurgent groups

9. Lack of trust between district residents and local government

10. Insecurity (criminal and insurgent)

II. Foreign destabilizing influences

12. Lack of GIRoA financial investment in the districts

13. Lack of GIRoA transparency

14. Inadequate transportation networks

15. Seasonal flooding

16. Lack of basic service delivery (health, education, and security)

17. Lack of agricultural infrastructure

18. Uneven allocation of GIRoA resources

19. Lack of potable water

20. Lack of unity among communities

21. Tribal conflicts

In terms of CMPs, the most common finding across all districts related to the residents' view that their local government was unable or unwilling to deliver necessary public services within the health, education, agriculture, and rural infrastructure sectors. Frequent discussions were held between district residents and their government officials regarding poorly equipped schools and clinics and the declining quality or absence of rural roads, bridges, irrigation canals, and flood protection walls that severely impeded community access to the District Centers and exposed their lands to the continued threat of seasonal flooding.

To alleviate these conditions, SIKA-West supported district government efforts to engage with provincial ministries to pay attention to these needs, requesting that provincial line departments reassess the amount of resources made available to district schools and clinics to ensure that basic necessities were being met. This was coupled with grant award agreements to rehabilitate schools and clinics on the condition that these structures were actively in use and an agreement was in place with the respective line ministryDepartment of Health (DoH), Department of Education (DoE), or others-that the beneficiary community possessed the technical capacity to undertake the rehabilitation efforts. Additionally, these project designs were screened by MRRD to avoid any duplication of efforts under NSP or NABDP programming. Likewise, with community requests for the district government to invest in the rural road networks and flood protection walls, the district governments would liaise with their provincial Department of Public Works (DoPW); Department of Agriculture, Irrigation, and Livestock (DAIL); and provincial DRRD counterparts to review whether similar types of district development programming were already being planned before moving forward to consider the technical feasibility of these requests.

Additional concerns that were raised within the KSWs related to an overall lack of trust between district communities and their local governments due to an absence of regular communication, lack of transparency, and failure to engage with communities on district development priorities. The KSW model alleviated these concerns as it was designed specifically to expand and improve engagement between local government and district entities, enhance communication, and ensure a transparent process prior to deciding on district development priorities. Results of SIKA-West's efforts are conveyed in the MISTI Wave 5 report, reflecting 80\% favorable ratings for District Governors, 70\% favorable ratings for district governments, and $74 \%$ favorable ratings for local leaders among residents within the 16 target districts.

Community disputes and tribal conflicts were an important consideration for KSW discussion, and SIKA-West played an important role in addressing longstanding disputes, preventing grievances from being exploited by insurgents and fueling further instability. To assist in these conflict mitigation efforts, SIKA-West established Tribal Conflict Resolution Committees (TCRCs). Members of the TCRCs were local community 
leaders, respected for their wisdom and experience in dealing with these types of matters. Membership was voluntary, and TCRCs were led by the District Governors. While SIKAWest supported these efforts by providing conflict resolution training, mentoring, and logistical support to TCRC members, the program was careful to limit the amount of resources provided so as to warrant continued sustainability of this programming with available GIRoA resources. In total, 63 tribal conflicts were addressed across all districts on a range of matters including land and water disputes, armed conflict internally between tribal clans and externally between tribes, and water disputes and inheritance claims involving multiple tribal clans.

\section{KEY RESULTS AND ACHIEVEMENTS}

854 CDCs and DDAs participated in the KSWs and worked in collaboration with their District Governments to improve local governance and district development programming.

Strong female participation in KSWs reflected the value placed by DGOs on both male and female perspectives with regard to district governance programming.

Extensive collaboration and cooperation between IDLG and MRRD to undertake joint district stabilization and governance efforts. The presence of MRRD DSWs within KSWs enabled these forums to benefit from the inclusion of NSP and NABDP services to maximize available resources.

Recognized long-term funding and sustainability agreements with MRRD and IDLG to continue supporting the KSWs after the conclusion of the SIKA-West program.

$\mathbf{8 0} \%$ favorable view of district governors, $70 \%$ favorable view of DGOs, and 74\% favorable view of local leaders (DDAs, CDCs, tribal elders) in SIKA-West target districts according to the MISTI Wave 5 report.

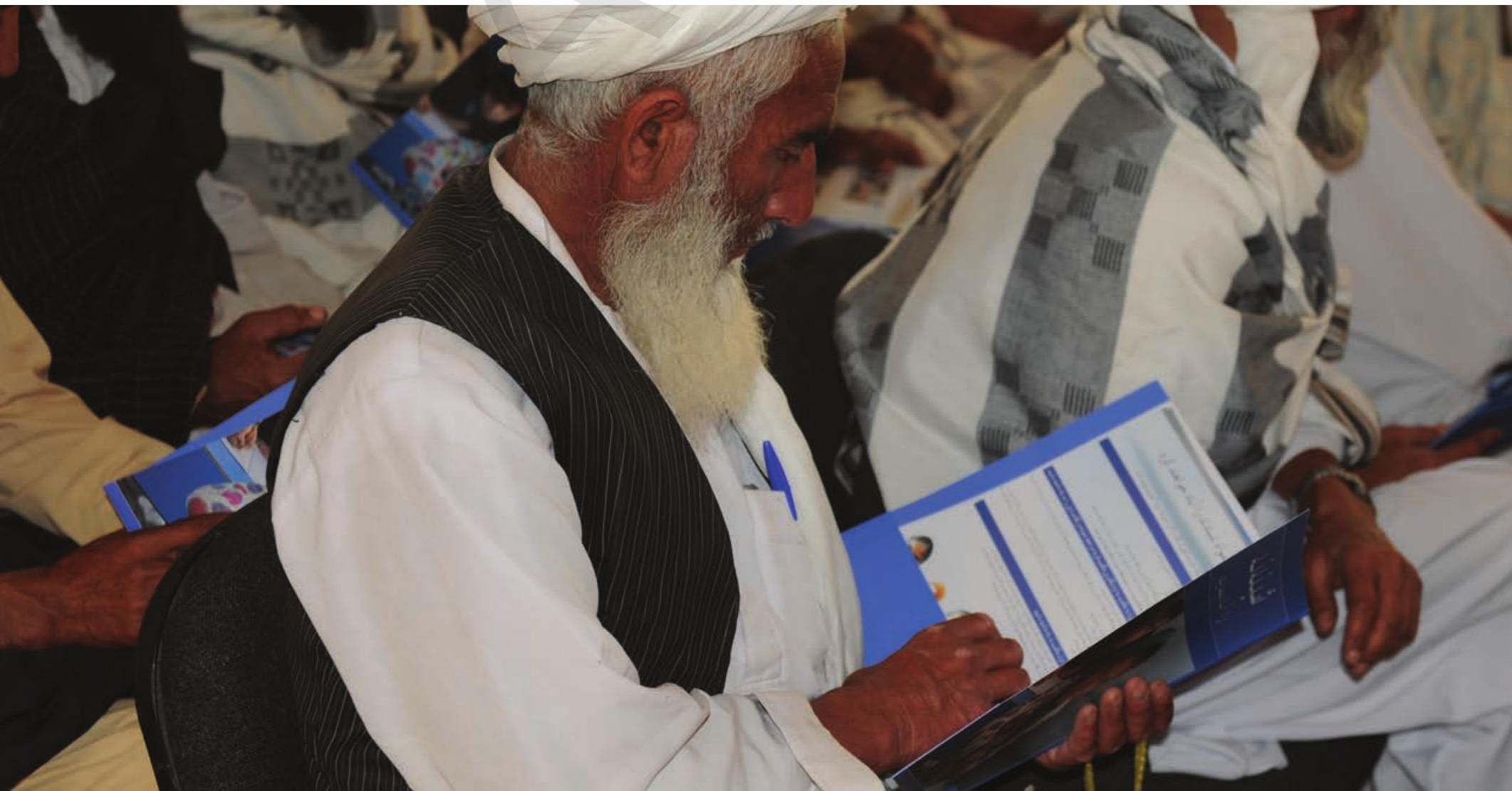





\section{KSW Community Engagement Matrix}

After identifying viable solutions to screened and prioritized CMPs, the district government prepared a PPA listing GIRoAled decisions on how best to resolve community grievances. PPAs usually contained between five and ten project solutions.

The PPA was shared with SIKA-West and MRRD to ensure that the grievances identified were effectively screened and fit CMP/SOI criteria, were feasible and compliant with USAID and MRRD project guidelines (e.g., vertical structures were disallowed under NSP guidelines), and did not duplicate existing MRRD programming (under NSP and NABDP). Identified CMPs and solutions that did not fit the screening criteria or lacked sufficient linkage were sent back to the KSW for reexamination, discussion, and inclusion in future PPAs, with additional mentoring and capacity-building support provided.
SIKA-West provided soft capacity-building solutions to GIRoA, whereas hard solutions (e.g., flood protection measures) were uploaded into the District Stabilization Matrix (DSM) for further review prior to being placed into a DPP for MRRD and USAID approval. Once approved, individual project solutions within the DPP were prepared as in-kind or fixedobligation grant (FOG) applications and submitted to USAID for review (and vetting if in excess of $\$ 25,000$ ) and approval.

After USAID approval, the grantee (DDA/CDC) received the grant award agreement, followed by an introductory Project Management Training (PMT) introducing the conditions of the agreement, technical specifications, project management requirements, implementation timeline, quality standards, and budget and M\&E practices. The grantee received onsite mentoring from SIKA-West and MRRD DSW partners during the life of the project.

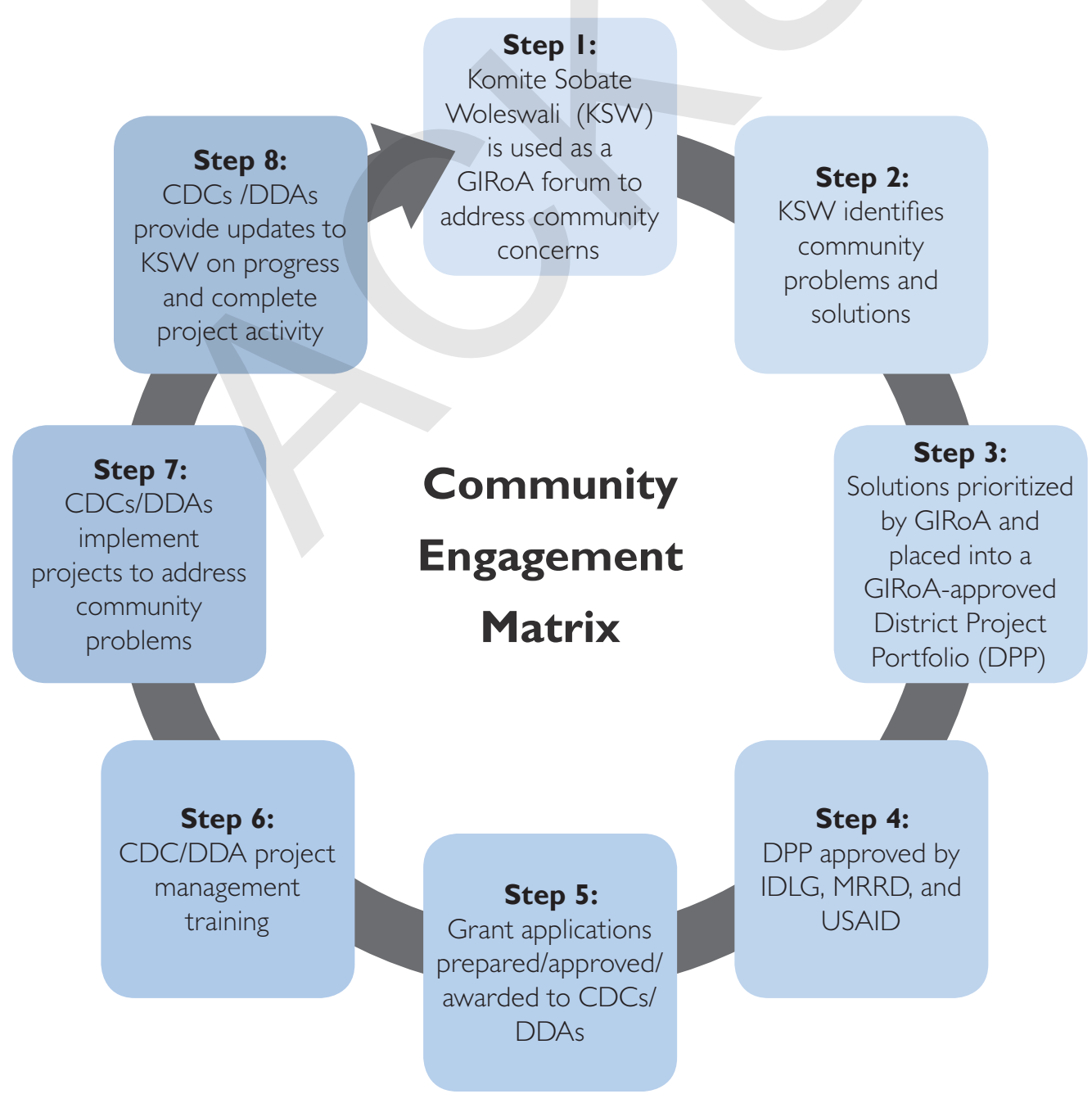




\section{KSW Impacts}

The following were the impacts of KSWs:

- $315 \mathrm{KSWs}$ were held across 16 districts and four provinces, with a tracked attendance record of 17,405 district entity stakeholders, producing 21 common CMPs/SOls, 650 GIRoA-led solutions (both soft capacity building and hard infrastructure), I 17 District Project Portfolios (DPPs), and 535-grant funded activities valued at $\$ 9,730,778$ to improve local government service delivery to I,290, I 16 district residents in Farah, Badghis, Ghor, and Herat provinces.

- As a result of $\mathrm{KSW}$-identified deficiencies within local governance capacities, 12,562 GIRoA personnel and district entity leadership received training and mentoring using approved IDLG and MRRD materials, guidelines, and frameworks.

- KSWs provided a neutral venue for the resolution of community disputes under the leadership of the district government, further cementing local government leadership and legitimacy.

\section{KEY RESULTS AND ACHIEVEMENTS}

- 402 transportation, agriculture, and irrigation, 64 education and health, 63 vocational, and 6 governance grant-funded projects identified and awarded by SIKAWest to address CMPs and improve local government service delivery to district populations.

- Strong female participation and engagement, resulting in a shift from traditional support for vocational programming to a more focused view on district service infrastructure (health and education), which served to better address both male and female district resident grievances and served to undermine past discriminatory views. Female participation continues even after SIKA-West logistical and financial support has been withdrawn.

- Increased district entity and community buy-in to local government leadership on matters related to district governance and development programming. This explicit acknowledgement of leadership served to strengthen the legitimacy of DGOs in the target districts.
- KSWs improved coordination amongst multiple GIRoA ministries at the district and provincial level (health, education, agriculture, security, rural rehabilitation, legal, women's affairs, labor, etc.).

- Strong buy-in was evident from IDLG and MRRD, who recognized the contribution of the KSW to improved local governance and agreed to continue funding KSWs after the closure of SIKA-West.

- The KSW process was seen by district entities as a way for their local government to be more responsive to their needs and concerns.

- DEs were able to move effectively from shorter term stabilization concerns to longer term district development programming. KSWs are continuing under DGO leadership, maintaining links with MRRD, provincial line ministries, and third-party donors to continue improved governance and service delivery efforts.

- District residents (male and female) had a voice in addressing their concerns and grievances and implementing locally appropriate solutions.

"With the assistance of SIKA-West, District Social Workers played a significant role in monitoring and evaluating MRRD programming at the district level; in addition to supporting implementing CDC's with the technical guidance to ensure a high level of project quality. DSW's are a critical link between MRRD and district communities and their efforts built confidence amongst district residents that MRRD was responsive to their needs."

BADGHIS DRRD DIRECTOR ( BADGHIS PROVINCE): MR. SAYED RASOUL AKBARI (AUGUST 20I5) 


\section{SUCCESS STORY}

\section{Long Overdue: Peace to a 30-Year Conflict between the Taimany Ha and Reza Tribes}

Since 1984, the Taimany Ha and Reza tribes within Shahrak District have been in violent conflict with one another. While the battle began with the murder of prominent leaders from both tribes, the continued violent retaliations have led to the death, injury, and displacement of countless district residents. While there were occasional calls for calm, neither side was able to come to the table and negotiate a peaceful end.

In partnership with MRRD and IDLG, the Stability in Key Areas-West (SIKA-West) program established the Chaghcharan Tribal Conflict Resolution Committee (TCRC). Made up of leading provincial government officials, tribal leaders, and ulema, the TCRC was specifically tasked with identifying and addressing long-running and destructive tribal conflicts.

Led by the Ghor provincial government, with technical support provided by the SIKA-West program, the Chaghcharan TCRC engaged with the Taimany Ha and Reza tribal leaders in December 2013. Over the course of eight days, both sides submitted to the authority of the government and outlined the abuses committed, damage inflicted, compensation owed, and overall desire for a fair peace.

Under the guidance of the TCRC, a peace treaty was finally signed, which included the following terms:

(a) Immediate opening of all roads in the district

(b) Forbidding armed members of either tribe from traveling in the other's territory

(c) Forbidding illegal taxation of district residents

(d) Allowance of the immediate return of all displaced district residents

This government-led, negotiated peace will enable the Ghor provincial government to support further development efforts for Shahrak District, development that could not take place until peace had first been established.

Taimany Ha and Reza Tribal Leaders Embrace After Agreement on Peace Deal in Shahrak

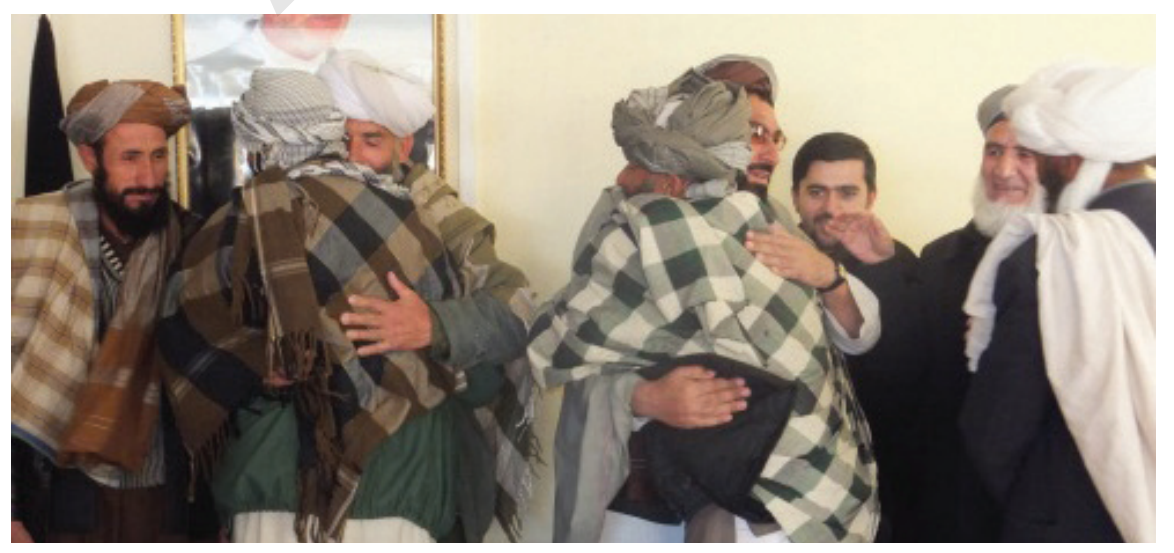



reviewed, corrected, and updated in the years to come. Prior to printing and distribution, the SPCs were reviewed and approved by the program's DGO, DRRD, and USAID partners, and public dissemination plans were agreed to, focusing distribution at the provincial and district level.

The SPCs were designed to be distributed to the provincial DRRD offices and DGOs, where personnel were present who possessed the capabilities to both understand and communicate the SPC content to residents. The SIKA-West team coupled the distribution of the SPCs with focused mentoring and training and organized provincial service provider fairs to further promote resource awareness and availability. Editable, soft copies of the SPCs were provided to our provincial and district partners so that content could be updated in the years to come.

To complement the SPC production and distribution, a service provider hotline was established within the provincial DRRD offices, enabling designated personnel to receive and record provincial and district residents' calls and provide current information on the availability of line ministry and nongovernmental services. Due to the existence of semi-literate populations within the target districts, it was critical that SIKA-West also employ mobile phone technology to increase awareness. As a component of the program handover, MRRD committed to sustaining and funding both the use of the SPC and operation of these established provincial hotlines.
"THE SIKA-WEST PROGRAM WAS SUCCESSFUL IN IMPROVING THE KUSHK-E-RABAT SANGI DGO'S MANAGEMENT FUNCTIONSTHROUGH A BETTER UNDERSTANDING AND IMPLEMENTATION OF CURRENT SCOPE OF WORK, INCREASED COMMUNICATIONS WITH LOCAL COMMUNITIES, IMPROVED ORGANIZATIONAL MANAGEMENT IN TERMS OF FILING, RECORDKEEPING SYSTEMS, AND DAILY PROCESSING OF RECORDS, AND IMPROVED INTERNAL COORDINATION WITH THE DEVELOPMENT AND IMPLEMENTATION OF MONTHLY AND QUARTERLY WORK PLANS." MR. SHIR AQA SARWARI (AUGUST 20I5), KUSHK-E-RABAT SANGI DISTRICT GOVERNOR (HERAT PROVINCE).

\section{KEY RESULTS AND ACHIEVEMENTS}

- 986 (907 male and 79 female) GIRoA officials and DEs trained on how to develop and use the SPC and hotline. This training was centered within SIKA-West's four provincial DRRDs and I3 DGOs so that its partners would better understand the range and availability of services at the provincial and district level.

- Four quarterly service provider fairs were conducted within Herat, Badghis, Ghor, and Farah enabling provincial and district providers to publicize the type and range of their services and inform 8,000 residents on how they can apply.

- Four provincial service provider hotlines were established, one within each DRRD office, enabling residents to routinely call and receive contact details as well as a general overview of available GIRoA and non-governmental service providers within the province.

- The program identified, prioritized, and undertook 23 CMP solutions through the KSWs using the SPC, linking stabilization and governance resiliency efforts to existing and available resources. Service providers included DGOs; the Department of Agriculture, Irrigation, and Livestock (DAIL); the Department of Education (DoE); Afghan Aid; World Vision; and the International Committee of the Red Cross (ICRC).

- SIKA-West distributed 6,000 SPCs and 20,000 SPC hotline cards within the target districts in Farah, Herat, Ghor, and Badghis provinces. 


\section{SUCCESS STORY}

\section{District Government Links Farmers to Service Providers \& New Markets}

Shindand District is home to almost 170,000 residents, many of whom depend directly and/or indirectly on farming and animal husbandry for their daily income. Considering the importance of these activities, the Shindand District Government, with the support of the Herat Department of Rural Rehabilitation \& Development (DRRD) and the MRRD/IDLG Stability in Key Areas (SIKA) -West program, took the initiative to launch a "Market Day", linking district farmers with agricultural service providers that could provide goods, training and access to new markets. With the support of the SIKA-West Communications \& Public Outreach.

Department, the District Government selected the venue, arranged for service providers to be present and invited district farmers. On June Ist, 2014, more than 100 farmers attended the Shindand District Government "Market Day" event and engaged with the Tarhe Naw Food Processing Company, Babyee Zaferan (Saffron) Company, Improved Agricultural Seed Company and Holland Veterinary Committee among others. Early results include an agreement by the Holland Veterinary Committee to provide veterinary trainings and toolkits, while the Babyee Zaferan Company has committed to providing saffron cultivation trainings and purchasing saffron harvests.

"Organizing such events will help the farmers to increase their products, link with the markets and earn a Halal income," Mr. Juma Khan, a farmer from Rajan village, Shindand District.

\section{Farmers Exchange Contact Details With the Babyee Zaferan Company} at the Shindand District Government

Market Day on June 0I 2014

"It is the harvesting time, now you (the farmers) can contact the agricultural service providers and find market for your products."

MR.ABDUL GHAFOOR AFZALI SHINDAND DISTRICT AGRICULTURE MANAGER

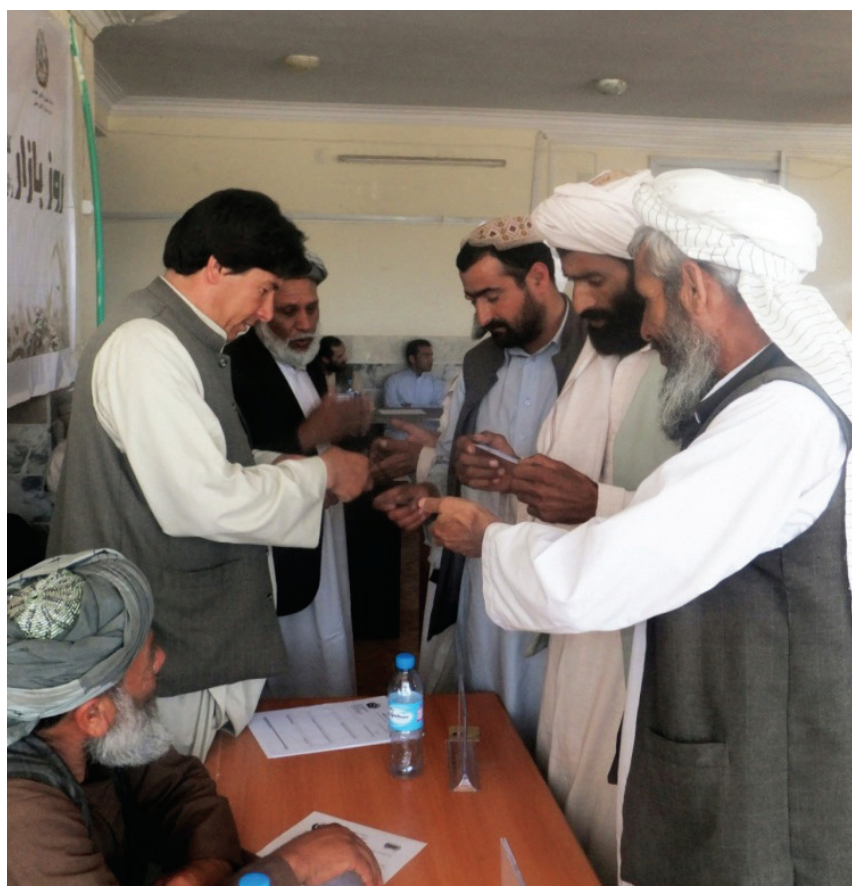




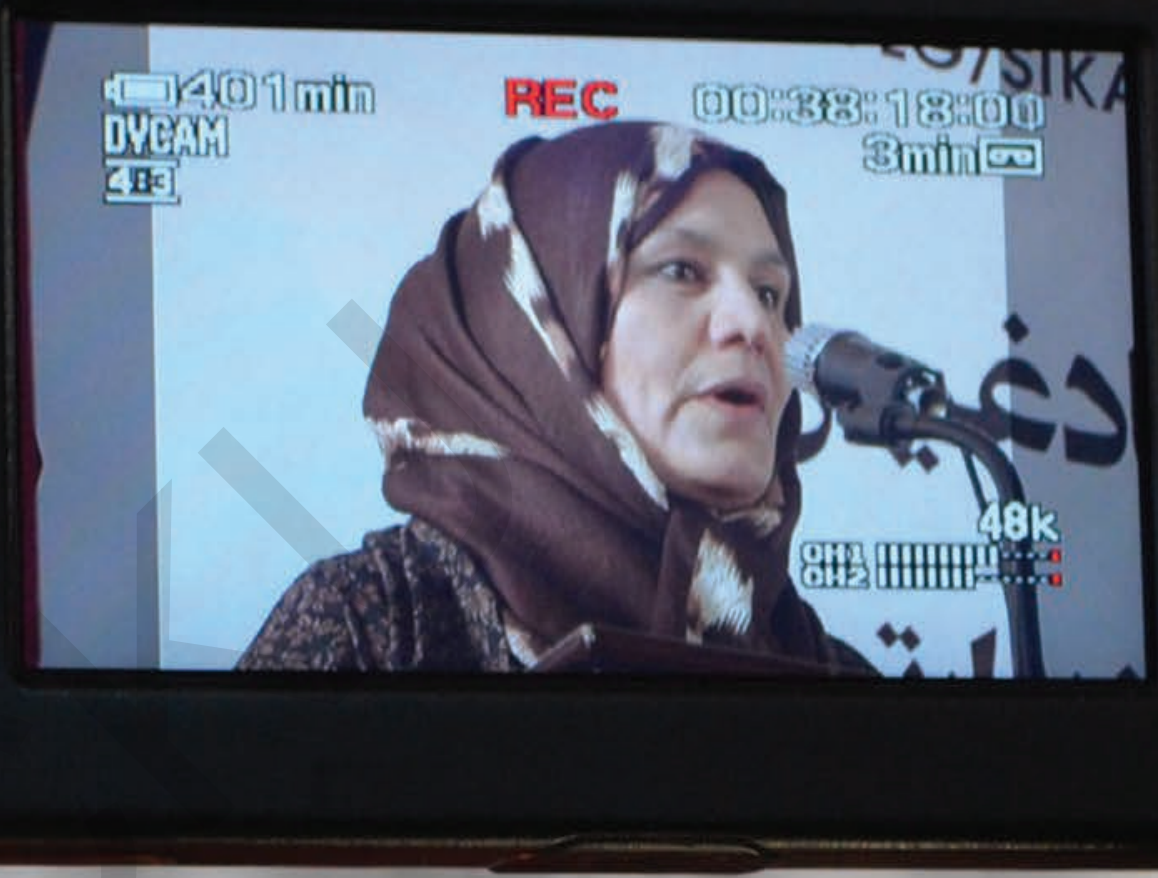




\title{
III. Communications and Outreach
}

\author{
Provincial Authorities to improve the ability to communicate \\ with District Entities to help them better understand their \\ populations' needs and prioritize basic service delivery \\ interventions.
}

SIKA-West was based on the understanding that for local government to improve stabilization and governance, it must have robust two-way communication systems, both internally between district, provincial, and national GIRoA departments and externally between local government and its citizens. In line with IDLG's approved communications strategy, SIKA-West worked in 13 districts with district government partners to develop communication plans to raise awareness on the existing DGO line departments' programming (administrative, health, agriculture, education, and security) and services available for district residents. SIKA-West collaborated with IDLG on the development and promotion of district government communication plans, which served to raise public awareness regarding DGO programming and highlight the availability of district resident services.

These plans were key components of renewed efforts to reengage local governments with their citizens, identify grievances, improve cooperation, address service delivery needs, support stabilization and governance efforts, and build effective and sustainable relationships between local government personnel and key disseminators of information within the district populations (DDAs, CDCs, tribal elders, ulema, etc.). Twenty-seven (27) individual communication plans were developed with DGOs and DEs, to accomplish the following:

- Identify both internal and external communications deficiencies by undertaking comprehensive needs assessments, determining where stakeholder engagement needs improvement, and designing workshops and mentoring approaches to address these gaps and deficiencies.

- Introduce available and affordable print, media, SMS, and hotline messaging, in addition to traditional public forums and community visits, to reenergize communications activities.

- Establish and maintain strong working relationships between DGOs, DEs, opinion leaders, and district populations to encourage support for current local governance and stabilization programming.

- Ensure that district stakeholders understand DGO or DE messaging and that communications are clear, timely, and consistent.

- Enable feedback loops through hotlines and public meetings to assess message effectiveness and amend or improve communications programming. 


\section{KEY RESULTS AND ACHIEVEMENTS}

- 18 radio and TV events, reaching 208,904 district residents, promoting local government activities and informing residents how to access existing line department services.

- I9I,5 I 2 printed flyers, brochures, and posters, promoting local government transparency, existing services, and public announcements to keep district populations informed on local government affairs.

- 13 DGO hotlines established, enabling district residents to easily contact their local government to follow up on available services; request support to address grievances; or provide feedback on recent district governance, stabilization, and development efforts.

The individual communication plans that were developed varied, depending on the actor, extent of current communications programming in place, existing print and media capabilities and exposure, and current communications capabilities. Each plan used the following approach:

- Social, Technical, Economic, and Political (STEP) assessments to provide background on the actors, stakeholders, operating environment, internal and external communications capabilities, and communications resources. Information obtained from the STEP assessment was coupled with a Strengths, Weaknesses, Opportunities, and Threats (SWOT) analysis, enabling a full understanding of the DE, the environment, the stakeholders, positive and negative internal and external factors, and underlying communications challenges.

- The communication plan required clear objectives in line with IDLG communication strategies and the desires of the DGO/DE. Generally, these objectives favored building trust between the DGO/DE and district stakeholders, encouraging stakeholders to support governance, stabilization, and district development programming and improving internal and external communications.

- At the request of IDLG, communication plans were designed to be six to nine months in length, after which time progress was assessed and, if there was sufficient need, time, and resources, a second plan was implemented. All plans were approved by IDLG at the national, provincial, and district levels to ensure that they aligned with the overall IDLG communications strategy.

The SIKA-West DGO/DE communication plans accomplished the following:

\section{DISTRICT PUBLIC OUTREACH EVENTS AND ACTIVITIES}

SIKA-West DGO/DE partners organized and held 454 public meetings and outreach events, including district soccer tournaments, teachers and education, importance of farmers and available services, the value of youth associations, and engagement with district female leadership. These public events and others like them brought local government and district communities together. For many residents, it was the first time that GIRoA visited their communities or spoke directly to them about their concerns, increasing perceptions of local government legitimacy and transparency.

\section{RADIO AND TV EVENTS}

SIKA-West held 18 radio and television events, within its target districts. Radio was the primary medium for programming because it increased attendance at KSWs and

Chaghcharan resident receives SMS Message on GIRoA services (May 20l4)

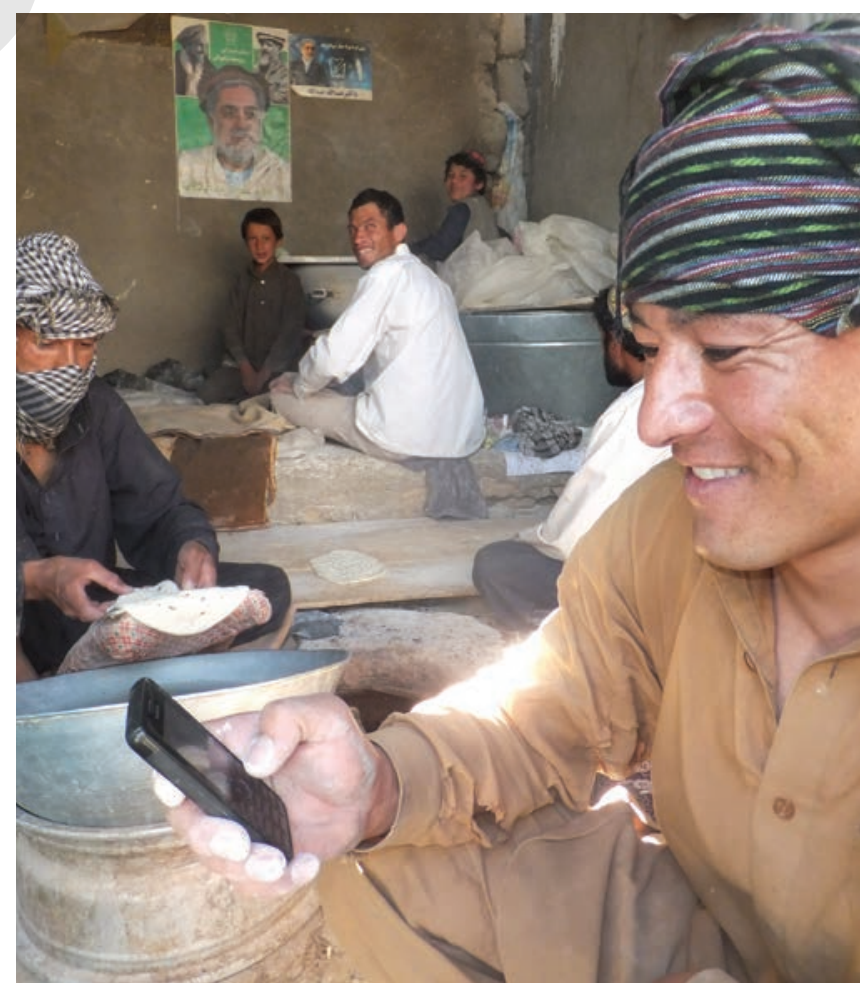




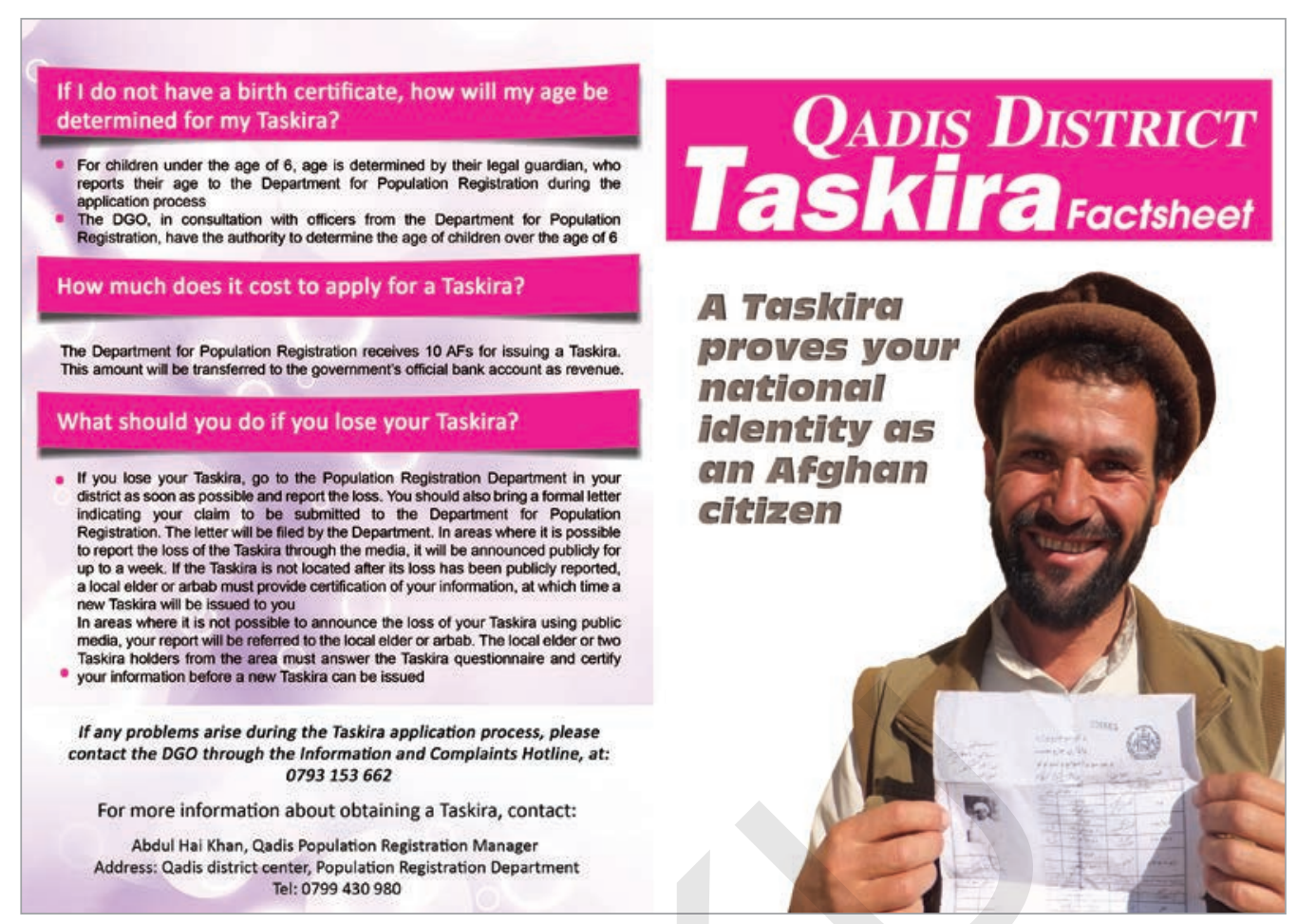

Qadis District Tazkira fact sheet prepared by SIKA-West and distributed by partners

other events. Recognizing this medium as a strength within communication plans, SIKA-West employed this resource to promote local governments' role in facilitating KSWs to identify and respond to key community grievances and to promote service provider catalogs and DGO hotlines. Radio programming included representation from DGOs and DDAs, CDCs, and Ulema.

\section{SMS CAMPAIGNS}

To maximize the reach of DGO and DE communications, SIKA-West sent 6,072 messages through 14 SMS campaigns to key district populations. These campaigns reinforced local governments' achievements in delivering services, provided information on how to reach DGO line

departments for support (health, education, agriculture, etc.), announced public events, and invited DEs to KSWs. SMS proved to be effective in reaching larger numbers of district residents as messages continued through word of mouth.

DGO Personnel Conducted 8 I Visits to District Communities Despite insecurity in a number of districts and transportation limitations, DGO personnel traveled to district communities, met village leaders, listened to and addressed concerns, inspected and assessed progress of SIKA-West infrastructure and vocational projects, spoke to residents, publicized SPC and

\section{GENDER MAINSTREAMING}

- 592 female DGO and DE leaders received communications and public outreach capacity building, with a focus on public speaking, advocacy, media training, and internal communications. Many individuals used this training to identify critical concerns within their districts during the monthly KSWs and advocate for local government support. Many were successful in having grant funds allocated to rehabilitate girls' secondary schools, health clinics, and village road networks and flood protection walls, which benefited both male and female district residents. Due to the success of this engagement, KSWs continued to invite female members to speak and take part in district governance and development discussions, reflecting a significant shift in attitude at the district level among DGOs and DE leadership.

- Capacity-building support was also successful in improving internal communications between female KSW members (DDA, CDC, and community leaders) and the provincial DoWA. While leading the provincial gender working groups, DoWA personnel are maintaining contacts with female district leadership so that they may benefit from current and future programming. 


\section{SUCCESS STORY}

\section{Hashar, Local Government Employs Volunteers}

The Muqur District Governor, Mr. Abdul Hadi Badghisi, with the support from USAID's Stability In Key Areas (SIKA) - West, initiated a public works project in Zad Naser Village which was completed using the traditional Hashar (Volunteer) concept. This activity was a component of the Muqur District Government Communication Plan, which serves to strengthen engagement between the district government and residents.

Residents of Zad Naser Village depend heavily on available water to support their crops and livestock. In early April, 20I4, members of this community requested support from the Muqur District Governor to assist them in cleaning an irrigation canal which provides water for 1 I 0 jeribs of farmland and had become blocked over time. Recognizing the importance of using available district resources to address residents' concerns, the District Governor and his staff assisted Zad Naser Village to organize a Hashar (Public Voluntary Scheme) to clean the irrigation canal on April 22, 2014.

"Hashar is a symbol of unity, we ourselves should work for the development of our community," Mr. Obaidullah, the District Chief of Police. "We, the farmers, appreciate the District Governor's support in addressing our problems," said, Mr. Mohammad Afzal, a farmer. "The District Governor's support encourages the farmers to increase their engagement in resolving their community problems independently" he added.

BY ORGANIZING THE HASHAR TO ADDRESS THE IRRIGATION NEEDS OF ZAD NASER VILLAGE,THE MUQUR DISTRICT GOVERNMENT TOOK THE LEADTO ADDRESS A COMMUNITY PROBLEM, USING AVAILABLE DISTRICT RESOURCES AND DISTRICT GOVERNMENT PERSONNEL.

"I am happy I am seeing this unity of farmers, this shows you can independently address your problems." MR.ABDUL HADI BADGHISI, MUQUR DISTRICT GOVERNOR

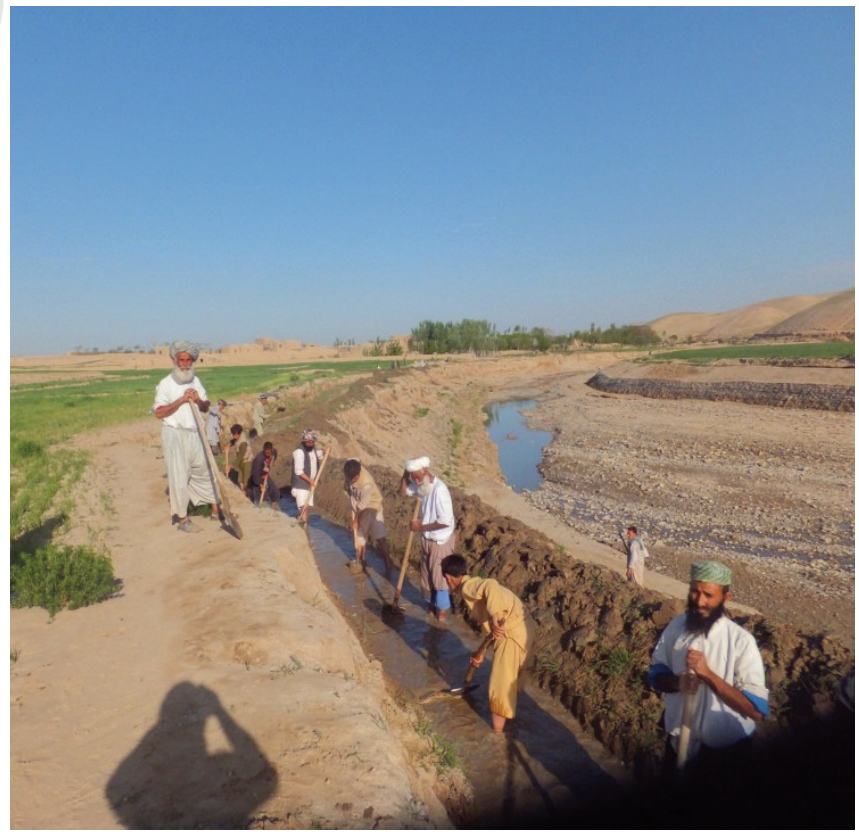




\title{
IV. Community Development
}

\author{
Provincial authorities to be able to improve basic service delivery \\ by using GIRoA, CDCs, DDAs, and ASOP DCCs, which gain \\ capacity to plan, design, implement, and monitor projects, with a \\ focus on labor-intensive projects and productive infrastructure.
}

Constrained by a lack of resources and technical skill sets, a key focus of SIKAWest was to provide grant funding and technical support to enable local governments to respond to identified CMPs through improved infrastructure and vocational service delivery.

Working in collaboration with IDLG, MRRD, DDAs, CDCs, and community leaders, SIKA-West utilized the existing MRRD Kandahar Model and integrated its community development and grant-funded program delivery into the existing district based NABDP and NSP programming cycles. SIKA-West regularly shared planned activities to ensure that there was agreement on the project location, scope, and budget and that duplication was avoided. SIKA-West also collaborated with its provincial partners to identify problematic CDCs that had failed to fully perform under MRRD programming. The program received MRRD capacity-building materials from the SIKA unit and CLDD in Kabul. These materials included NSP and NABDP manuals as well as technical engineering guidelines for infrastructure programming (roads, bridges, etc.).

SIKA-West employed the Kandahar Model, which hinges on greater community participation in the design, development, and implementation of district development programming. The goal is to provide a bottom-up approach to the identification and implementation of priority projects for district residents so that these residents have a voice in the development of their local communities. Through the use of the KSW to identify and award grant-funded programming and the employment of FOGs to ensure that CDC and DDA stakeholders had the opportunity to manage their own project implementation, SIKA-West attests that district stakeholders had a strong role in how district development programming was decided and that the program met every aspect of the Kandahar Model.

Within KSWs, members discussed and debated the most significant CMPs and SOls affecting their communities and, with the support of SIKA-West, identified appropriate GIRoA-led solutions. 


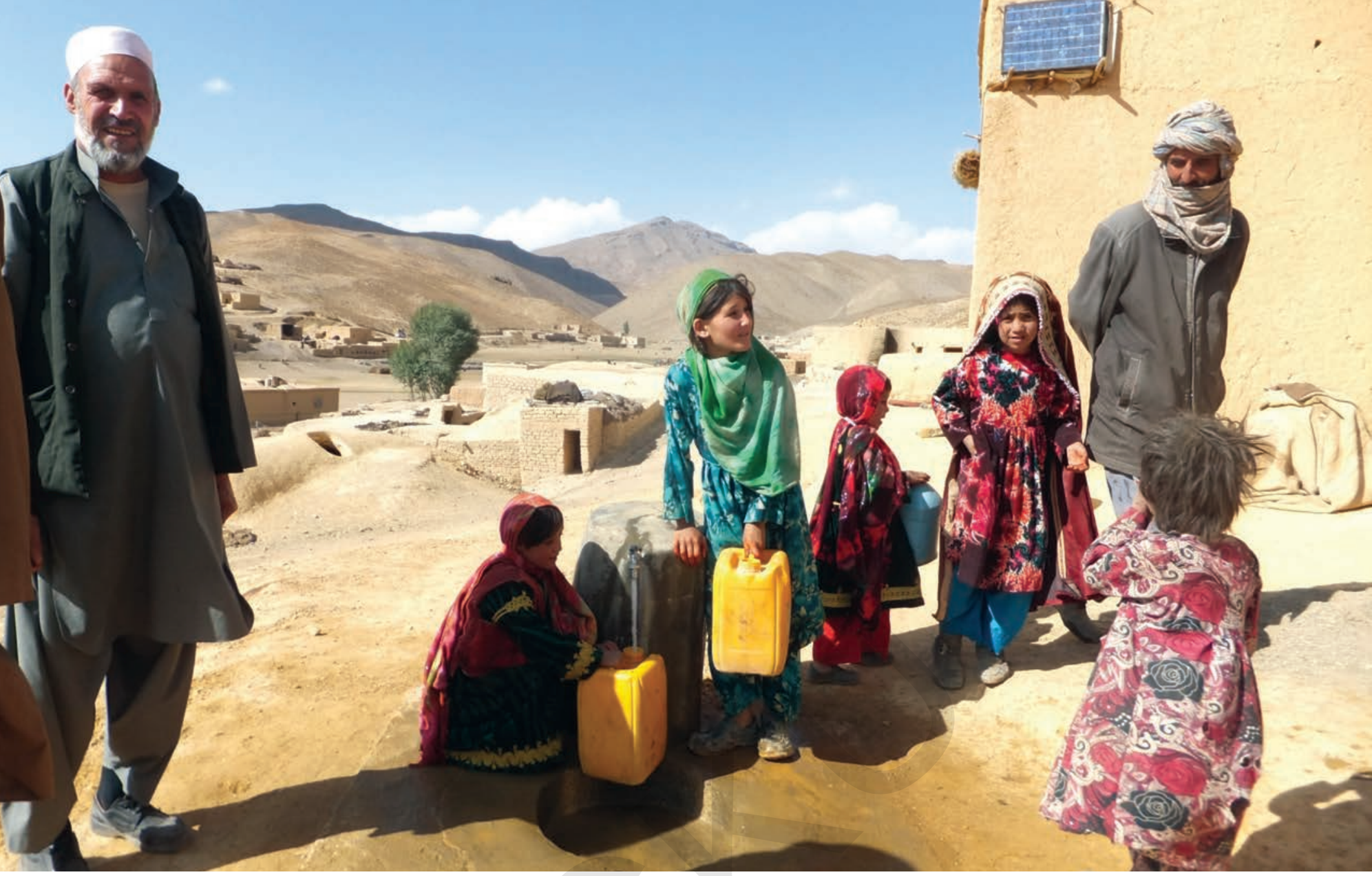

The Qarqa Now CDC Construction of a 34I0-Meter Long Water Piping Network

\section{KEY RESULTS AND ACHIEVEMENTS}

- 535 grant-funded projects valued at $\$ 9.7$ million, identified and awarded by SIKA-West to improve service delivery within its 16 target districts, benefitting 1,579,805 residents. Of these, 470 were infrastructure grants and 63 were vocational training grants. All required a minimum community contribution of $10 \%$.

- 343,053 (339,4I 5 male and 3,638 female) employment days provided to implement infrastructure grants and 104,530 (34,043 male and 70,487 female) training days provided under vocational training grants.

- $65 \%$ of residents within target districts reported improvements in service delivery by DEs.

- 402 transportation, agriculture, and irrigation, 64 education and health, 6 governance (DDA equipment) and 63 vocational grants identified, awarded, implemented, and managed by MRRD and IDLG stakeholders to support local stabilization, governance, and district development programming.

- $\quad$ I54 PMTs held, with 2,921 (2813 male and 108 female) grantees trained in project management roles and responsibilities, technical scope, budget, milestones, environmental considerations quality control, procurement, warehousing, and community contribution. 
The grant-funded infrastructure solutions identified by DEs and approved by MRRD and IDLG can be grouped under the following:

- Lack of flood protection infrastructure (gabions and stone masonry flood protection and retaining walls)

- Lack of access to potable water and irrigation water (water piping networks, irrigation canals, reservoirs)

- Inadequate educational facilities (school rehabilitation and equipment grants)

- Inadequate health facilities (clinic rehabilitation)

- Lack of investment in district infrastructure (road and culvert rehabilitation, bridge construction)

- Lack of skills sets and unemployment (vocational training)

Within 315 GIRoA-led KSWs, 21 common CMPs were determined, leading to 650 solutions, of which 535 were approved and finalized as grant award agreements. For a complete record of all grant-funded project activity, please refer to Annex B. Master Project Tracker.

After grant award agreements were finalized, SIKA-West worked closely with the grantee (DDA/CDC) to prepare for the first round of Project Management Training (PMT), which provided the grantees with a detailed overview of their project management roles and responsibilities, project scope, budget, milestone requirements, environmental considerations, quality control concerns, material procurement process, warehousing and storage, and community contribution. These events generally ran four days in length, with DGO personnel and MRRD DSWs taking a leading role in presenting materials to grantees, with technical support provided by SIKA-West personnel.

Once the project had broken ground, grantees were mentored on every aspect of the implementation with oversight provided by DGO personnel, DSWs, and SIKAWest personnel. Funding for the projects was disbursed after agreed milestones were completed, ranging in number from one to four (depending on the size and value of the project). Milestones were not approved without thorough verification and documentation (including GPS and photographs) provided by the grantees, IDLG, MRRD, and SIKA-West, ensuring a multi-tiered monitoring and verification approach. The projects were not considered complete unless approved by the project's IDLG and MRRD partners, reinforcing the view that this was local government-led district development and service delivery.
"SIKA-WEST PROGRAMMING, IN PARTICULAR CAPACITY BUILDING SUPPORT, IMPROVED LOCAL GOVERNANCE AND HELPED TO CLOSE THE GAP BETWEEN GOVERNMENT AND DISTRICT RESIDENTS.THE PROGRAM PROVIDED LOCAL COMMUNITIES WITHTHE FEELING THAT THEY HAVE A ROLE IN LOCAL GOVERNMENT.THROUGH STABILIZATION ACTIVITIES WHICH RESOLVED TRIBAL CONFLICTS AND PROVIDED DISTRICT DEVELOPMENT PROGRAMMING,THE SOBAT PROGRAM CHANGED PEOPLE'S MINDS AND THEY REALIZED THAT DISTRICT STABILIZATION EFFORTS WOULD REQUIRE ALL OF US WORKING TOGETHER."

\section{GHOR DEPUTY PROVINCIAL GOVERNOR ( GHOR PROVINCE): MR. MOHAMMAD AMIN TOKHI (AUGUST 20I5)}




\section{Local Government Delivering Results}

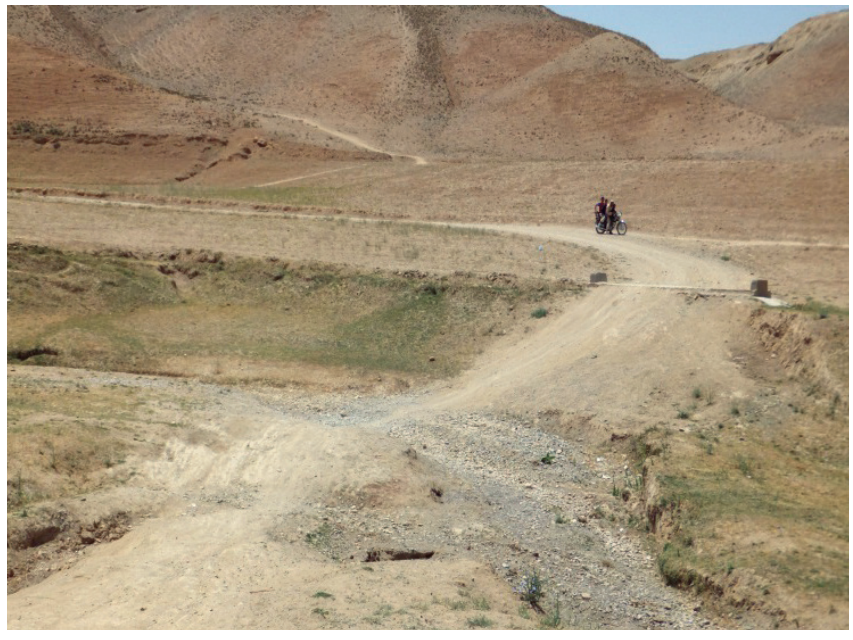

\section{BEFORE}

Chaghcharan Akhta Khana Culvert

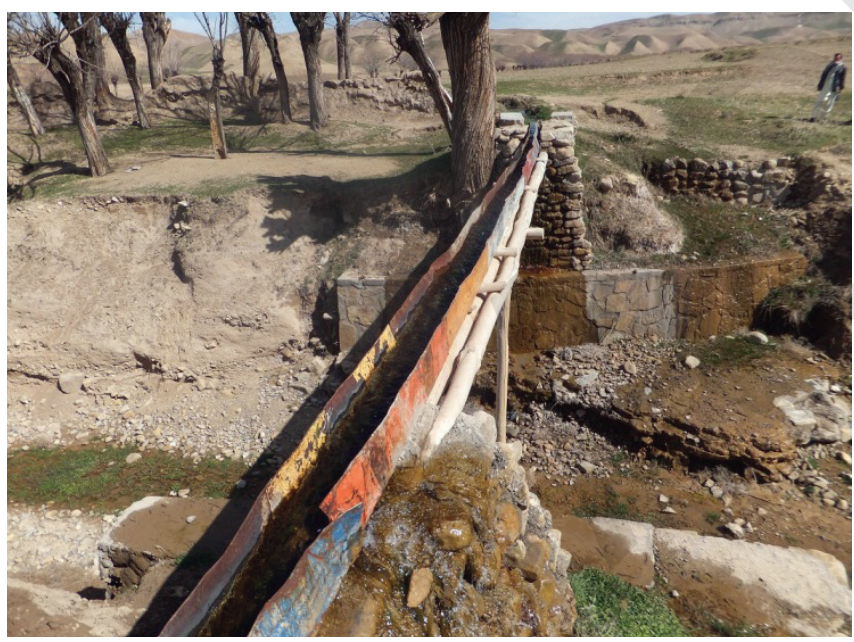

\section{BEFORE}

Poor Irrigation System for Farmers in Chap Rodha Village, Qadis District

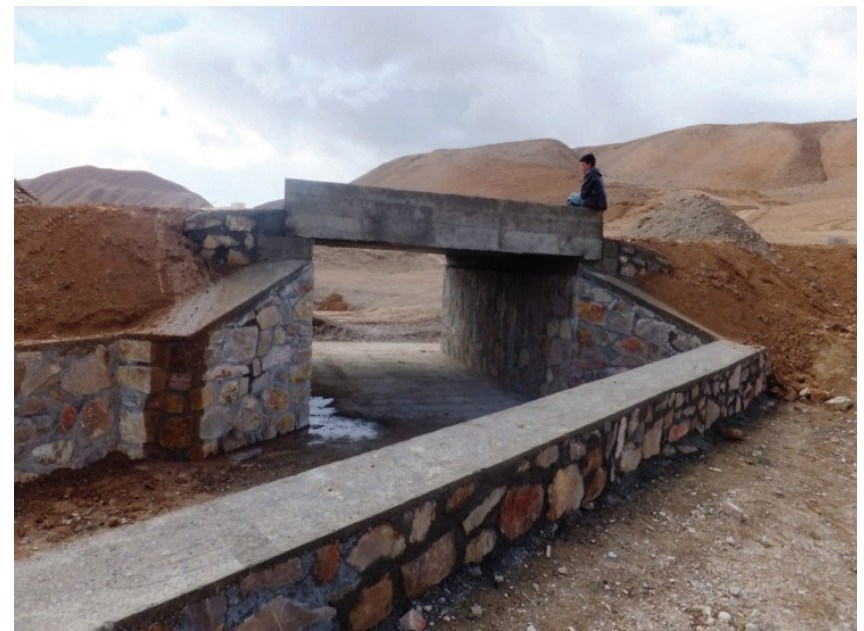

\section{AFTER}

Chaghcharan Akhta Khana Culvert

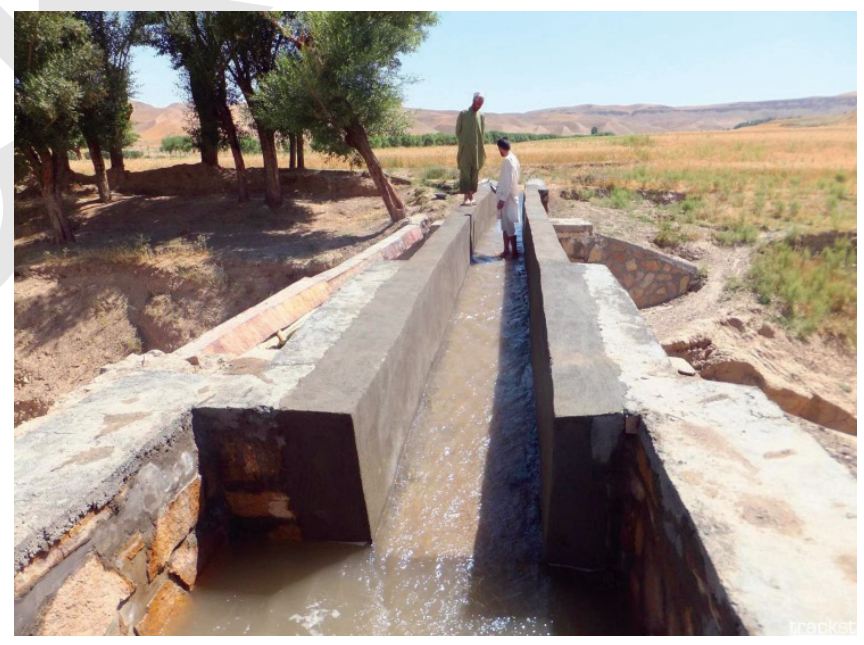

\section{AFTER}

The Chap Rodha KSW Successfully Construct an

Aqueduct to Provide Sufficient Water for I 50 Acres of Farmland 


\section{SUCCESS STORY}

\section{Local Government Reconnects District Community}

With oversight from the Kushk-e Rabat Sangi District Government and technical support from the Herat Department of Rural Rehabilitation \& Development, the Khowja Gul Baid Community Development Council successfully managed the construction of a Community Bridge ( 10 Meter Length \& 4 Meter Width) which improves connections for I,000 families within Khowja Gul Baidak Village and access to neighboring villages, as well as the District Center.

Valued at USD $\$ 44,026$, the construction of the Community Bridge employed 24 community laborers and was completed on June 10,2015. While residents have improved access within the community, the bridge has made it much easier for 320 students ( 150 boys, 170 girls) to travel from their homes to the village school which lies on the opposite side of the canal.

"Now that the bridge is constructed, students can cross the canal safely and go to their school which is located on the other side of the canal. Before that, students had to walk long distances using an alternative road," Mr. Abdullah Nasrat, Kushk-e Rabat Sangi District Government Executive Manager.

"We had difficulties getting to the hospital and marketplaces within the District Center because there was no bridge over the canal. This was especially true in winter, our thanks to the District Government for their support," Mr. Rangin, Khowja Gul Baid CDC Chairman.

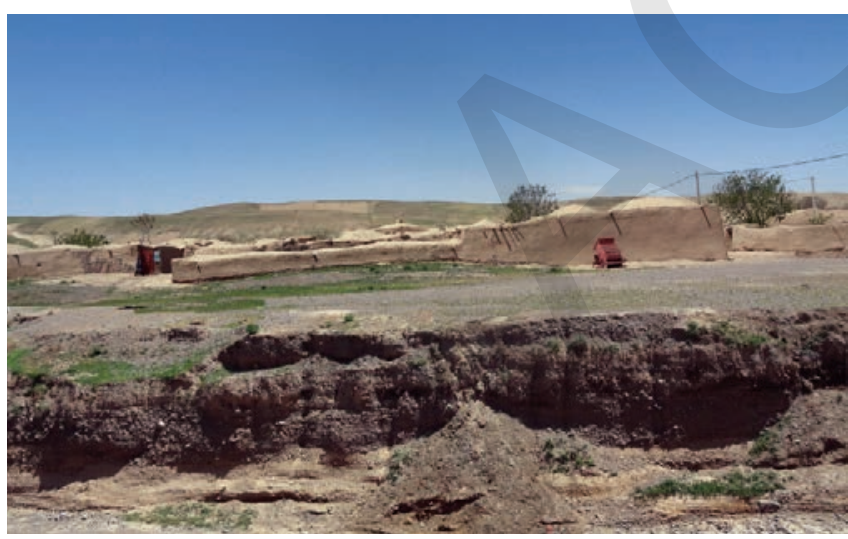

\section{BEFORE}

For years, residents in Khowja Gul Baidak Village, Kushk-e Rabat Sangi District, Herat Province were separated by a canal that runs through the community, preventing students on one side of the canal from easily traveling to the village school on the other side.

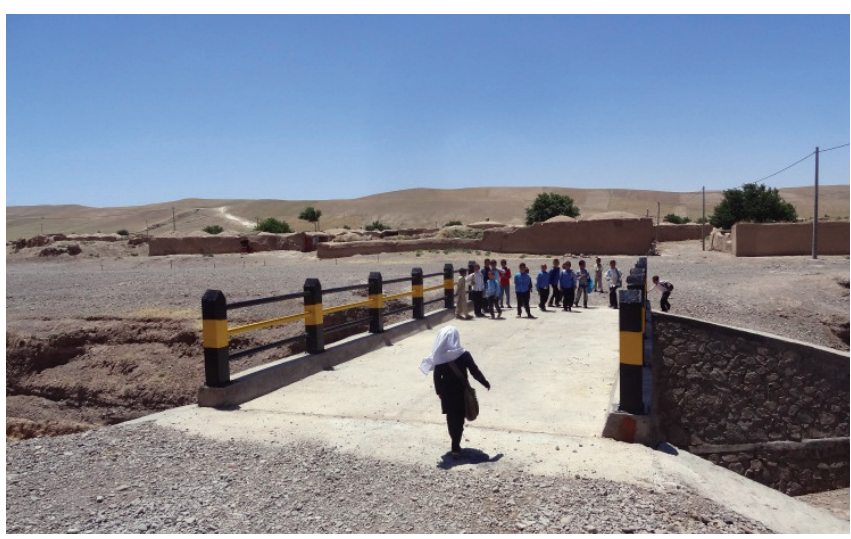

\section{AFTER}

Funded by the USAID Stability In Key Areas (SIKA)-West program, with oversight and technical support from the Kushk-e Rabat Sangi District Government and Herat DRRD, the Khowja Gul Baid Community Development Council constructed a Community Bridge in Khowja Gul Baidak Village. 



\title{
V. Governance
}

\author{
Build and improve upon current administrative and service \\ delivery knowledge/skill sets, which will improve the \\ effectiveness and resiliency of GIRoA and equip provinciall \\ district partners with the tools necessary to address local \\ government stabilization and governance objectives.
}

Recognizing that each of the SIKA-West IR program components (stabilization, resource development, and communications and public outreach and community development) contained its own capacity-building components, the role of the governance department was to focus on improving existing administrative and governance systems within the target DGOs, enabling this support to add value to the other program component activities. Governance programming was designed around existing MRRD and IDLG-approved capacity-building guidelines, frameworks, training materials, and District Government Capacity Indexes, which enabled SIKA-West personnel to identify and address weaknesses within the administrative capacities of DGOs and focus their programmatic efforts.

The primary focus of SIKA-West's governance programming was to strengthen and improve district governments' existing capabilities and the delivery of administrative services to resident populations. This was accomplished by focusing support on those services that were present and funded by available GIRoA budgets, ensuring the sustainability of these services after the program concluded. In addition, strategic support was also provided to DGOs and DEs to support their governance and service delivery roles when engaged in program-supported KSW leadership, resource identification and development, grant-funded tracking, and coordination with multiple line ministries (MRRD, DoE, DoH, and DOLSA).

Prior to the launch of programming, capacity assessments were undertaken to identify the following: (a) existing capabilities and skill sets of DGO personnel and DEs and to what extent these individuals were engaged in local governance or service delivery programming; (b) current range and scope of service delivery programming and resources utilized; (c) requirements for service delivery and existing gaps; and (d) need for targeted technical and material support.

The capacity assessments were based on four progressive development stages: (a) start-up phase; (b) developmental phase; (c) consolidation phase; and (d) sustainable phase. Each performance phase was divided into its respective sub-performance areas and indicators. Each indicator was scored, reflecting overall beneficiary performance, and used as an implementation guideline. 
District Government Capacity Index Scale

\begin{tabular}{c|l|l}
\hline Score & Phase & Definition \\
\hline $\mathbf{I - 2}$ & Start-up & $\begin{array}{l}\text { Below minimum requirements: DGO is a long way from being a mature institution and requires intensive } \\
\text { capacity building. }\end{array}$ \\
\hline $\mathbf{5 - 4}$ & Developmental & At minimum requirements: DGO is on the path to maturity but still needs to enhance performance. \\
\hline $\mathbf{7 - 8}$ & Sunsolidation & $\begin{array}{l}\text { Above minimum requirements: DGO has made significant progress toward the desired level of maturity } \\
\text { and independence, understanding roles and responsibilities, but could improve with capacity building } \\
\text { inputs in specific areas. }\end{array}$ \\
\hline & $\begin{array}{l}\text { Well above minimum requirements: The DGO has reached the desired level of maturity and } \\
\text { independence. It provides good governance and meets all expectations with respect to its role and } \\
\text { responsibilities. Improvements may be needed where the DGO is not doing as well, with the support of } \\
\text { specific capacity inputs. }\end{array}$ \\
\hline
\end{tabular}

The capacity index scale was populated based on the findings of the assessments, which employed the capacity assessment methodology (see table on next page).

While the DGOs within SIKA-West target regions required a broad range of capacity-building support, it was critical to focus efforts on the overall DGO management, which would in turn benefit individual line department sectors (health, education, labor, agriculture, etc.). For the most part, DGOs fell into the range of start-up phase or developmental phase. At these levels, basic management needed to be improved, employing existing resources and building a sustainable platform for follow-up capacity-building support.

Government Function - Management Components:

I. Staff input

2. Staff capability

3. Staff training

4. Recordkeeping and file systems

5. Delegation

6. Personnel systems

7. Administrative procedures

8. Public outreach

9. Media relations

\section{Planning}

II. Monitoring and evaluation

Also refer to the District Government Organizational Chart on following page.

Following the IDLG-approved capacity assessments, SIKAWest implemented the following:

\section{I.STAFF INPUT SUPPORT}

To address a lack of coordination and communication among DGO personnel and line departments, SIKA-West worked closely with DGOs to establish monthly coordination meetings enabling line departments (sectorial, finance, law, etc.) to provide updates on activities and program targets and request technical and material assistance from provincial line departments. This practice, which remains in place today, ensures that DGO personnel remain informed on district-wide GIRoA programming and can track activities. SIKA-West also supported quarterly meetings between District Governors and the Provincial Governor, ensuring that governance programming updates were being clearly communicated and feedback was received. This practice also remains in effect using existing GIRoA budget resources.

\section{Capacity Assessment Methodology}

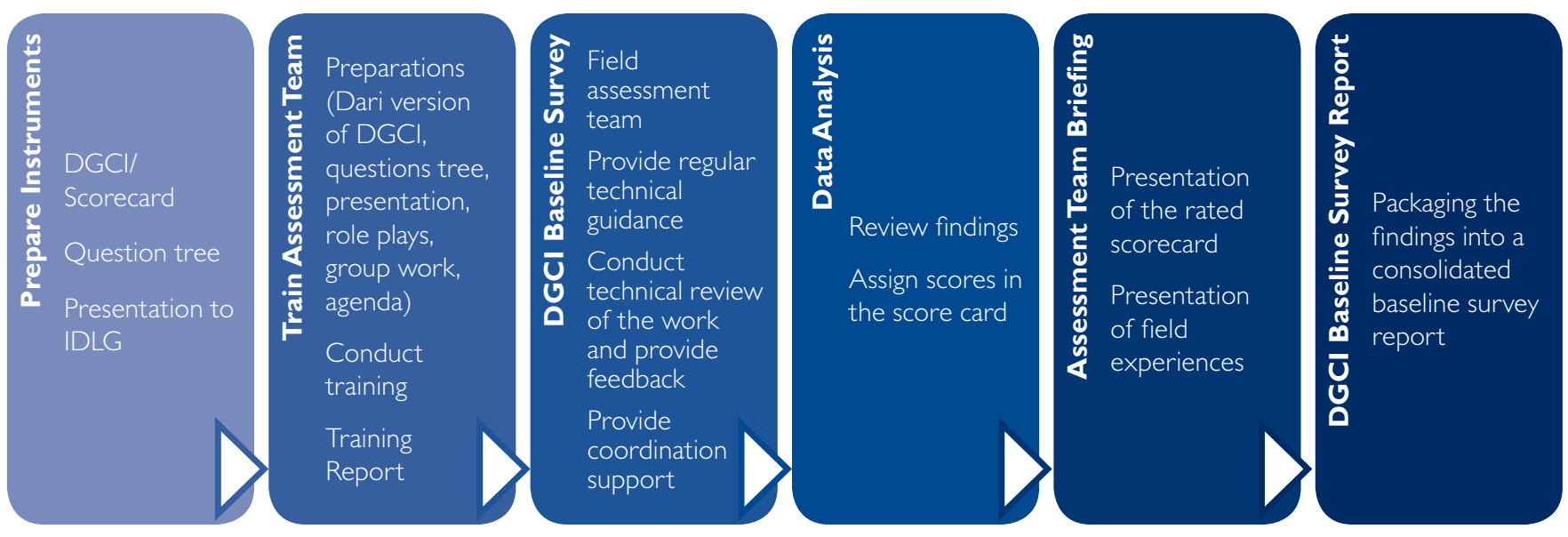




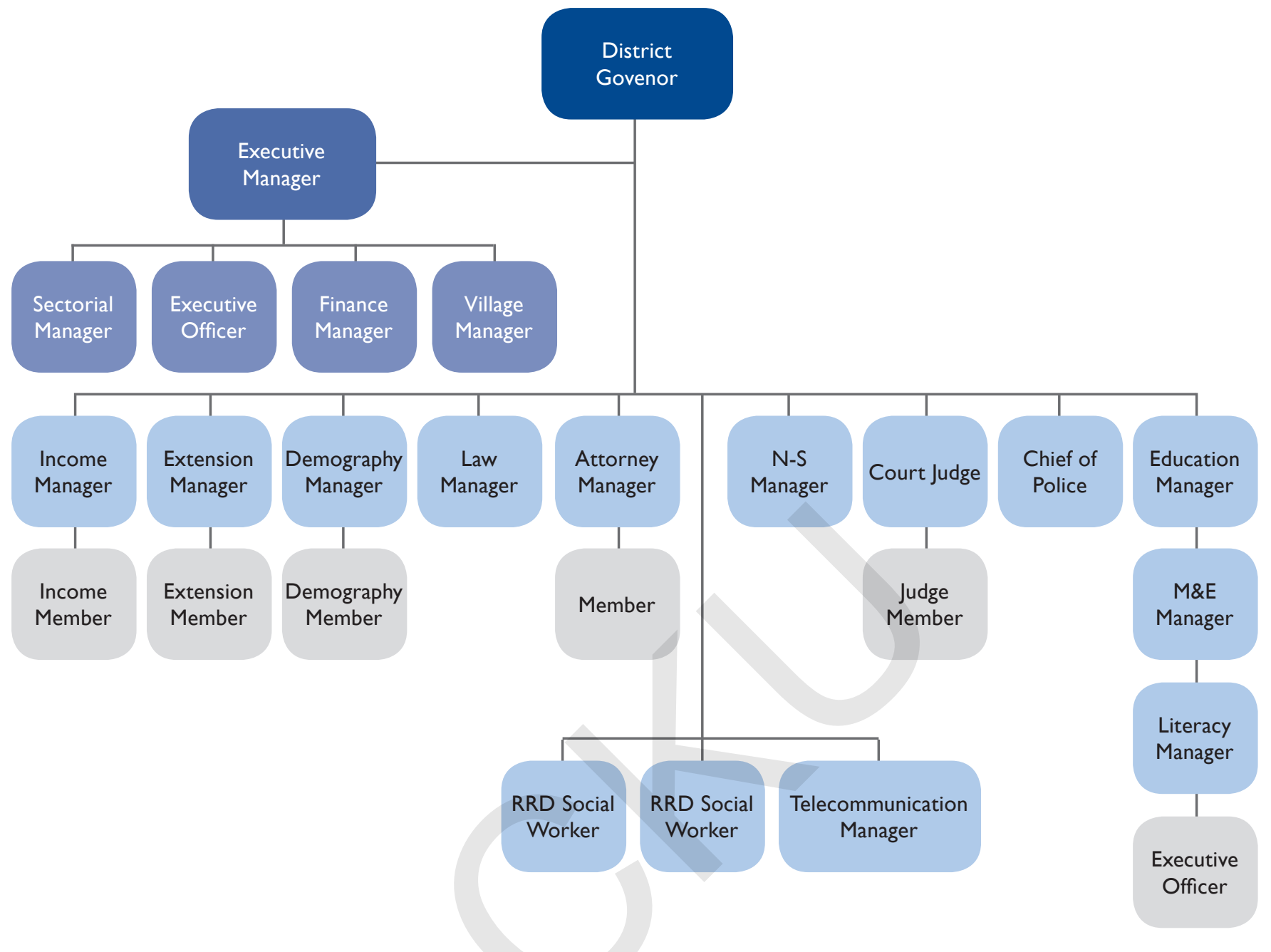

DGO Organizational Chart

\section{COMMON RESULTS OF DGO/DE CAPACITY ASSESSMENTS}

- Many personnel were not suitably prepared for their roles in administration, human resources, finance, organizational management, recordkeeping, communications, and community engagement, lacking experience, education, and technical ability.

- Internal technical support or mentoring to DGO personnel was lacking, either by provincial counterparts or the IDLG capacity-building unit.

- Many DGO personnel were unable to perform in their roles and deliver needed administrative services to residents. Simple administrative tasks were being routinely referred to the PGOs as DGOs were unable to perform.

- DGO absenteeism was a significant problem in less-secure districts (Bala Baluk, Khak-e-Safed, Shindand, and Shahrak). In some cases, only the district executive manager was present, with remaining employees residing in the provincial centers.

- Some DGOs did not have all of their available positions filled for long periods of time due to a lack of resources.

- Material resources (furniture and administrative materials) to perform tasks effectively was often lacking. SIKA-West was unsuccessful in learning the real value of DGO budgets. 


\section{STAFF CAPABILITY}

To tackle capacity deficiencies, SIKA-West personnel used approved IDLG governance materials, raising internal organizational and administrative systems to a minimum acceptable level. Examples of these efforts include the following:

(a) In January 20 I4, with the support of SIKA-West, the Bala Baluk District Government (Farah Province) personnel provided Tazkiras (national ID cards) to members of the district's Kuchi (nomadic) population. Without these Tazkiras, the Kuchi populations were unable to enjoy GIRoA-run health and education services within the district. While the Kuchis had applied for these documents in the past, district personnel, stating that it was not their responsibility, repeatedly sent them to the PGO. After the establishment of new organizational systems and review of personnel job descriptions by governance personnel, it was clear that the DGO must provide this service. With support from the DG, Tazkira issuance resumed in an organized fashion and continues today. The feedback from the district population was overwhelmingly positive.

"THE SIKA-WEST PROGRAM WAS SUCCESSFUL

IN IMPROVING THE KRS DGO'S MANAGEMENT

FUNCTIONS THROUGH A BETTER

UNDERSTANDING AND IMPLEMENTATION OF CURRENT SCOPE OF WORK (SOW'S); INCREASED COMMUNICATIONS WITH LOCAL COMMUNITIES; IMPROVED ORGANIZATIONAL MANAGEMENT IN TERMS OF FILING, RECORDKEEPING SYSTEMS AND DAILY PROCESSING OF RECORDS;AND IMPROVED INTERNAL COORDINATION WITH THE DEVELOPMENT AND IMPLEMENTATION OF MONTHLY AND QUARTERLY WORKPLANS."

KUSHK-E-RABAT SANGI DISTRICT GOVERNOR (HERAT PROVINCE): MR. SHIR AQA SARWARI (AUGUST 20I5) (b) In February 20 I4, with the support of SIKA-West, the Bala Baluk DGO (Farah Province) organized the delivery of 2,500 saplings from the provincial DAIL to district farmers. Lobbied by the district farmers for support to deal with soil erosion, the DG arranged for a request for saplings to be submitted through the District Agriculture Department to their provincial office. While this was pending, DGO personnel organized a list of recipients and delivery arrangements. Within a matter of weeks, the saplings arrived and were distributed and planted, reflecting that improved coordination and organizational planning at the DGO level.

\section{THE FIRST DISTRICT STABILIZATION COMMITTEE (DSC) ELECTED FOR BALA BALUK DISTRICT}

On August 8, 2012, despite ongoing fighting between Afghan forces and anti-government elements, more than 30 people from the volatile Bala-Baluk District in Farah Province, traveled to the district center during the holy Ramadan period to participate in a meeting to create the first District Stabilization Committee (DSC) under the USAID funded, Stability in Key Areas (SIKA)West project.

Despite their exhaustion from fasting, participants consisting of district authorities, District Development Assembly (DDA) members, Community Development Council (CDC) members, and representatives from the local Afghan National Police (ANP), Afghan National Army (ANA), and Youth organizations attended the meeting at the District Governor's Office to elect the 15 members of the DSC. The DSC members included the District Governor as Chair, five DDA members, the District Police Chief, one representative from the ANA and seven line department members.

The meeting was an example of a "sustainable process", a fundamental undercurrent in the SIKA-West project scope. It was organized in coordination with local government officials, a process which district entities (DEs) will be able to maintain following the proposed 2014 withdrawal. As part of this sustainable approach, participants did not receive a cash allowance to attend the event.

The meeting resulted in the election of 15 individuals who will help identify sources of instability in Bala-Baluk District and will propose mitigation activities which will help bolster government support at the district level. 


\section{STAFF TRAINING}

In all, I 62 formal trainings were provided, many with multiple modules coupled with daily on-the-job mentoring, as SIKA-West personnel worked side-by-side with DGO staff to improve their management and performance capabilities. The formal trainings and on-the-job training focused on the following:

- Conflict and disaster management

- Work plan development

- Project management

- General leadership/management principles

- Gender mainstreaming

- Financial management

- General administration training

- Procurement and budgeting

- Inventory asset management

- Organizational management

- Filing systems and record keeping

- Job description

- Review/development/coaching
"IT IS THE DUTY AND RESPONSIBILITY OF ALL PEOPLE IN BALA-BALUKTO BRING STABILITY INTO OUR HOMES."

\section{MR. SAID MOHAMMAD, BALA-BALUK DISTRICT GOVERNOR}

These formal trainings were designed to build and maintain the minimum organizational and management requirements within the DGOs. All training materials were a component of the SIKA-West and IDLG governance training plan and were approved in advance by the IDLG SIKA Unit. For many junior DGO personnel, this was the first opportunity they had in years to receive any form of organized capacitybuilding programming. In all, 72 training suites (modules, presentations, manuals, and handouts) were provided, including but not limited to risk assessment methodologies, strategic communications, time and task management, budgeting, general administration, human resources, work plan development, and report writing, with copies of these materials left behind within the DGO library after the handover of SIKA-West programming.

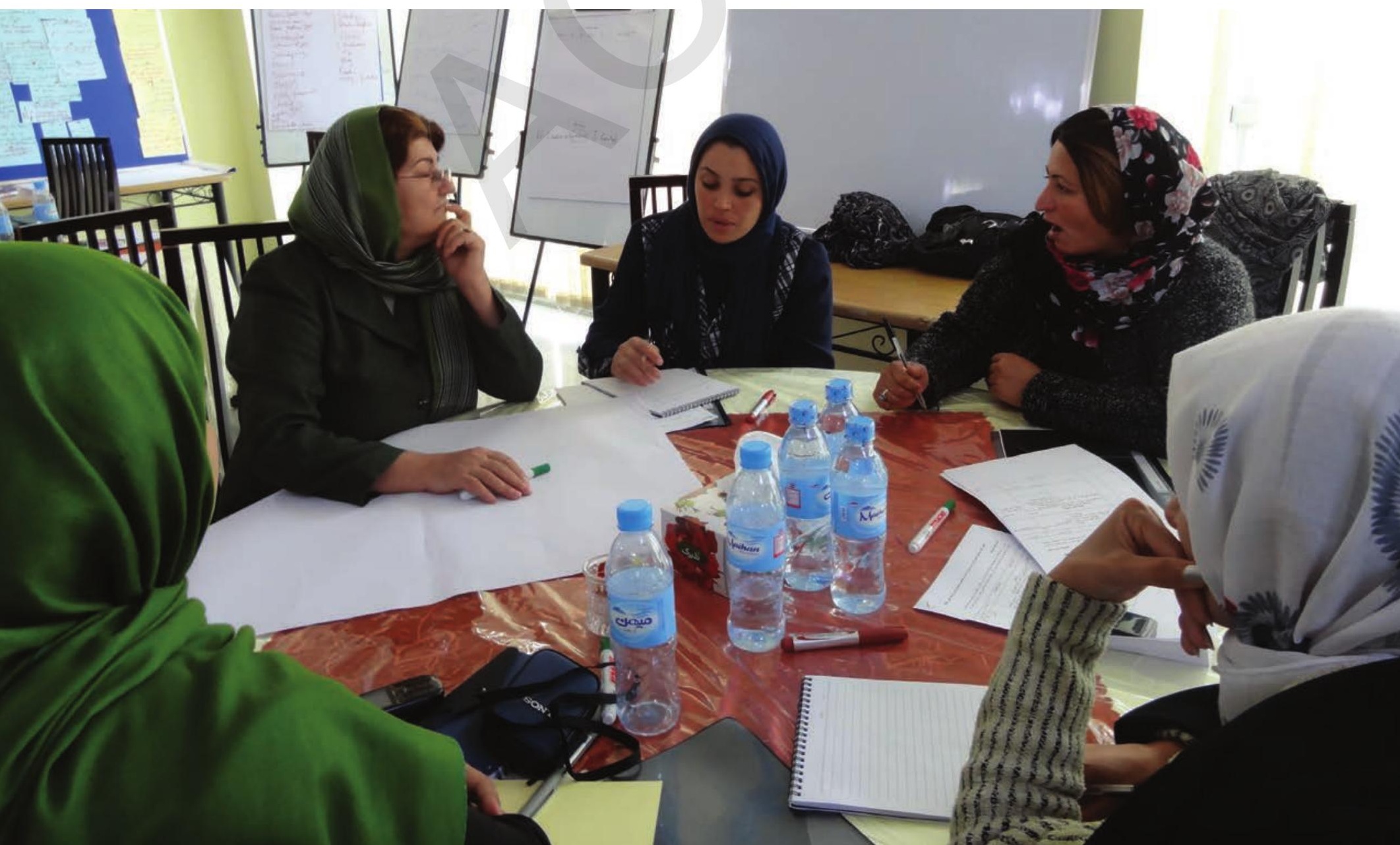




\section{RECORDKEEPING AND FILE SYSTEMS}

Within the majority of partner DGOs, recordkeeping and filing systems were limited, resulting in large numbers of documents being misplaced or unable to be located when required. This deficiency was addressed by SIKA-West, which worked closely with the DGO executive leadership to ensure that work product and critical documents were organized and properly filed, accessible when required and recorded in soft copy form where computerized equipment was already in place.

5. Administrative Procedures The focus was to ensure that district administrative services were formalized into guidelines so that both DGO personnel and district residents understood how to access these services and what steps and information were required. Key examples included (a) guidelines for obtaining Tazkiras (national identity cards; (b) receipt of secondary school diplomas from the Ministry of Education (MoE); (c) Receiving pensions from the Department of Labor, Social Affairs, Martyrs, and Disabled
(DoLSA); and (d) obtaining marriage certificates from district courts. The range of existing administrative services varied across DGOs, depending on available personnel and budget resources to cover administrative-material requirements. The results of SIKA-West governance programming reflect reasonable improvements in overall DGO organizational management, administrative service delivery, recordkeeping, and human resources, revealing increased technical capacities in these keys areas and improved DGO personnel's understanding of their roles and responsibilities. However, these gains are fragile and still place the project's DGO partners within the developmental phase. To build on these successes, a steady focus needs to be maintained on these DGO capacities, with particular emphasis placed on continued assessments, regular capacity-building support by IDLG, engagement and feedback from district populations, strategic planning with respect to key services and available financial resources, and continued internal communications between DGOs and PGOs.

PASHTUN ZARGHUN DISTRICT GOVERNOR HOLDS PRESS CONFERENCE AT PROJECT SITE VISIT OF A 44 METER FLOOD PROTECTION WALL IN QALA YOUSEF KHAN VILLAGE

“AS A RESULT OF SIKA-WEST EFFORTS, NOW THE LOCAL GOVERNMENT AND RESIDENTS ARE ABLE TO IDENTIFY THEIR PROBLEMS AND FIND SOLUTIONS"

MR. FARHAD RAUFIAN, PASHTUN ZARGHUN DISTRICT GOVERNOR. 


\section{SUCCESS STORY}

\section{Say “No To Corruption" Drama}

Recognizing the importance of tackling corruption, the Kushk-e-Rabat Sangi District Government staff with the support of the Stability In Key Areas West (SIKA-West) program and Herat Theater Office organized an Anti-Corruption Drama at the District Centre on February 9th 2014.

The drama aimed to raise awareness amongst district government staff on both the dangers of corruption and highlight their responsibilities in combating this problem.

Present during the drama, were district government line department personnel, members of the district anti-corruption unit, local influential leaders and district residents. Posters and pens with various anti-corruption messages were distributed to the audience. One of these messages read "Together We Will Eradicate Corruption."

"Corruption erodes our national values and negatively affects our economy. The President has created the Anti-Corruption Department in order to tackle corruption in the Civil service and I will make sure that all issues related to corruption are followed up quickly to ensure good governance," Mr. Abdullah Nasrat, the District Executive Manager.

'SAY NO TO CORRUPTION' WASTHE MAIN MESSAGE OF THE ANTI-CORRUPTION DRAMA PERFORMED INTHE KUSHK-ERABAT SANGI DISTRICT CENTER

"We are all Muslims and our religion is strongly against corruption. Corruption is not only distasteful but also prohibited in Islam." MR. RANJOUR, ANTI-CORRUPTION DEPARTMENT

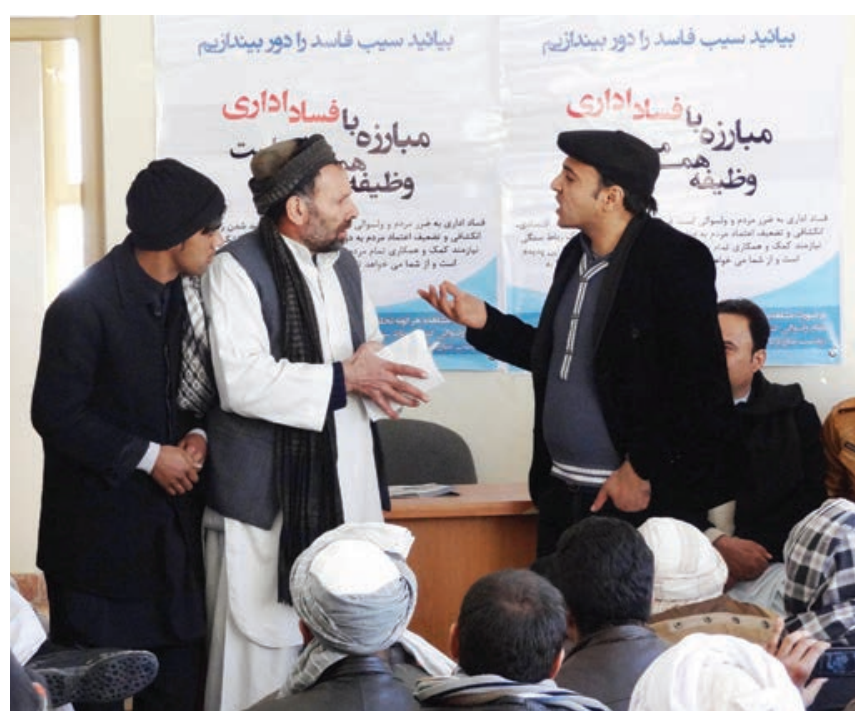




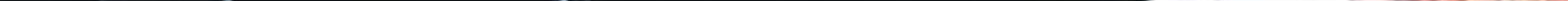




\section{Gender Mainstreaming}

SIKA-West gender mainstreaming programming integrated male and female district resident and government personnel perspectives and input into GIRoA-led stabilization and governance activities. Employing the KSW as a district programming pivot point, SIKA-West identified and supported male and female community leaders, ensuring that sufficient resources were available to enable both groups to actively engage in KSW discussions, identify and address CMPs, understand how to access provincial and district resources, improve their capacity to communicate their needs, and play a leading role in the implementation of district development.

\section{Stabilization}

A key component of SIKA-West was the inclusion of both male and female views, perspectives, and concerns when identifying, prioritizing, and screening community grievances and deciding upon GIRoA-led solutions. With the support of SIKA-West, district government and provincial DRRD partners understood the importance of all viewpoints to ensure that local governance and district development were responsive and effective to all their residents. Each of the program's $22 \mathrm{KSWs}$ incorporated female participation, through mixed KSW meetings (where male and female members were present) or separate male and female KSWs in those districts where GIRoA deemed it culturally appropriate.

Female KSW participants (GIRoA personnel, DDA members, CDC members) can now take a leading role in the identification and prioritization of district concerns, improving the delivery of GIRoA-led basic services. Through mentoring and technical support, female KSW participation focused on district health and educational concerns, improving accessibility for district residents to critical GIRoA services and building confidence among female leaders that their concerns would be recognized and prioritized by local government authorities.

Female KSW members were provided with monthly capacity-building support and mentoring to ensure their understanding of the SAM process and of how to prioritize and screen CMPs/SOls, identify viable solutions, and discuss the appropriate allocation of GIRoA or available third-party resources. Each month, in advance of the upcoming 
KSW, gender officers would work with female participants to discuss the status of overall district stabilization programming efforts, review the participants' understanding of the SAM process, highlight priorities, prepare talking points, and obtain feedback on the impact of recent GIRoA-led service delivery efforts. Within mixed KSWs, the program enabled a large number of female participants to speak publicly for the first time and share their views on district community grievances. Their ability to clearly and effectively communicate their concerns led to local governments supporting 66 femalefocused district interventions where resources could be applied to address immediate needs in health care, education, rural infrastructure, and vocational training.

Examples of GIRoA-led interventions identified by female KSW participants include the following:

- In February 2013, concerned about the mortality rate of young mothers and children in remote communities within Pusht Rod District (Farah Province), female KSW members successfully lobbied their district government to fund and launch community-based health education courses for village midwives in district communities. These

\section{Governance}

SIKA-West focused on improving the administrative and governance capabilities of both male and female GIRoA personnel. During the implementation time frame, none of its partner DGOs employed female personnel in an administrative capacity; however, SIKA-West was able to concentrate its gender mainstreaming efforts to encourage productivity of male and newly hired female staff within the Farah, Ghor, and Badghis PGOs (reflecting the award of Farah Center, Chaghcharan, and Qala-e-Naw districts during the base and option periods).

SIKA-West governance programming was designed around existing MRRD and IDLG guidelines, frameworks, and materials, with a focus on strengthening local governments' capacity to improve their governance competencies and delivery of administrative services to resident populations. Of the I,459 GIRoA personnel and DE leadership that received capacity-building support in governance administration systems, I39 were female. SIKA-West worked with female KSW members in Farah Center, Chaghcharan, and Qalae-Naw to ensure that they learned how to improve their organizational behavior and understanding of GIRoA administrative systems, including (I) inventory tracking, filing, and record keeping; (2) organizational management; (3) procurement and finance systems; (4) disaster risk management; (5) work plan development; (6) civil service courses, implemented through an Afghan-led NGO called Coordination of Humanitarian Assistance (CHA), successfully raised awareness among women regarding the importance of prenatal care and the availability and contact details of local health services, while also linking these women to other available services.

- In September 20 I4, female leaders within Lash Wa Juwayn District (Farah Province) noticed a drop-off in attendance at the local Naw Abab Secondary School. They realized that the falloff was due to the poor conditions of the building's surrounding walls, causing parents to fear for the safety of their children. During the KSW meeting, female leaders spoke and were successful in having the district government award funds to build a new 200 meter long surrounding wall.

- In August 20 I4, to improve the quality of medical care received by all district residents, the female members of the Kohsan District (Herat Province) KSW convinced their district government to rehabilitate the Kohsan Health Clinic as it was falling into disrepair, benefiting 9,000 male and female district residents who use the clinic on a regular basis.

\section{FEMALE KSW PARTICIPATION}

- Sixty-six infrastructure and vocational grant-funded projects were identified and awarded through the KSWs to specifically address female district resident grievances. Twenty percent of these grant awards were focused on school rehabilitation, flood protection, and rural road rehabilitation efforts, reflecting to KSW members the important benefits obtained when all district stakeholders have an opportunity to participate.

- Female perspectives and inputs are now an accepted component of the KSW discussions, whereas in the past, female input was almost nonexistent. Local governments now recognize that female resident input has a pronounced and positive effect on stabilization, governance, and development programming for all district residents.

- After withdrawing all technical, logistical, and financial support from the GIRoA-led KSWs in March 2015, SIKA-West witnessed the continued participation of female KSW members at the invitation of both local government officials and male district leadership. This practice was not in effect in 2012 when SIKA-West started and reflects a complete change in attitude at the district level. 
law; and (7) report writing. Female KSW participants used these skill sets to organize themselves and fully participate in KSW discussions and prioritization of community needs; link their groups to existing DOWA-led gender mainstreaming programming; and, for those who were GIRoA employees, improve their administrative efforts in providing services to district populations.

Examples of GIRoA-led governance initiatives led by female KSW participants include the following:

\section{Resource Development}

SIKA-West ensured that both male and female KSW participants were aware of and able to access available GIRoA and donor-funded resources and services. The program's creation of SPCs, DRRD service provider hotlines, and DGO hotlines were all designed to maximize resource awareness among male and female district residents and link available services to address KSW-identified CMPs.

Of the $986 \mathrm{GIRoA}$ personnel and DE leadership who were trained on the development and use of SPCs, 79 were female members of the existing KSWs. These women were actively engaged within KSW forums and were able to disseminate SPC catalog information and hotline phone numbers to larger numbers of district women.
- Female KSW participants in Farah Center organized themselves to lobby the Farah DoE to renew its efforts in providing required capacity-building support to female secondary school teachers in Lash Wa Juwayn District. In February 2015, without financial or logistical support from SIKA-West, the DoE provided 36 female schoolteachers with coaching on the existing secondary school curriculum, providing both guidance on pedagogical approaches and feedback on questions raised. This was the first time that such focused support had been provided to female district schoolteachers in a number of years.
Examples of female engagement include the following:

- Promotion of health, education, agriculture, and rural infrastructure programming, available to both male and female district residents, during SIKA-West-organized provincial service provider fairs in Herat, Ghor, Badghis, and Farah.

- Showcasing of district female residents goods and services by provincial DoWA authorities to promote cottage industries.

- Use of DGO hotlines by female district residents to request local government support in addressing grievances.

- Use of DRRD SPC hotlines to obtain information and contact details on available GIRoA and donor-funded services.

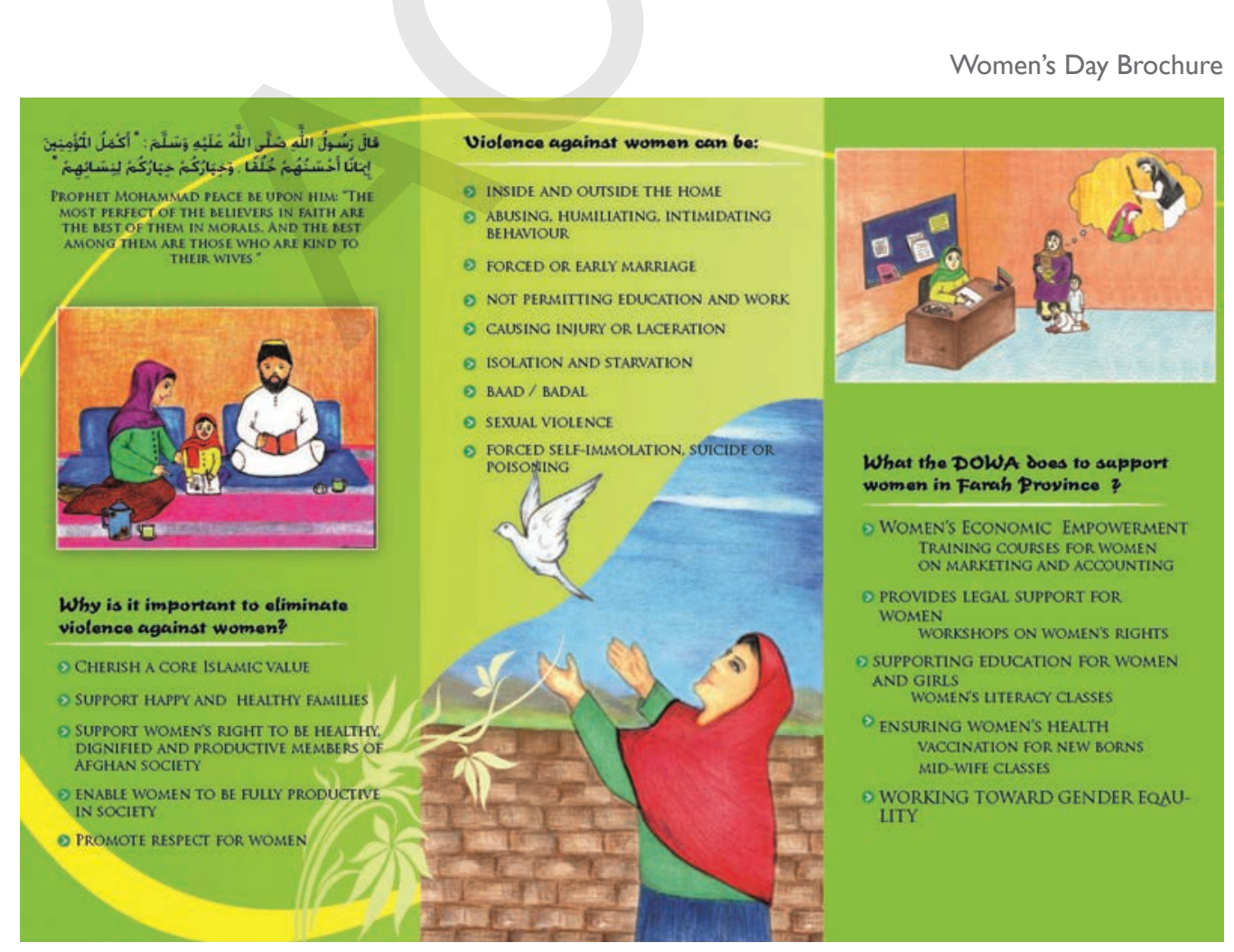




\section{Communications and Public Outreach}

To enable male and female KSW members to fully participate in the stabilization and governance dialogue, SIKA-West needed to ensure that it supported a robust two-way communication system between local government and its citizens. The program's gender mainstreaming focus was to enable district residents to improve their capabilities in both clearly communicating their views with local government authorities and receiving steady exposure to DGO actions, capabilities, and achievements.

Of the 3,222 GIRoA personnel and DEs trained in improved communications capabilities, 592 were female and were drawn from the existing ranks of KSW members, as well as community leaders. With the support of SIKA-West, these women received focused support on improving their capabilities in public speaking, advocacy, media training, and internal communications and used these skill sets to connect GIRoA resources with district communities in need.
Examples of female engagement include the following:

- Successfully advocated for local governments to provide resources for 66 grant-funded vocational and infrastructure projects in 16 target districts, benefitting 132,292 male and female residents. These interventions were a direct result of female KSW members actively speaking and participating in stabilization discussions and convincing their local government representatives to take action. Female membership continues to play a critical role in independently funded GIRoA-led KSWs that have continued even as SIKA-West has closed down.

- Female KSW members played an integral role in identifying 23 GIRoA- and third-party donor-funded service delivery interventions to assist district populations in addressing critical needs (benefiting 969 male and 46 female district residents).

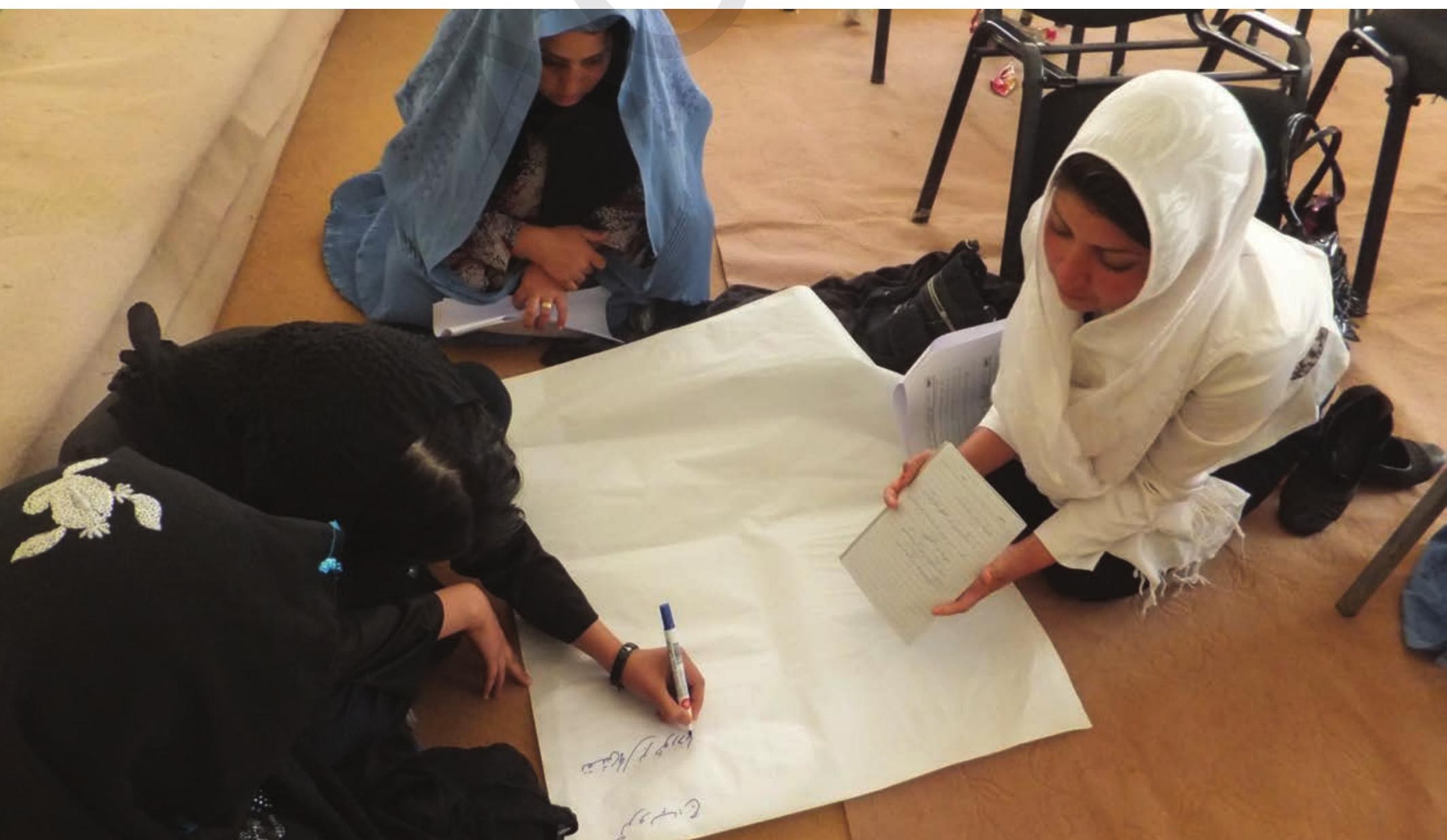









\section{Monitoring and Evaluation}

\section{PERFORMANCE MONITORING PLAN (PMP)}

Performance Management Plan (PMP) The PMP was developed based on the contract AID-306-C- I2-00004 between AECOM and USAID, dated January 29,20 I2. It was subsequently revised in June 2014 pursuant to lessons learned through the implementation of programming during the base period as well as recommendations received from the Measuring Impact of Stabilization Initiatives (MISTI) mid-term evaluation conducted in February 2014.

The SIKA-West program operated under the hypothesis that "if the Government of the Islamic Republic of Afghanistan (GIRoA) is better able to provide for communities' stabilization needs, then the transition to long-term Afghan-led development programming will ultimately be more successful." SIKA-West employed the following "Theory of Change" to link the program's short-term activities to its longer term stabilization and governance objectives: "Support the rapid transition of Afghanistan to a more stable and productive state, through the promotion of democracy, rule of law, and sustainable economic development that is responsive to citizen needs."

The PMP presents a results framework broken down by SIKA-West's specific set of Intermediate Results (IRs) and sub-IRs, which in turn are related to indicators. The PMP includes a broad array of standard and custom performance indicators to track

\section{KEY RESULTS AND ACHIEVEMENTS}

- 171 weekly updates, 40 monthly reports, I4 quarterly reports and 79 success stories produced and approved by USAID.

- Collaborated with and supported MRRD DSWs to conduct 377 grantfunded project site visits, to assess ongoing programming and provide feedback to the provincial DRRD offices.

- 75 formal M\&E trainings provided to DSWs, DGOs, and DEs, covering project site assessments, report writing, basics of monitoring, Trackstick use, project photography, and GPS collection. On-site mentoring further supported all formal trainings.

- Multi-tiered monitoring approach with internal and external assessments employed to regularly review and improve programming components. 
the progress of individual program components and assess the impact of SIKA-West programming. The indicators were divided into two major categories:

I. Strategic/program indicators (foreign assistance framework, STAB- $U$, gender) and custom program indicators

2. Indicators by level: impact, outcome, and output indicators

\section{INTERNAL MONITORING,VERIFICATION, REPORTING,AND ASSESSMENT}

One of the goals throughout the life of the program was to provide metrics on a range of key programming activities that enabled SIKA-West to:
I. monitor progress toward its overall programming strategic objectives;

2. monitor overall program implementation in line with contractual indicators; and

3. learn from both successes and obstacles and adjust implementation tactics as needed to ensure program success.

\section{Project in the Numbers}

The following table shows SIKA-West's progress toward achieving PMP indicator targets:

\begin{tabular}{|c|c|c|c|c|c|}
\hline Indicator Name and Number & $\begin{array}{l}\text { Target } \\
\text { Year I }\end{array}$ & $\begin{array}{l}\text { Target } \\
\text { Year } 2\end{array}$ & $\begin{array}{l}\text { Target } \\
\text { Year } 3\end{array}$ & $\begin{array}{l}\text { Cumulative } \\
\text { Target }\end{array}$ & $\begin{array}{l}\text { Cumulative } \\
\text { Result }\end{array}$ \\
\hline $\begin{array}{l}\text { SI: Number of sub-national government entities receiving } \\
\text { USG assistance to improve their performance }\end{array}$ & 42 & 110 & 360 & 512 & 854 \\
\hline $\begin{array}{l}\text { S2: Percent of Afghans reporting that their district } \\
\text { government is responsive to the needs of local people }\end{array}$ & NA & NA & $60 \%$ & $60 \%$ & $70 \%$ \\
\hline $\begin{array}{l}\text { S3: Number of District Entities with USG assistance for } \\
\text { citizens to engage their sub-national government }\end{array}$ & NA & 233 & 75 & 308 & 906 \\
\hline S4: Number of activities with community contribution & 72 & 201 & 100 & 373 & 535 \\
\hline $\begin{array}{l}\text { S5: Number of Afghans trained (see indicators 2.3, 3.3, } \\
\text { 4.4) }\end{array}$ & NA & 5,272 & 5,000 & 10,272 & $\begin{array}{c}\text { I2,562 }(9,529 \\
\text { male, } 3,033 \\
\text { female })\end{array}$ \\
\hline $\begin{array}{l}\text { S6: Number of persons employed by stabilization program } \\
\text { activities }\end{array}$ & NA & 479 & 1,000 & I,479 & $\begin{array}{c}\text { I3,424 (I 3,384 } \\
\text { male, } 40 \\
\text { female) }\end{array}$ \\
\hline S7: Number of person-days of employment created & 9,000 & 46,800 & 30,000 & 85,800 & $\begin{array}{c}343,053 \\
(339,415 \text { male, } \\
3,638 \text { female })\end{array}$ \\
\hline $\begin{array}{l}\text { S8: Number of stabilization activities implemented } \\
\text { through grants to district entities (see indicator } 4.3 \text { ) }\end{array}$ & 72 & 201 & 75 & 348 & 535 \\
\hline $\begin{array}{l}\text { S9: Number of SOls against which stabilization activities } \\
\text { have been executed }\end{array}$ & NA & 12 & 7 & 19 & 22 \\
\hline $\begin{array}{l}\text { SI0: Number of stabilization work sessions conducted for } \\
\text { district entities (see indicator I.2) }\end{array}$ & 88 & 100 & 130 & 318 & 319 \\
\hline $\begin{array}{l}\text { SII: Number of districts in which SAM is utilized to } \\
\text { develop programs (see indicator 1.2) }\end{array}$ & 7 & 10 & 16 & 16 & 16 \\
\hline $\begin{array}{l}\text { SI2: Number of GIRoA officials trained in aspects of } \\
\text { government administration (see indicators } 2.3 \text { and } 3.3 \text { ) }\end{array}$ & NA & 323 & 100 & 423 & $\begin{array}{c}\text { I,459 (I,320 } \\
\text { male, I39 } \\
\text { female })\end{array}$ \\
\hline
\end{tabular}




\begin{tabular}{|c|c|c|c|c|c|}
\hline Indicator Name and Number & $\begin{array}{l}\text { Target } \\
\text { Year I }\end{array}$ & $\begin{array}{l}\text { Target } \\
\text { Year } 2 \\
\end{array}$ & $\begin{array}{l}\text { Target } \\
\text { Year } 3\end{array}$ & $\begin{array}{l}\text { Cumulative } \\
\text { Target }\end{array}$ & $\begin{array}{c}\text { Cumulative } \\
\text { Result }\end{array}$ \\
\hline $\begin{array}{l}\text { SI3: Number of female participants in USG-assisted } \\
\text { programs designed to increase access to productive } \\
\text { economic resources and basic services (assets, credit, } \\
\text { income, or employment) }\end{array}$ & NA & 1,525 & 100 & 1,625 & 3,028 \\
\hline $\begin{array}{l}\text { SI4: Number of interventions that increased participation } \\
\text { of women in district entity activities (KSWs) }\end{array}$ & 27 & 36 & 100 & 163 & 173 \\
\hline $\begin{array}{l}\text { I.I Number of partnered district governments (and } \\
\text { percentage of total) that show improved understanding of } \\
\text { local SOls }\end{array}$ & 10 & 10 & 16 & 16 & $100 \% 16 / 16$ \\
\hline $\begin{array}{l}\text { I. } 2 \text { Number of stabilization work sessions conducted } \\
\text { with district entities }\end{array}$ & 88 & 100 & 130 & 318 & 319 \\
\hline $\begin{array}{l}\text { 1.3 Number of activities included in District Project } \\
\text { Portfolios as a result of stabilization workshops }\end{array}$ & 70 & 240 & 75 & 385 & 650 \\
\hline $\begin{array}{l}\text { 2.I Number of District Entities able to access stabilization } \\
\text { services provided by GIRoA organizations and line } \\
\text { departments }\end{array}$ & NA & 16 & 16 & 16 & 16 \\
\hline $\begin{array}{l}2.2 \text { Number of SOI-mitigating activities that are } \\
\text { implemented in collaboration with providers identified in } \\
\text { the Service Providers Catalogue }\end{array}$ & 7 & 10 & 5 & 22 & 23 \\
\hline $\begin{array}{l}\text { 2.3 Number of people trained on Service Provider } \\
\text { Catalog usage }\end{array}$ & NA & NA & 100 & 100 & $\begin{array}{l}986 \text { (907 male, } \\
79 \text { female) }\end{array}$ \\
\hline $\begin{array}{l}\text { 3.I Number of people (percentage) reporting } \\
\text { improvement in the responsiveness of GIRoA district } \\
\text { entities with regards to SOI resolution }\end{array}$ & NA & NA & $65 \%$ & $65 \%$ & $69 \%$ \\
\hline $\begin{array}{l}\text { 3.2 Number of public outreach or public consultation } \\
\text { activities conducted by DEs with USG assistance }\end{array}$ & 9 & 16 & 24 & 49 & 535 \\
\hline $\begin{array}{l}\text { 3.3 Number of people trained in communications and } \\
\text { outreach }\end{array}$ & 300 & 1,291 & 500 & 2,091 & $\begin{array}{l}3,222(2,630 \\
\text { male, } 592 \\
\text { female })\end{array}$ \\
\hline $\begin{array}{l}\text { 3.4 Number of PAs and DEs with a communication } \\
\text { strategy or plan in place }\end{array}$ & 9 & 8 & 15 & 32 & 27 \\
\hline $\begin{array}{l}\text { 4.I Percentage of people reporting improvement in } \\
\text { service delivery by DEs and PAs }\end{array}$ & NA & NA & $60 \%$ & $60 \%$ & $65 \%$ \\
\hline $\begin{array}{l}4.2 \text { Number of person-days of employment created } \\
\text { through SIKA-West interventions }\end{array}$ & 9,000 & 46,800 & 30,000 & 85,800 & $\begin{array}{c}343,053 \\
(339,415 \text { male, } \\
3,638 \text { female })\end{array}$ \\
\hline $\begin{array}{l}\text { 4.3 Number of grant activities completed in support of } \\
\text { stabilization goals }\end{array}$ & 72 & 120 & 75 & 267 & 535 \\
\hline $\begin{array}{l}\text { 4.4 Number of person-days of training implemented } \\
\text { through grants }\end{array}$ & 280 & 9,600 & 3,000 & 12,880 & $\begin{array}{c}104,530 \\
(34,043 \text { male, } \\
70,487 \text { female })\end{array}$ \\
\hline
\end{tabular}




\section{MONITORING AND VERIFICATION}

SIKA-West employed a multi-tiered approach to collecting and verifying program data:

a) All field programming activities were verified by district and provincial SIKA-West personnel before being crosschecked against programming department field reports. Only those activities that were cross-checked, verified, and authenticated with supporting documentation were recorded and uploaded into M\&E databases.

b) Authenticated records included documents with original signatures, GPS and date/time-stamped photographs, and use of Trackstick technology (which recorded the movements of personnel).

c) The SIKA-West HQ team cross-checked their M\&E field personnel reports by contacting stakeholders at random to confirm that events had taken place, site visits were conducted, resources were distributed, and so forth.

d) District Entity stakeholders reported on field activities at the monthly KSWs, providing SIKA-West personnel the opportunity to cross-reference their updates against program department reports.

e) Both of SIKA-West's MRRD and IDLG partners received weekly updates on program progress, which was reviewed and confirmed by their respective regional coordinators. SIKA-West program activities were verified by MISTI, its third-party M\&E provider, to confirm that reported programming was in fact taking place.

\section{REPORTING}

SIKA-West ensured that program reporting was transparent and shared with all respective stakeholders, providing the opportunity for review, feedback, and recommendations on

\section{MRRD DISTRICT SOCIAL WORKERS}

- SIKA-West supported its MRRD partners by recruiting, employing, and training an additional twelve DSWs to assess stabilization and governance programming, enabling its partners to have a minimum of at least two DSWs per target district. At the conclusion of our program, SIKA-West requested that MRRD hire its contracted DSWs directly to continue to benefit from their program training, field experience, and skill sets. They are being considered for employment, depending on future NABDP or NSP funding.

- The MRRD DSWs played an integral role in KSW engagement, taking part in discussions on community grievances, providing updates on existing NSP and NABDP programming within the 16 districts, and enabling SIKA-West to complement GIRoA-led district development programming and avoid any duplication of efforts.

- With support from SIKA-West and MRRD's CLDD, the DSWs proved to be an effective monitoring tool for the four provincial DRRD partners, providing confirmations on programming activities and enabling MRRD to stay current on SIKA-West programming.

future courses of action. To facilitate increased engagement, SIKA-West translated program reports for MRRD and IDLG partners at the national, provincial, and district level. Reporting approaches were as follows:

a) Weekly, monthly, and quarterly programming reports were shared with USAID, MRRD, and IDLG (national, provincial, and district level).

b) Promotional materials (photo captions, before-and-afters,

\section{KEY RESULTS AND ACHIEVEMENTS}

- Circulated reports and success stories in local language to national, provincial, and district stakeholders.

- Shared and publicized USAID-approved program materials through MRRD and IDLG social media outlets (websites and Facebook), enabling program partners to reach a larger audience when promoting GIRoA-led stabilization and governance programming.

- Collaborated with and supported MRRD DSWs to conduct 377 grant-funded project site visits, to assess ongoing programming and provide feedback to the provincial DRRD offices.

- 75 formal M\&E trainings provided to DSWs, DGOs, and District Entities, covering project site assessments; report writing, basics of monitoring, Trackstick use, project photography, and GPS collection. All formal trainings were further supported by on-site mentoring. 
snapshots, etc.) were translated and shared with MRRD and IDLG national, provincial, and district counterparts, enabling them to promote GIRoA services through their own social media outlets.

c) Weekly program updates on SIKA-West grant-funded infrastructure and vocational programming were provided to MRRD and IDLG counterparts and uploaded into GIRoA databases to inform future district development activities.

d) Regular information uploads to USAID's Afghan Info ${ }^{4}$ and TraiNet ${ }^{5}$ databases provided updates on program progress, funds expended, stakeholders engaged, and beneficiaries identified.

\section{PROGRAM ASSESSMENTS}

SIKA-West employed internal and third-party assessments to regularly review current program performance against existing PMP indicators and inform the future direction of programming components.

Assessments included the following:

a) Baseline Assessment: Provided an understanding of the perceptions of base period district residents toward GIRoA prior to the launch of SIKA-West activities.

b) Mid-Term Assessment: Designed to measure SIKAWest's performance in capacity building, perceptions of service delivery, and local government legitimacy. As with the baseline assessment, this mid-term exercise continued to inform programming activities until the end of the contract.

c) Communications and Public Outreach Focus Groups: Provided feedback on the effectiveness of DGO communication and public outreach activities in selected districts. The findings obtained were used to inform future communications and public outreach programming. Please see Annex F.

\section{d) District Government Capacity Index}

Assessments: Designed to assess DGO organizational and management capabilities, identify gaps in technical capacities, and provide recommendations to inform future DGO governance capacity building efforts. Please see Annex $\mathrm{H}$.

\footnotetext{
4 The Afghan Info database is a web-based system for data relating to number and value of grant-funded activities and associate beneficiaries; number of trainees; and number of Afghan nationals, Third-Country Nationals (TCNs), and U.S. Citizens employed on the program.

5 The TraiNet system is a web-based system for data on capacity-building activities, including types of training, location, start and end dates, trainees, and value of the training provided.
}

e) MISTI Monthly Verification Reports: Provided independent monitoring and verification data on SIKAWest activities and feedback associated with those findings. By the close of the project, a total of 165 grant-funded projects were verified.

f) MISTI Wave Reports: MISTI undertook five cycles of assessments that analyzed, monitored, and evaluated SIKA-West's impact within its target districts. The evaluations focused on the overall stability and resilience trends and provided insights on the evolving program stakeholders' perceptions.

g) MISTI Mid-Term Evaluation: This evaluation (January 2012 - November 2013) assessed the program's performance, relevance, and success within the context of stabilization and governance programming and informed future program management decisions.

h) MISTI Final Evaluation: This evaluation (December 2013 - August 31, 2015) assessed the overall performance and impact in achieving strategic objectives and will inform the Office of Democracy and Governance (ODG) and USAID Mission management on whether SIKA-West achieved the desired results.

\section{MISTI FINDINGS}

Mid-Term Assessment: (a) SIKA-West has been successful in including women and ensuring their participation in the KSW process. Within the cultural norms of Afghanistan, this is a considerable achievement; (b) the monthly KSW meetings were effective at attracting the communities to the district center, increasing the authority and exposure of district entities to their constituents.

Verification Reports: 154 grant-funded projects (95\%) were executed as reported, with the final I pending MISTI reverifications.

Wave Reports: (a) Perceptions of the Afghan government continue to improve since the baseline, with nearly seven in ten respondents saying the Afghan government is well regarded in their area; (b) since the baseline, respondents have become more likely to believe that that their district governor, district government, and local village leaders are responsive to the needs of local people in their area. 



\section{Way Forward}

\section{Challenges, Lessons Learned, and Recommendations}

\section{AFGHANIZED PROGRAMMING APPROACHES}

When launching SIKA-West stabilization and governance programming, some materials included contractual and PMP language that proved difficult to translate and was not easily understood by provincial and district partners. To address this, SIKA-West was proactive in revising programming terminology, ensuring that the program's Afghan partners understood and were able to incorporate this language into their general discussions and approaches on GIRoA-led governance and district development efforts (e.g. Sources of Instability/SOls was changed to Community Major Problems/CMPs, Mitigation Activities was changed to Solutions, etc.).

An additional concern for SIKA-West was to avoid the establishment of new entities that would prove to be unsustainable and instead to employ existing GIRoA structures and approaches to implement programming. With KSWs, the program accomplished this task, incorporating DDAs (and their district development programming updates under NABDP) and CDCs (with their NSP programming updates) under one forum. This enabled district government leadership to have a comprehensive overview of ongoing district development programming.

Future programming should focus on the Afghanized approach, incorporating clear terminology that can be easily understood and translated by provincial and district populations and utilizing existing GIRoA structures, all with the intended effect of maximizing available resources and strengthening sustainability.

\section{AREA OF OPERATION SELECTION}

During the SIKA-West base period, a number of districts awarded did not match elements of the USAID-approved priority district criteria, particularly (a) functioning CDCs/DDAs and (b) permissive security conditions allowing MRRD, USAID, and the IP to effectively operate and monitor SIKA activities in the district. These districts selected by MRRD, IDLG, and USAID at the national level, without input from provincial and district government authorities, were Khak-e-Safed and Bala Baluk (Farah Province), Shindand (Herat Province), and Shahrak (Ghor Province). While this was challenging, SIKA-West did support a range of stabilization and governance programming within these areas but could have been more effective as a program had it been engaged in other districts that closely matched the criteria provided (e.g., 
SIKA-West was required to withdraw from Khak-e-Safed District in April 2014 when the DGO was attacked, overrun, and destroyed by insurgents).

When USAID exercised the option period and expanded SIKA-West programming into six more districts, SIKAWest wanted to ensure that previous oversights made in district selection were not repeated. Working closely with its partners, SIKA-West ensured that provincial and district GIRoA actors were able to provide input, based on existing USAID criteria. This approach was quite effective, enabling MRRD and IDLG to make informed selection decisions that provided SIKA-West with districts that closely matched the district criteria. When future local governance and stabilization programming is designed, SIKA-West recommend that district areas of operation be selected in coordination with provincial and district entities, who are best placed to provide valuable and sound feedback, which may prove invaluable to Implementing Partners (IPS) and can have a significant impact on the overall success of their programming.

\section{IMPLANTED PERSONNEL MODEL}

A key component of the SIKA-West program was to provide its MRRD and IDLG partners with implanted personnel at the provincial and district level, enabling them to support key programming components and improve the overall delivery of basic services. A great deal of program resources and capacitybuilding efforts were invested, and as the SIKA-West program came to an end, the program approached its partners to determine whether a select number could be employed by GIRoA so that they may benefit from SIKA-West's investment. SIKA-West did not secure any agreements but took independent steps to promote available IDLG and MRRD vacancies internally, with limited success. It is recommended that, when future USAID programming involves supporting GIRoA actors with embedded personnel, due consideration be given to having advance agreements in place that allow these personnel to fill available vacancies within GIRoA at the conclusion of the program, enabling a continued and sustainable benefit.

\section{INSECURITY WITHIN TARGET DISTRICTS}

SIKA-West was faced with a range of security concerns over the life of the program and suffered both kidnappings and injuries to its personnel over the past three and a half years (ultimately all personnel were safely returned to the program). To mitigate the risks to staff within these environments, the SIKA-West Operations/Security Department took a proactive stance to establish key working relationships with local ANSF, which provided key information on district conditions and guided field programming actions. SIKA-West also shared these updates with the USAID Mission and were applauded for the detailed updates provided. It is recommended that future programs continue to build on these relationships with local ANSF to assist their programming efforts in insecure environments.

\section{VALUE OF GIROA LIAISON UNITS}

When SIKA-West began provincial and district engagement during the base period, it did not have the support of existing MRRD and IDLG SIKA units. Without these units in place, communication with IDLG and MRRD ministries was often difficult as it was unclear within the ministries who would take a leading role in supporting the program. The lack of dedicated SIKA units affected communication efforts and made it problematic, at times, to obtain ministry support when addressing programming challenges. These issues were quickly resolved with the establishment of the SIKA units, which proved invaluable in supporting SIKA-West's field work, communicating program objectives to provincial and district GIRoA partners, and ensuring that program reports and updates were regularly shared with the respective ministries. In the event that future USAID programming involves partnering with GIRoA, it is recommended that the SIKA unit model be emulated. 


\section{RECOMMENDATIONS}

$\checkmark$ Programming approaches should be "Afghanized' to maximize sustainability efforts. Program language, structures, field activities, and other elements should, to the extent possible, follow or integrate with existing GIRoA approaches to maximize the use of existing resources, avoid program duplication, and strengthen sustainability.

$\checkmark$ When partnered with GIRoA, the selection of potential areas of operation should include input from provincial and district entities that live and work within those regions prior to final decisions being made. A number of districts selected during SIKA-West's base period did not include provincial or district input.

$\checkmark$ If unable to secure an agreement with MRRD and IDLG partners to hire formerly embedded program personnel, it is recommended that consideration be given to formalize such agreement between GIRoA and USAID in advance so that continued benefits may be drawn from personnel who have received a great deal of financial investment.

$\checkmark$ The MRRD and IDLG SIKA unit model proved to be effective in improving coordination between the SIKA-West program and the MRRD and IDLG ministries. It is recommended that this model be followed with future USAID programming (where partnered with GIRoA).

$\checkmark$ To mitigate the risks of programming in non-permissive environments, future programs need to establish strong working relationships with ANSF, who are best placed to provide accurate and timely information on security conditions within the region. 



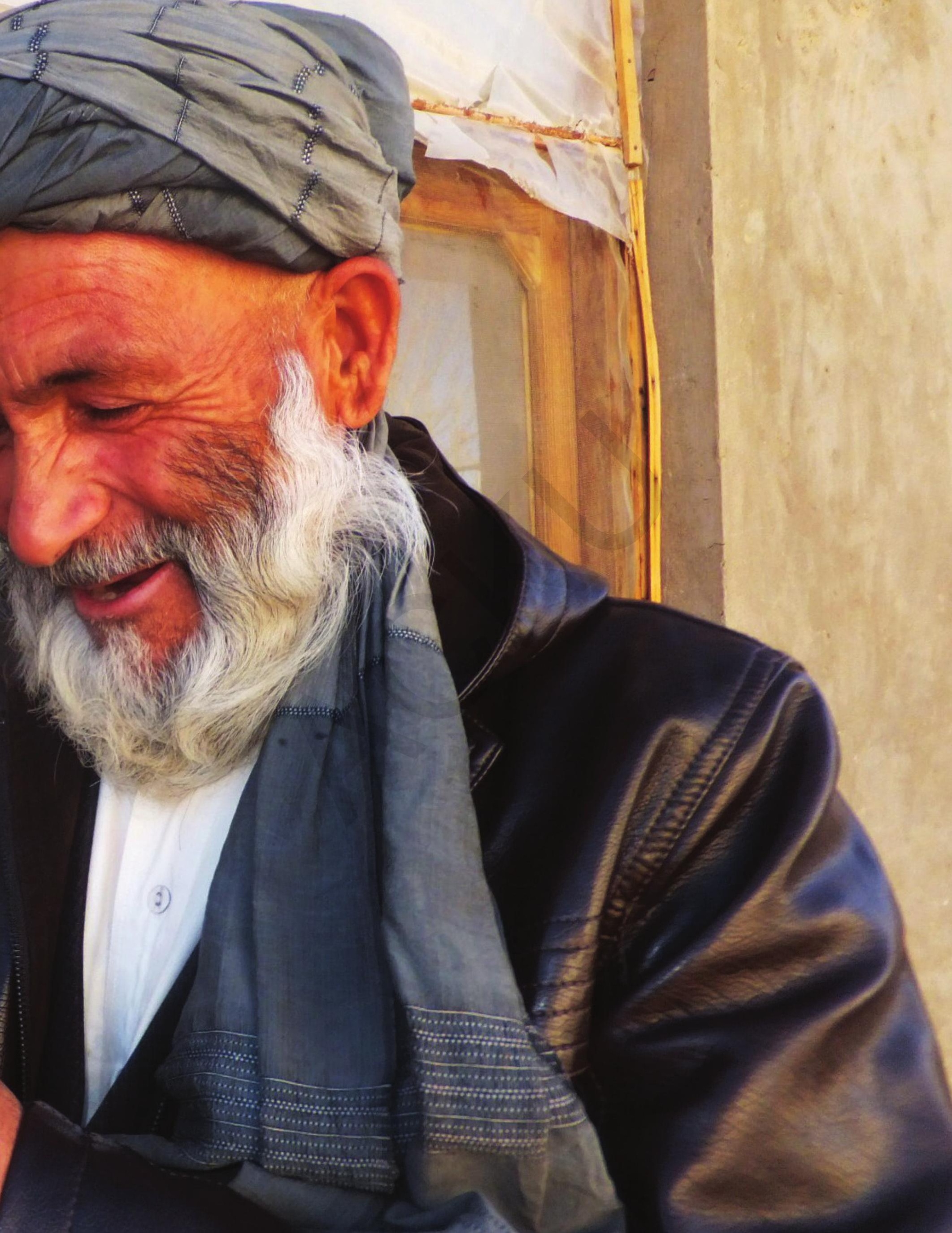




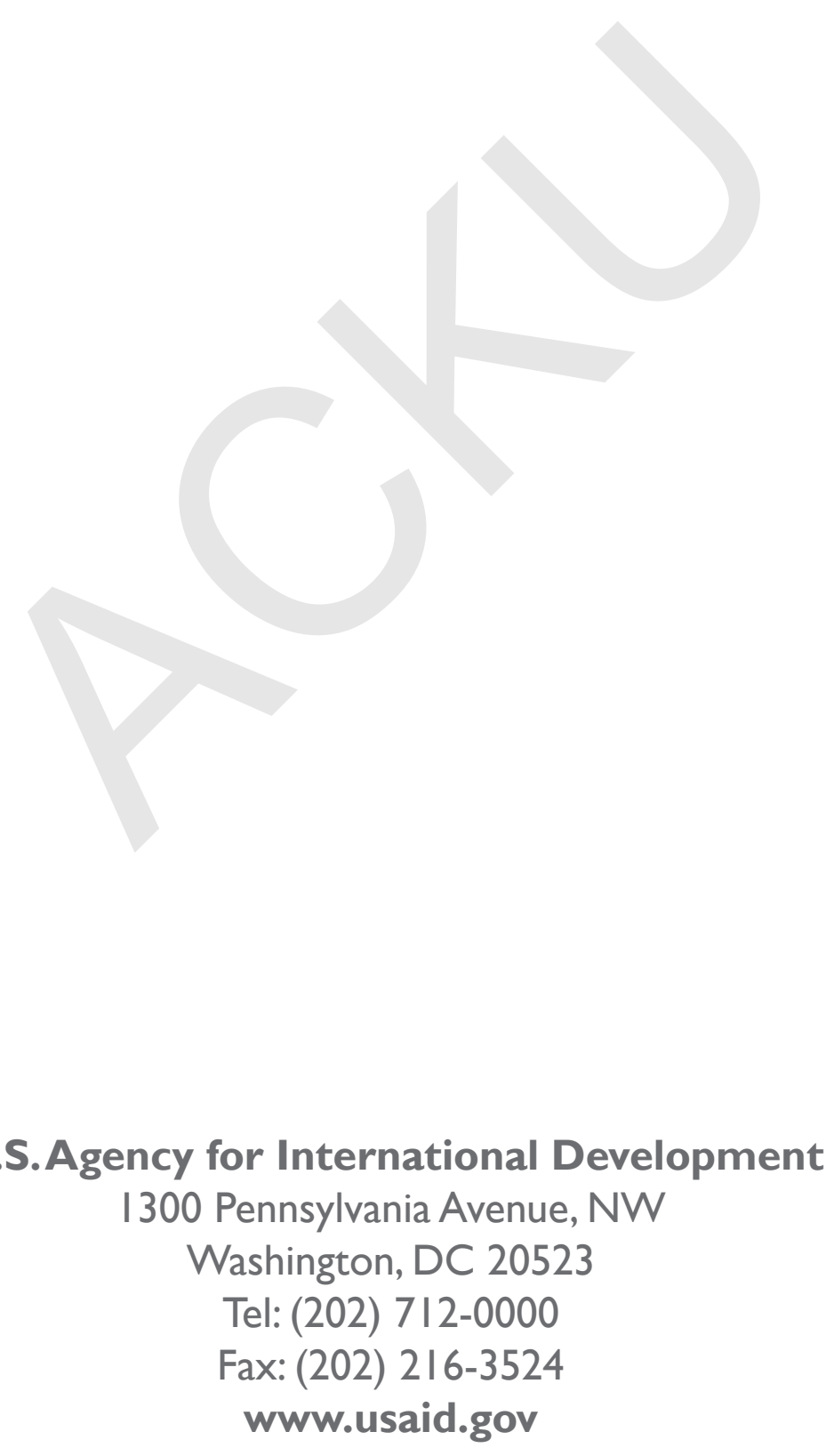

